\title{
Um estudo empírico sobre classificação de símbolos matemáticos manuscritos
}

\author{
Marcelo Valentim de Oliveira
}

DisSERTAÇÃO APRESENTADA

AO

Instituto de MATEMÁtica e Estatística

DA

Universidade DE SÃo Paulo

PARA

OBTENÇÃO DO TÍTULO

DE

Mestre em CiênCIAS

Programa: Mestrado em Ciência da Computação

Orientador: Prof ${ }^{a}$. Dr ${ }^{\mathrm{a}}$. Nina S. T. Hirata

Durante o desenvolvimento deste trabalho o autor recebeu auxílio financeiro da CAPES

São Paulo, agosto de 2014 


\section{Um estudo empírico sobre classificação de símbolos matemáticos manuscritos}

Esta versão da dissertação contém as correções e alterações sugeridas pela Comissão Julgadora durante a defesa da versão original do trabalho, realizada em 25/08/2014. Uma cópia da versão original está disponível no

Instituto de Matemática e Estatística da Universidade de São Paulo.

Comissão Julgadora:

- Prof ${ }^{a}$. Dr ${ }^{\mathrm{a}}$. Nina S. T. Hirata (orientadora) - IME-USP

- Prof. Dr. Flávio Soares Corrêa da Silva - IME-USP

- Prof. Dr. André Ponce de Leon F. de Carvalho - ICMC-USP 


\section{Agradecimentos}

Agradeço primeiramente aos meus pais, Renato e Denise, pelo apoio e dedicação para me guiar até aqui.

Agradeço à minha namorada Rovena, pelo constante carinho e encorajamento, deixando meus dias mais felizes.

Agradeço à minha orientadora Prof ${ }^{\mathrm{a}}$. Dr ${ }^{\mathrm{a}}$. Nina S. T. Hirata, por todos os ensinamentos, ajudas, conselhos e dedicação durante todo esse tempo.

A todos meus amigos que me ajudaram na decisão de fazer o mestrado, e contribuíram de alguma forma para o meu trabalho.

A todos os estudantes do laboratório de eScience do IME que dedicaram seu tempo para contribuir para a minha coleta de dados.

À CAPES e ao CNPq pelo auxílio financeiro.

E a todos que estiveram presentes na minha vida durante o período desse mestrado. 


\section{Resumo}

OLIVEIRA, M. V. Um estudo empírico sobre classificação de símbolos matemáticos manuscritos. 2014. Dissertação - Instituto de Matemática e Estatística, Universidade de São Paulo, São Paulo, 2014.

Um importante problema na área de reconhecimento de padrões é o reconhecimento de textos manuscritos. O problema de reconhecimento de expressões matemáticas manuscritas é um caso particular, que vem sendo tratado por décadas. Esse problema é considerado desafiador devido à grande quantidade de possíveis tipos de símbolos, às variações intrínsecas da escrita, e ao complexo arranjo bidimensional dos símbolos na expressão. Neste trabalho adotamos o problema de reconhcimento de símbolos matemáticos manuscritos para realizar um estudo empírico sobre o comportamento de classificadores multi-classes. Examinamos métodos básicos de aprendizado para classificação multi-classe, especialmente as abordagens um-contra-todos e todos-contra-todos de decomposição de um problema multi-classe em problemas de classificação binária. Para decompor o problema em subproblemas menores, propomos também uma abordagem que utiliza uma árvore de decisão para dividir hierarquicamente o conjunto de dados, de modo que cada subconjunto resultante corresponda a um problema mais simples de classificação. Esses métodos são examinados usando-se como classificador base os modelos de classificação vizinhos-mais-próximos e máquinas de suporte vetorial (usando a abordagem um-contra-todos para combinar os classificadores binários). Para classificação, os símbolos são representados por um conjunto de características conhecido na literatura por HBF49 e que foi proposto recentemente especificamente para problemas de reconhecimento de símbolos on-line. Experimentos foram realizados para avaliar a acurácia dos classificadores, o desempenho dos classificadores para número crescente de classes, tempos de treinamento e teste, e uso de diferentes sub-conjuntos de características. Este trabalho inclui uma descrição dos fundamentos utilizados, detalhes do pré-processamento e extração de características para representação dos símbolos, e uma exposição e discussão sobre o estudo empírico realizado. Os dados adicionais que foram coletados para os experimentos serão publicamente disponibilizados.

Palavras-chave: símbolos matemáticos, classificação multi-classe, decomposição hierárquica, escrita manuscrita, grande número de classes. 


\section{Abstract}

\section{OLIVEIRA, M. V.An empirical study on handwritten mathematical symbol clas-}

sification. 2014. Dissertation - Instituto de Matemática e Estatística, Universidade de São Paulo, São Paulo, 2014.

An important problem in the field of Pattern Recognition is handwriting recognition. The problem of handwritten mathematical expression recognition is a particular case that is being studied since decades. This is considered a challenging problem due to the large number of possible mathematical symbols, the intrinsic variation of handwriting, and the complex $2 \mathrm{D}$ arrangement of symbols within expressions. In this work we adopt the problem of recognition of online mathematical symbols in order to perform an empirical study on the behavior of multi-class classifiers. We examine basic methods for multi-class classification, specially the one-versus-all and all-versus-all approaches for decomposing multi-class problems into a set of binary classification problems. To decompose the problem into smaller ones, we also propose an approach that uses a decision tree to hierarchically divide the whole dataset into subsets, in such a way that each subset corresponds to a simpler classification problem. These methods are examined using the k-nearest-neighbor and, accompanied by the oneversus-all approach, the support vector machine models as base classifiers. For classification, symbols are represented through a set of features known in the literature as HBF49 and which has been proposed recently specially for the problem of recognition of online symbols. Experiments were performed in order to evaluate classifier accuracy, the performance of the classifiers as the number of classes are increased, training and testing time, and the use of different subsets of the whole set of features. This work includes a description of the needed background, details of the pre-processing and feature extraction techniques for symbol representation, and an exposition and discussion of the empirical studies performed. The data additionally collected for the experiments will be made publicly available.

Keywords: mathematical symbols, multiclass classification, on-line handwriting hierarquical decomposition, large classification problems. 


\section{Sumário}

Lista de Abreviaturas $\quad$ xi

Lista de Símbolos $\quad$ xiii

$\begin{array}{ll}\text { Lista de Figuras } & \text { XV }\end{array}$

Lista de Tabelas $\quad$ xvii

1 Introdução $\quad 1$

1.1 Reconhecimento de Expressões Matemáticas . . . . . . . . . . . . . . . 1

1.1.1 Ambiguidades . . . . . . . . . . . . . . . . 2

1.1.2 Reconhecimento de Símbolos Isolados . . . . . . . . . . . . . . . . . . 3

1.2 Problemas com Grande Número de Classes . . . . . . . . . . . . . . . . . . . 3

1.3 Objetivos do Trabalho . . . . . . . . . . . . . . . . . . 4

1.4 Estrutura do Texto . . . . . . . . . . . . . . . . . . . . . . 4

2 Classificação Multi-classe $\quad 7$

2.1 Classificadores . . . . . . . . . . . . . . . . . . 7

2.1 .1 Vizinhos-Mais-Próximos . . . . . . . . . . . . . . . . 9

2.1 .2 Árvores de Decisão . . . . . . . . . . . . . . . . . . . . . . . . . . 9

2.1.3 Máquinas de Suporte Vetorial . . . . . . . . . . . . . . . . . . . . 12

2.2 Extensão para o Problema Multi-classe . . . . . . . . . . . . . . . . 15

2.2.1 Um-Contra-Todos . . . . . . . . . . . . . . . . . . . . . 15

2.2 .2 Todos-Contra-Todos . . . . . . . . . . . . . . . . 16

2.3 Avaliação de Desempenho . . . . . . . . . . . . . . . . . . . 16

2.3.1 Conjunto Treino/Teste . . . . . . . . . . . . . . . . 16

2.3.2 Validação Cruzada . . . . . . . . . . . . . . . . . . . . . 17

2.3.3 Matriz de Confusão . . . . . . . . . . . . . . . . . . . . . . . . . 17

3 Abordagem Hierárquica de Decomposição do Problema de Classificação 19

3.1 Critério de Parada . . . . . . . . . . . . . . . . . . . . . . . . . . 20

3.2 Preenchimento das Folhas . . . . . . . . . . . . . . . . . . 21

3.3 Algoritmo de Treinamento . . . . . . . . . . . . . . . . . 22 
4 Representação, Coleta e Pré-processamento de Dados

4.1 Representação de Dados . . . . . . . . . . . . . . . . . . . . . . . . 24

4.2 Notações . . . . . . . . . . . . . . . . . . . . . . . . . 25

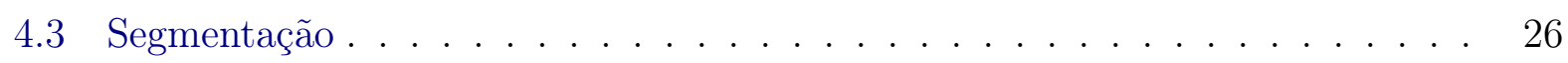

4.4 Pré-processamento de Dados . . . . . . . . . . . . . . . . . . . . 27

4.4 .1 Pré-processamentos de Traços Individuais . . . . . . . . . . . . . 28

4.4 .2 Pré-processamentos de Símbolos Individuais . . . . . . . . . . . . . 33

5 Extração de Características $\quad 35$

5.1 Características Dinâmicas . . . . . . . . . . . . . . . 35

5.2 Características Visuais . . . . . . . . . . . . . . . . . . 38

$\begin{array}{lll}6 & \text { Experimentos } & 47\end{array}$

6.1 Descrição dos Dados Usados . . . . . . . . . . . . . . . . . . . 47

6.1.1 Classes Presentes no Problema . . . . . . . . . . . . . . 47

6.1.2 Pré-processamento de Símbolos e Extração de Características . . . . 49

6.2 Treinamento e Teste de Classificadores . . . . . . . . . . . . . . . . . 51

6.2.1 Classificador Base . . . . . . . . . . . . . . . . . 51

6.2.2 Validação dos Classificadores . . . . . . . . . . . . . 51

6.3 Um-contra-todos e Todos-contra-todos Aplicados ao Problema Completo . . 51

6.3.1 Conjunto Completo de Exemplos . . . . . . . . . . . . . . . 52

6.3.2 Conjunto de Exemplos com Distribuições Equivalentes de Classe . . . 53

6.4 Degradação do Desempenho com o Aumento do Número de Classes . . . . . 54

6.5 Método de Separação de Classes Aplicado ao Problema Completo . . . . . . 57

6.5.1 Comparação de Taxas de Acerto . . . . . . . . . . . . . . 57

6.5.2 Estruturas das Árvores . . . . . . . . . . . . . . . . . . 58

6.5.3 Taxa de Divisão . . . . . . . . . . . . . . . . . . . . . . . . . . . . 58

6.5.4 Tempos de Processamento . . . . . . . . . . . . . . . . . . 59

6.5.5 Variação do Número Máximo de Classes Para Cada Folha . . . . . . 60

6.6 Erros por Classe . . . . . . . . . . . . . . . . . . . . . . 62

6.7 Seleção de Características . . . . . . . . . . . . . . . . . . . 63

7 Conclusão $\quad 67$

7.1 Resumo do Trabalho Realizado . . . . . . . . . . . . . . . . . . 67

7.2 Conclusões . . . . . . . . . . . . . . . . . . . . . . . 68

7.3 Trabalhos Futuros . . . . . . . . . . . . . . . . . 69

$\begin{array}{ll}\text { A LibSVM } & 71\end{array}$

B Natureza dos Dados Utilizados no Trabalho $\quad 73$

B.1 Formato dos Dados Armazenados . . . . . . . . . . . . . . . . . 73 
B.2 Bases de Dados . . . . . . . . . . . . . . . . . . . . 75

B.2.1 MathBrush .......................... 75

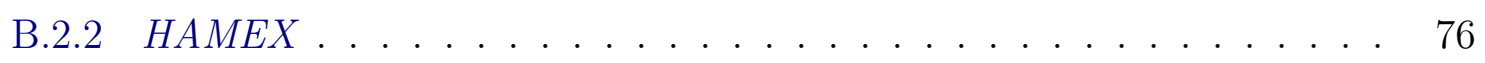

B.2.3 $M \operatorname{fr} D B \ldots \ldots \ldots \ldots \ldots$

B.2.4 ExpressMatch ............................ 77

$\begin{array}{ll}\text { C WEKA } & 81\end{array}$

Referências Bibliográficas $\quad 85$ 


\title{
Lista de Abreviaturas
}

\author{
$k$-NN $\quad k$-Vizinhos-Mais-Próximos ( $k$-Nearest-Neighbors) \\ SVM Máquina de Suporte Vetorial (Support Vector Machine) \\ UCT Um-Contra-Todos \\ TCT Todos-Contra-Todos \\ DAD Decomposição por Árvore de Decisão
}




\section{Lista de Símbolos}

$\begin{array}{ll}\mathcal{P} & \text { Ponto coletado } \\ \mathcal{T} & \text { Traço formado de pontos coletados } \\ \mathcal{S} & \text { Símbolo formado de traços coletados } \\ n & \text { Número de pontos em um traço } \\ N & \text { Número de pontos em um símbolo } \\ L_{i, j} & \text { Comprimento da trajetória entre os pontos } \mathcal{P}_{i} \text { e } \mathcal{P}_{j} \\ \mathcal{P}_{m} & \text { Ponto médio dentro da trajetória total do símbolo } \\ B & \text { Caixa envoltória do símbolo } \\ w & \text { Largura de B } \\ h & \text { Altura de B } \\ c=\left(c_{x}, c_{y}\right) & \text { Ponto central a B } \\ \mu=\left(\mu_{x}, \mu_{y}\right) & \text { Centro de gravidade do conjunto de pontos de um símbolo } \\ \theta_{i} & \text { Ângulo entre três pontos consecutivos com ponto central } \mathcal{P}_{i}\end{array}$




\section{Lista de Figuras}

1.1 Similaridade entre símbolos de fração e subtração. . . . . . . . . . . . . . . . 2

1.2 Expressão com símbolo ambíguo (" $z$ " ou "2") . . . . . . . . . . . . . . . 3

1.3 Expressão com estrutura ambígua, com possibilidades " 22 " ou " $2_{2} "$. . . . . 3

2.1 Exemplo ilustrativo de hiperplano separador em um espaço bidimensional. . 13

2.2 Exemplo de matriz de confusão para um problema de 3 classes, $A, B$ e $C$. . 18

3.1 Esquema de decomposição de um nó. . . . . . . . . . . . . . . . . . . . . 21

4.1 Sistema de coordenadas com coleta de pontos de uma escrita da letra "a". . 24

4.2 Ângulo de virada $\theta_{i} \ldots \ldots \ldots \ldots \ldots \ldots$. . . . . . . . . . . . . . . 27

4.3 Exemplo de suavização. . . . . . . . . . . . . . . . . . . . . . . . 29

4.4 Escrita de um símbolo " -" com gancho. . . . . . . . . . . . . . . . . . . 30

4.5 Escrita de um símbolo " -" após a eliminação de ganchos. . . . . . . . . . . 31

4.6 Símbolo " $\pi$ " com indicação dos ângulos de cada um de seus três traços. . . . 33

4.7 Posição do quatrado $M \times M$ no sistema de coordenadas. . . . . . . . . . . . 34

4.8 Escrita de um "b" com sua respectiva caixa envoltória, e o quadrado $d \times d$ pontilhado. . . . . . . . . . . . . . . . . . . . 34

5.1 Exemplo ilustrativo de símbolos com marcações em suas trajetórias direcionadas para baixo. . . . . . . . . . . . . . . . . . . . . 38

5.2 Espaço angular de ângulos absolutos com suas oito regiões e vetores centrais. 40

5.3 Espaço angular de ângulos relativos com suas quatro regiões e vetores centrais. 41

5.4 Exemplo de um conjunto de pontos e seu casco convexo. . . . . . . . . . . . . 44

5.5 Exemplo de cálculo de $P$ a partir de três pontos não-coolineares. . . . . . . . 45

5.6 Obtenção dos valores de $r$ e $\Theta$ para o ponto $\mathcal{P}_{3}$. . . . . . . . . . . . . . . 45

5.7 Cálculo dos ângulos $\alpha$ e $\beta$ a partir de três pontos consecutivos. . . . . . . . . 46

6.1 Exemplos de símbolos da classe "." após aplicação dos pré-processamentos. 48

6.2 Gráfico mostrando a progressão do desempenho do UCT e do TCT com o aumento do número de classes. . . . . . . . . . . . . . . . . . 55

6.3 Gráfico mostrando a progressão do desempenho do UCT e do TCT com o aumento do número de classes e distribuição de classes uniforme. . . . . . . . 56 
6.4 Progressão dos tempos de treinamento e teste do UCT e do TCT com o aumento do número de classes. . . . . . . . . . . . . . . . . . 56

6.5 Estrutura completa da árvore de 32 folhas. . . . . . . . . . . . . . . . . . . 61

6.6 Estrutura completa da árvore de 15 folhas. . . . . . . . . . . . . . . . . 61

6.7 Estrutura completa da árvore de 9 folhas. . . . . . . . . . . . . . . . . . 62

6.8 Estrutura completa da árvore de 8 folhas. . . . . . . . . . . . . . . . . . . 62

6.9 Estrutura completa da árvore de 6 folhas. . . . . . . . . . . . . . . . . . 62

6.10 Gráfico com progressão do erro com a inserção gradual de características. . 64

B.1 Exemplo de entrada de um modelo de expressão com rotulação manual. . . . 78

B.2 Exemplo de entrada de uma instância transcrevendo um modelo. Modelo na parte superior e transcrição na parte inferior. . . . . . . . . . . . . . 78

B.3 Exemplo de uma correspondência calculada entre duas expressões. . . . . . . 79

C.1 Tela inicial da interface gráfica do WEKA. . . . . . . . . . . . . . . . . 81

C.2 Tela inicial do Explorer sem dados inseridos. . . . . . . . . . . . . . . . . . . 82

C.3 Tela inicial do Explorer com dados inseridos. . . . . . . . . . . . . . . . . . 82

C.4 Tela da aba com a seção de seleção de características. . . . . . . . . . . . . . . 83 


\section{Lista de Tabelas}

6.1 Categorias de Símbolos Eliminadas . . . . . . . . . . . . . . . . . . 49

6.2 Conversões de Rótulos . . . . . . . . . . . . . . . . . . . . . . . . . . 49

6.3 Distribuição Final de Classes . . . . . . . . . . . . . . . . . . . 50

6.4 1-NN, AD, UCT e TCT - Taxas de Acerto . . . . . . . . . . . . . 52

6.5 1-NN, UCT e TCT Com Distribuição Uniforme de Classes - Taxas de Acerto 53

6.6 Classes Inseridas a Cada Teste . . . . . . . . . . . . . . . . . 54

6.7 1-NN, AD, UCT, TCT e DAD - Taxas de Acerto . . . . . . . . . . . 58

6.8 DAD - Taxas de Acerto e Taxas de Divisão . . . . . . . . . . . . . . . . . . . 59

6.9 1-NN, AD, UCT, TCT e DAD - Tempos de Treinamento e Teste . . . . . . . 59

6.10 DAD - Variação do Parâmetro de Quantidade de Classes - Estruturas das Árvores . . . . . . . . . . . . . . . . . . . . . 6 60 


\section{Capítulo 1}

\section{Introdução}

Expressões matemáticas são uma parte muito importante de documentos científicos em diversas áreas. A entrada desse tipo de notação em computadores é em geral mais difícil do que a de textos compostos unicamente por letras, em virtude da variedade de símbolos existentes, e das relações espaciais bidimensionais que eles apresentam entre si. Esses símbolos podem ser digitados com extensões de teclado ou comandos especiais, porém, em termos de facilidade de uso, podemos argumentar que uma forma de digitalizar expressões através de escrita a mão seria mais vantajosa.

Com o uso de dispositivos de captura de escrita (como tablets, ou notebooks com tela sensível ao toque, acompanhados de caneta especial), é possível tornar cada vez mais simples e natural a digitalização de texto dessa natureza. Sendo assim, se mostra interessante a investigação de formas para reconhecer expressões matemáticas automaticamente, baseado na escrita.

\subsection{Reconhecimento de Expressões Matemáticas}

Em expressões matemáticas comuns, existem dois tipos de símbolos: símbolos básicos, compostos por letras e números; e símbolos especiais, que incluem símbolos de ligação e operadores. Operadores, que determinam uma operação a ser realizada entre símbolos, são divididos em dois tipos: os operadores explícitos são representados por símbolos, enquanto os operadores implícitos correspondem a relações espaciais não escritas. Além disso, mesmos símbolos podem ter significados diferentes em contextos diferentes de expressão. Ao tentar reconhecer uma expressão matemática, todas essas propriedades, para cada símbolo ou operador, têm que ser levadas em consideração.

O processo de reconhecimento de expressões matemáticas compreende três grandes passos (Chan e Yeung, 2000). A princípio é necessário segmentar os símbolos. Vários símbolos, como "=", ou "i", possuem mais de uma componente e portanto é preciso que elas sejam agrupadas corretamente para que cada objeto corresponda a um símbolo inteiro. Em seguida é efetuado o reconhecimento de símbolos individuais. Esse reconhecimento pode ser realizado, 
por exemplo, utilizando um conjunto de dados representando as formas visuais dos símbolos para construir um sistema de inferência. A tarefa de ajustar um sistema a dados de um determinado domínio, e posteriormente usá-lo para inferir a qual categoria um novo objeto do mesmo domínio corresponde, é chamada de classificação, e as categorias são chamadas de classes. Por fim, uma análise estrutural é necessária, a fim de descobrir as relações entre cada símbolo, e assim formar a expressão completa. Na análise estrutural, todos os caracteres e símbolos precisam ser agrupados em uma estrutura hierárquica que representa os vários tipos de relação que eles podem possuir entre si.

Em (Chan e Yeung, 2000), (Tapia e Rojas, 2007) e (Álvaro et al., 2014) podem ser encontradas citações para diversos trabalhos relacionados ao problema de reconhecimento de expressões matemáticas, incluindo uma grande variedade de métodos já experimentados.

\subsubsection{Ambiguidades}

O problema de reconhecimento de expressões matemáticas pode apresentar vários tipos de ambiguidades nas formas de escrita (Miller e Viola, 1998). Por exemplo, a figura 1.1 mostra duas expressões contendo dois números separados por um operador. Considerando cada símbolo isoladamente após ter sua escala normalizada, a barra de fração e o operador de subtração são visualmente idênticos. Por isso, um sistema de reconhecimento de símbolos isolados provavelmente não seria capaz de diferenciar os dois símbolos. Com o uso de informações estruturais da posição de cada símbolo dentro de sua expressão, essa distinção em específico poderia ser feita facilmente.

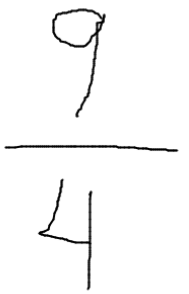

(a) Expressão com fração.

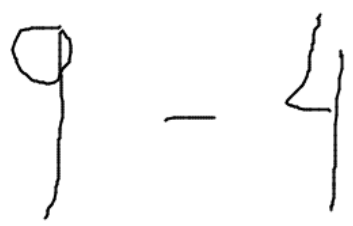

(b) Expressão com subtração.

Figura 1.1: Similaridade entre símbolos de fração e subtração.

Símbolos podem também mostrar ambiguidades se, dependendo da forma com que eles são escritos, apresentarem similaridade em seus padrões de escrita. Por exemplo, a letra "z", quando escrita com as pontas mais arredondadas, pode ser confundida com o número "2". A expressão mostrada na figura 1.2, por exemplo, pode ser lida como $2+3 z-7$ ou $2+32-7$.

Ambiguidades também podem aparecer na estrutura das expressões. Na expressão apresentada na figura 1.3, o segundo "2", por ser menor e estar localizado ligeiramente abaixo, pode ser interpretado como um símbolo subscrito ao "2" anterior, ao invés de um único número "22". Essa ambiguidade também pode ser desfeita se tivermos a informação que, em geral, números não são subscritos a outros números. 


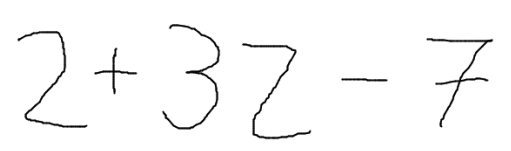

Figura 1.2: Expressão com símbolo ambíguo ("z" ou "2").

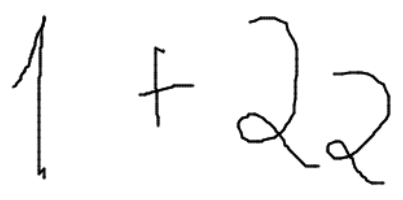

Figura 1.3: Expressão com estrutura ambígua, com possibilidades " 22 " ou " 22 ".

Usualmente informações da natureza dos símbolos e informações do contexto em que eles se situam nas expressões, assim como regras conhecidas sobre a linguagem matemática, são usadas em conjunto para resolver ambiguidades.

\subsubsection{Reconhecimento de Símbolos Isolados}

Um dos principais fatores que diferem o problema de reconhecimento de símbolos matemáticos isolados (desconsiderando a análise estrutural da expressão) de um problema comum de reconhecimento de objetos é a grande quantidade de categorias existentes no domínio. Além de letras (de mais de um alfabeto) e dígitos, o problema apresenta uma grande quantidade de símbolos usados estritamente em notação de expressões matemáticas. Obter bons resultados em um sistema de reconhecimento de um grande número de classes torna-se então o maior desafio.

Além disso, quando for importante diferenciar estilos de escrita, como itálicos e diferentes fontes, muitas classes podem ter padrões de escrita bem parecidos, tornado-as difíceis de diferenciar com o uso de classificadores.

\subsection{Problemas com Grande Número de Classes}

Como foi comentado anteriormente, um dos principais desafios referentes à classificação de símbolos matemáticos é a grande quantidade de classes. Vários outros problemas compartilham esse desafio, como o reconhecimento de caracteres do alfabeto chinês (Chang, 2008), ou o reconhecimento de palavras inteiras (Günter e Bunke, 2003). O desenvolvimento e a experimentação de possíveis soluções para contornar essa dificuldade são então de grande relevância para estudos de reconhecimento de padrões.

O que torna essa característica um obstáculo para o bom desempenho do classificador é o aumento da complexidade do problema. Com mais classes pertencentes ao domínio, mais 
formas visuais diferentes existem para serem diferenciadas. Isso pode diminuir o desempenho de um classificador em dois aspectos: primeiro em termos de taxa de acerto, já que o separador precisa ser mais complexo para ser capaz de segregar mais grupos de exemplos; e segundo em termos de tempo de execução, já que o aumento da complexidade de um separador de classes geralmente implica em um custo computacional maior para que esse separador seja determinado.

$\mathrm{Na}$ literatura da área são propostas diferentes abordagens para contornar o problema de degradação de desempenho com o aumento do número de classes. Dentre elas destacam-se aquelas que buscam a decomposição do problema de classificação em sub-problemas mais simples, para então haver a combinação dos resultados dos classificadores projetados para cada sub-problema.

\subsection{Objetivos do Trabalho}

Neste trabalho o problema a ser investigado é o de reconhecimento de símbolos isolados em expressões matemáticas manuscritas. O problema de segmentação de símbolos não será tratado aqui, isto é, será considerado que os símbolos a serem reconhecidos já se encontram corretamente segmentados. O problema de análise estrutural também não será abordado, uma vez que estamos tratando símbolos isolados e não expressões como um todo.

O objetivo primário do trabalho é então investigar algumas abordagens de reconhecimento estatístico de padrões para tratar o problema de reconhecimento de símbolos matemáticos.

Os objetivos específicos deste trabalho são:

- estudar alguns métodos existentes para decomposição de problemas de classificação em sub-problemas mais simples, e então combinação dos resultados para a obtenção de uma solução do problema original;

- avaliar o desempenho dos classificadores estudados no contexto de reconhecimento de símbolos matemáticos manuscritos, utilizando-se de dados reais coletados;

- analisar as abordagens implementadas em termos de eficácia, eficiência e simplicidade ao serem aplicadas ao problema.

\subsection{Estrutura do Texto}

Conceitos importantes de construção de classificadores, avaliação de desempenho e métodos específicos de reconhecimento de padrões são apresentados no capítulo 2.

No capítulo 3 é descrita uma abordagem hierárquica que é proposta com o intuito de se estudar o efeito da divisão de problema de reconhecimento de símbolo matemáticos manuscritos em sub-problemas menores. 
No capítulo 4 a natureza dos dados do problema é mais detalhada. A forma como os dados são representados é discutida, assim como os métodos de pré-processamento que são aplicados.

Em seguida, o capítulo 5 descreve as características a serem extraídas do conjunto de dados processado.

Os experimentos realizados com os métodos descritos aplicados aos dados apresentados são mostrados e discutidos no capítulo 6.

Por fim, as principais conclusões inferidas dos estudos realizados são sintetizadas no capítulo 7 . 


\section{Capítulo 2}

\section{Classificação Multi-classe}

Resolver o problema de reconhecimento de símbolos matemáticos manuscritos se resume a construir um sistema que recebe um conjunto de objetos (no caso os símbolos) de tipos indeterminados, e retorna as classes (no caso os nomes dos símbolos) às quais eles pertencem. Esse tipo de tarefa pode ser realizada por classificadores, que são treinados por modelos de aprendizado computacional para realizar inferências sobre objetos não-classificados. Classificar símbolos matemáticos é também um problema multi-classe, já que compreende um domínio com mais de duas classes, pois existem mais de dois tipos de símbolos possíveis a serem identificados.

Muitos modelos comuns de classificação funcionam estritamente com problemas binários, ou seja, de duas classes. Os modelos que trabalham com mais classes muitas vezes apresentam uma deterioração significante nos resultados. Por esse motivo, a literatura apresenta várias abordagens para combinar diferentes classificadores binários com o intuito de resolver um problema multi-classe (Aly, 2005). Essas abordagens, em geral, consistem em decompor de alguma forma o problema maior em sub-problemas mais simples.

Este capítulo tem como objetivo introduzir os conceitos necessários de aprendizado e classificação, assim como discutir o problema multi-classe e algumas possibilidades para tratá-lo.

\subsection{Classificadores}

Dado um domínio de objetos pertencentes a diferentes categorias (ou classes), classificação é a tarefa de atribuir rótulos de classe a qualquer objeto pertencente a esse domínio. Esses objetos podem ser de qualquer natureza, e supõe-se que seja possível extrair deles padrões de informação que permitirão separar os objetos em grupos, cada um correspondendo a uma classe. No caso deste trabalho, o domínio de objetos em questão é o de símbolos presentes em expressões matemáticas.

Neste trabalho representamos objetos formalmente por conjuntos de características. Associamos a cada objeto um vetor de características (ou atributos) $\mathbf{x}=\left(x_{1}, x_{2}, \ldots, x_{D}\right) \in \mathbb{R}^{D}$ 
de mesmo tamanho. É importante que todos os vetores tenham o mesmo significado, isto é, os valores $x_{1}$ precisam representar conceitualmente a mesma característica em todos os objetos, da mesma forma que os valores $x_{2}$, e todos os outros seguintes.

Uma representação de características para símbolos matemáticos poderia ser, por exemplo, uma representação vetorial dos valores dos pixels da imagem correspondente. Outra representação possível poderia ser obtida extraindo características geométricas e topológicas do símbolo, por meio de processamento de imagens.

Representando os objetos dessa forma, podemos descrever formalmente um classificador como uma função

$$
f: \mathbb{R}^{D} \rightarrow Y=\left\{y_{1}, \ldots, y_{K}\right\}
$$

na qual $Y$ representa o conjunto de rótulos associados a $K$ classes.

Quando temos um problema de classificação com número de classes $K=2$, dizemos que este é um problema de classificação binária, ou simplesmente problema binário neste texto. Qualquer domínio de problema que possua $K>2$ classes é chamado de problema de classificação multi-classe.

Considerando classificadores em um contexto de sistemas computacionais, é necessário que tenhamos à disposição um modelo computacional que seja capaz de efetuar classificações dos objetos. Esses classificadores são em geral obtidos a partir de amostras de exemplos em um processo conhecido como treinamento.

O aprendizado de classificadores pode ser supervisionado ou não-supervisionado. No caso supervisionado, os exemplos de treinamento estão associados ao respectivo rótulo da classe, enquanto que no caso não-supervisionado não existe informação de classe.

Uma maneira ingênua de construir um classificador para um domínio de dados rotulados é dispor de uma base de dados com todos os padrões de dados possíveis, assim como sua correspondente classe. Um classificador, portanto, só precisaria corresponder o novo exemplo a algum objeto na base de dados, e retornar sua classe. Sabemos porém que em problemas reais, dispor de uma base de dados desse tipo quase nunca é possível. Implementar classificadores apenas através de uma busca na base de dados portanto é inviável (Alpaydin, 2004).

É necessário o uso de algum modelo de treinamento capaz de extrair informações críticas da base de dados, e usá-las de alguma forma a eficientemente realizar predições com relação às classes para os objetos ainda não classificados.

No caso supervisionado, dado um conjunto $X=\left\{\left(\mathbf{x}_{i}, y_{i}\right): \mathbf{x}_{i} \in \mathbb{R}^{D}, y_{i} \in\left\{y_{1}, \ldots, y_{K}\right\}, i=\right.$ $1, \ldots, N\}$, o processo de treinamento então consiste em encontrar uma função $f$ que recebe um novo vetor de características $\mathbf{x}$ e retorna um rótulo de alguma das classes representadas no conjunto $X$, tal que alguma medida de desempenho (como taxa de acerto) seja otimizada.

Existem diversas técnicas, muitas amplamente utilizadas, para encontrar essa função $f$ de classificação. Dentre elas, usaremos neste trabalho o classificador dos vizinhos-mais-próximos 
(Duda et al., 2000), as árvores de decisão (Mitchell, 1997) e as máquinas de suporte vetorial (do inglês Support Vector Machine, ou SVM) (Vapnik, 1995).

\subsubsection{Vizinhos-Mais-Próximos}

O método dos $k$ vizinhos-mais-próximos ( $k$-Nearest Neighbors, ou $k$-NN) (Duda et al. , 2000) é um dos classificadores mais simples e populares na área de reconhecimento de padrões. Ele não realiza nenhum processo no passo de treinamento, deixando a criação do "modelo" para o teste de cada instância. Especificamenete, dada uma medida de similaridade $d_{s}\left(x_{a}, x_{b}\right)$ entre dois exemplos, calcula-se a medida entre o exemplo a ser classificado e cada um dos exemplos no conjunto de treinamento e determina-se os $k$ exemplos mais próximos (isto é, os $k$ exemplos que apresentam maior similaridade).

Em geral, como medida de similaridade, usamos a distância euclidiana entre os exemplos. Considerando que $x_{a, i}$ corresponde à $i$-ésima característica do exemplo $x_{a}$, temos $d_{s}$ da forma

$$
d_{s}\left(x_{a}, y_{b}\right)=\sqrt{\sum_{i=1}^{D}\left(x_{a, i}-x_{b, i}\right)^{2}}
$$

Como a similaridade aumenta com a diminuição da distância, então essa medida precisa ser minimizada.

A forma mais comum de classificar um novo exemplo de teste é então contando cada um dos $k$ rótulos encontrados a partir dos $k$ exemplos de treinamento mais próximos como um voto para a sua respectiva classe. A classe mais votada é atribuída ao exemplo de teste. Para o caso de classificação binária, o valor de $k$ é comumente escolhido como um número ímpar, como uma tentativa de evitar empates.

\subsection{2 Árvores de Decisão}

O aprendizado de árvores de decisão (Mitchell, 1997) é um método para aproximação da função $f$ que usa geralmente valores discretos de características. O método consiste em uma construção hierárquica de condicionais guiadas pelos valores das características. Isso quer dizer que a representação final do modelo será uma árvore, onde cada nó dividirá, começando da raiz, o conjunto de exemplos entre seus filhos, dependendo da característica sendo utilizada no nó corrente. Para cada nó, a característica é escolhida através de alguma métrica que quantifica a qualidade da divisão. O objetivo final em geral é construir a árvore de forma que todas as folhas contenham exemplos de uma única classe, sendo assim que, classificando um novo objeto não-rotulado, a folha a qual ele for atribuído informa o rótulo de classe a ser escolhido.

Existem várias possibilidades de métricas a serem usadas como medida de qualidade para as divisiões, a mais utilizada delas sendo o ganho de informação obtido através da diferença de entropia entre o conjunto total e o conjunto dividido. 
Nomeamos a entropia como $\varepsilon$ e o ganho de informação como $\Gamma$. Sendo assim, a entropia $\varepsilon(S)$ referente a um conjunto de dados $S$ é calculada por

$$
\varepsilon(S)=\sum_{j=1}^{K}-p_{j} \log _{2} p_{j},
$$

onde $K$ é o número de classes existentes no problema, e $p_{j}$ é a proporção de exemplos pertencentes à classe $y_{j}$ dentro do conjunto $S$. É importante notar que a entropia será nula caso todos os exemplos em $S$ pertençam à mesma classe, e será máxima caso as $K$ classes estejam igualmente distribuídas no conjunto $S$. Isso nos diz que a entropia pode ser vista como uma medida de impuridade em um conjunto de dados, no que diz respeito a distribuição de classes.

Como o objetivo da árvore de decisão é repartir conjuntos de dados isolando classes nas folhas, uma boa medida da qualidade de uma divisão é então a redução de entropia durante cada divisão. Calculamos então o ganho de informação, dado um conjunto de dados $S$ e uma característica $A$ (tal que $A$ corresponde a uma das $D$ características que representam os objetos),

$$
\Gamma(S, A)=\varepsilon(S)-\sum_{v \in \Omega(A)} \frac{\left|S_{v}\right|}{|S|} \varepsilon\left(S_{v}\right),
$$

tal que $\Omega(A)$ corresponde ao conjunto de todos os valores que a característica $A$ pode assumir, e $S_{v}$ é o subconjunto de todos os exemplos em $S$ cuja característica $A$ assume o valor $v$. Dessa forma calculamos então o ganho de informação obtido em dividir o conjunto $S$ utilizando a característica $A$. A característica que resultar no maior valor de $\Gamma$ é escolhida para ser usada nessa divisão.

Abaixo está descrito o algoritmo mais comumente utilizado para treinamento de árvores de decisão, apresentando operações com alto nível de abstração:

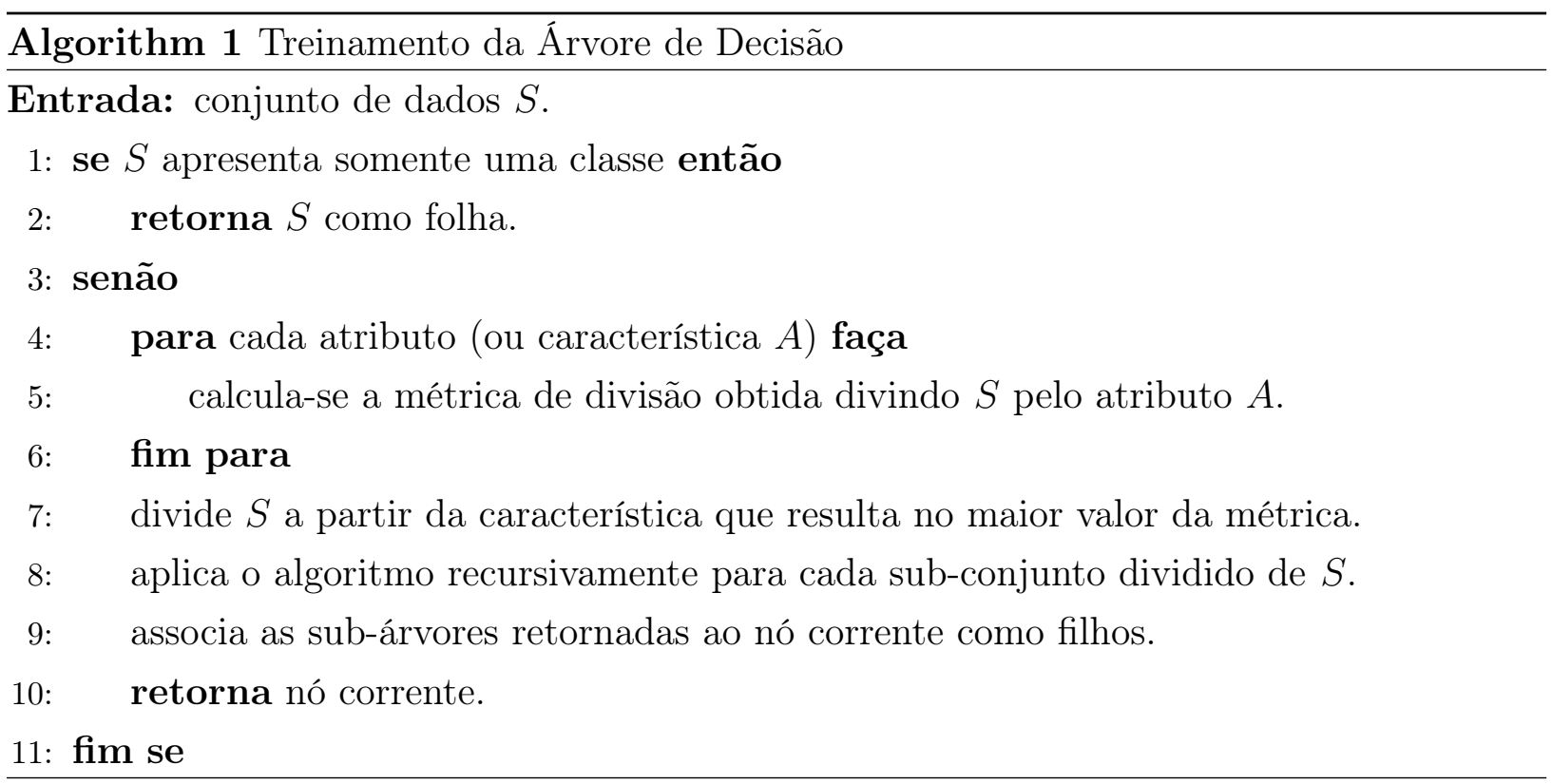


Como nosso problema utiliza características contínuas, são necessárias algumas adaptações no método descrito. O conjunto $\Omega(A)$ por exemplo não é mais um conjunto de tamanho determinado, por isso não é passível de ser percorrido completamente pelo somatório. Uma forma comum de lidar com esse problema é, para cada nó, encontrar o valor ótimo $v_{o}$ assumido pela característica $A$ que divide $S$ em duas partes (uma para exemplos que possuem $A \geq v_{o}$, e outra para exemplos que possuem $A<v_{o}$ ). Dessa forma otimizamos $\Gamma$ não só pelo atributo $A$, como também pelo valor $v$ assumido por $A$ que melhor divide o conjunto de dados.

Sendo $S_{v}^{+}$(filho direito) o subconjunto de $S$ onde se encontram somente exemplos com $x_{A} \geq v$, e $S_{v}^{-}$(filho esquerdo) o subconjunto que apresente somente exemplos com $x_{A}<v$, temos que as proporções de exemplos de cada filho são

$$
P_{e}=\frac{\left|S_{v}^{-}\right|}{|S|}
$$

$\mathrm{e}$

$$
P_{d}=\frac{\left|S_{v}^{+}\right|}{|S|} .
$$

A nova métrica de ganho de informação corresponde então a

$$
\Gamma(S, A, v)=\varepsilon(S)-\left[P_{e} \varepsilon\left(S_{v}^{-}\right)+P_{d} \varepsilon\left(S_{v}^{+}\right)\right]
$$

sendo $v$ necessariamente um valor assumido por $A$ em algum exemplo de $S$.

Além da medida de entropia utilizada comumente, algumas outras métricas de divisão podem ser usadas com o intuito de encontrar o critério mais apropriado ao problema em questão. Dentre elas, discutiremos a twoing e a gini (Breiman et al., 1984).

A métrica gini tem o objetivo geral de encontrar a classe com maior número de exemplos, e isolá-la de um conjunto maior de classes com número menor de exemplos. O valor chamado de índice gini é calculado usando a fórmula

$$
\operatorname{gini}(S)=1-\sum_{j=1}^{K} p_{j}^{2} .
$$

Assim como a entropia, a função gini utiliza as proporções $p_{j}$ de exemplos pertencentes à cada classe $y_{j}$ que está em $S$. Para calcular o valor final da métrica, denominado $\mathcal{G}$, apenas usamos a fórmula de ganho de informação com a função gini no lugar da função de entropia $\varepsilon$, obtendo

$$
\mathcal{G}(S, A, v)=\operatorname{gini}(S)-\left[P_{e} \operatorname{gini}\left(S_{V}^{-}\right)+P_{d} \operatorname{gini}\left(S_{v}^{+}\right)\right]
$$


A métrica twoing, aqui denominada de $\mathcal{W}$, é calculada por

$$
\mathcal{W}(S, A, v)=\frac{P_{e} P_{d}}{4}\left[\sum_{j=1}^{K}\left|p_{j}^{-}-p_{j}^{+}\right|\right]^{2}
$$

onde $p_{j}^{-}$corresponde à proporção de exemplos da classe $y_{j}$ pertencente ao lado esquerdo da separação por $v\left(x_{A}<v\right)$, e $p_{j}^{+}$corresponde à proporção de exemplos da mesma classe pertencente ao lado direito da separação $\left(x_{A} \geq v\right)$. O termo $\frac{P_{e} P_{d}}{4}$ maximiza uma distribuição igual de exemplos para cada filho, uma vez que o termo é máximo quando os dois lados possuem quantidade igual de exemplos. O termo do somatório maximiza a separação de cada classe para somente um lado, uma vez que $\left|p_{j}^{-}-p_{j}^{+}\right|$é máximo quando a classe $y_{j}$ é atribuída a somente um dos filhos. O objetivo da métrica é então maximizar essas duas características simultaneamente.

\subsubsection{Máquinas de Suporte Vetorial}

As SVMs são modelos estatísticos usados em problemas de classificação e análise de regressão (Haykin, 2007). A ideia principal da SVM é construir um hiperplano como superfície de decisão de tal forma que a separação entre os exemplos positivos e negativos seja máxima. As margens dessa separação são definidas por vetores, chamados vetores de suporte. As dimensões do espaço onde ficam situados os exemplos e o hiperplano que os separa correspondem às características dos exemplos.

Consideremos o mesmo conjunto de treinamento $X=\left\{\left(\mathbf{x}_{i}, y_{i}\right)\right\}$, onde $\mathbf{x}_{i}$ é o padrão de entrada para o $i$-ésimo exemplo. O hiperplano separa o espaço em duas regiões, por isso a SVM é um classificador intrinsecamente binário. Os valores de classe $y_{i}$ pertencem então ao conjunto $\{-1,1\}$, representando as classes negativa e positiva. A equação que representa um hiperplano ótimo que tem margem de separação máxima entre os exemplos das duas classes é da forma

$$
g(\mathbf{x})=\mathbf{w}_{o}^{T} \mathbf{x}+b_{o}
$$

onde $\mathbf{x}$ é um padrão de entrada, $w_{o}$ é o vetor de pesos ótimo, $b_{o}$ é o valor ótimo de viés e $g(\mathbf{x})$ é a função discriminante que fornece a medida algébrica da distância de $\mathbf{x}$ até o hiperplano. O sinal de $g(\mathbf{x})$ indica a que lado do hiperplano $\mathbf{x}$ se situa.

O processo de treinamento é dividido em dois passos principais. No primeiro deve ser feito o mapeamento não-linear dos vetores de entrada para um espaço de características. No segundo passo há a construção de um hiperplano ótimo definido como uma função linear de vetores. A fig. 2.1 apresenta um exemplo ilustrativo de um sistema de coordenadas formado por duas características $\left(x_{1}, x_{2}\right)$ para onde foram mapeados exemplos pertencentes a duas classes, com o hiperplano separador dividindo-as. A linha central que separa as duas classes corresponde ao hiperplano, e as duas linhas tracejadas paralelas a ela representam os limites 
da margem de separação determinados pelos vetores de suporte. O vetor w é um vetor normal ao hiperplano.

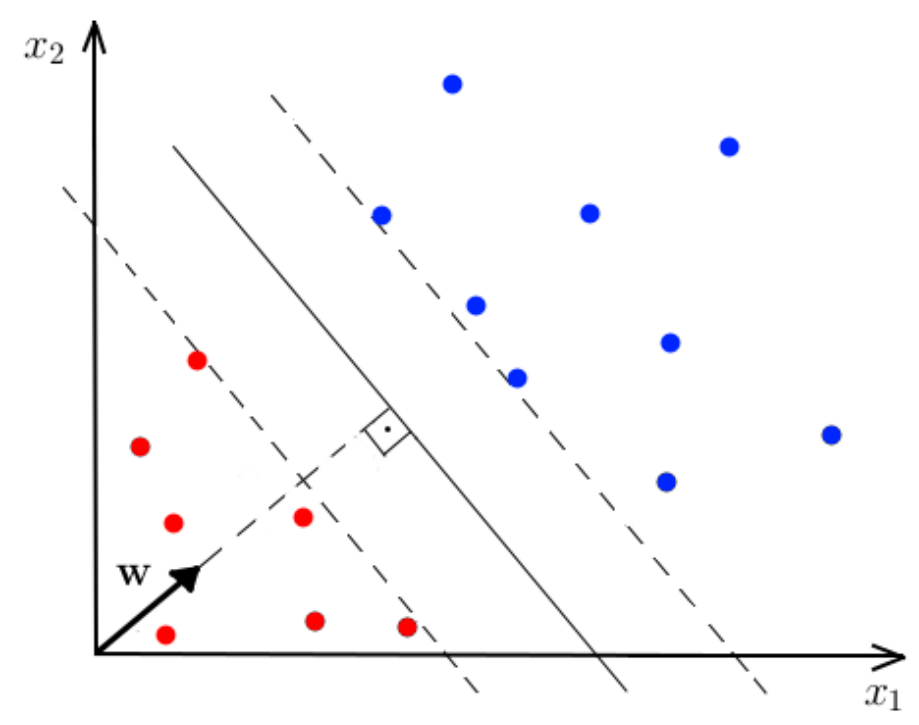

Figura 2.1: Exemplo ilustrativo de hiperplano separador em um espaço bidimensional.

O vetor $\mathbf{x}$, presente na equação 2.11 , pode também ser expresso como

$$
\mathbf{x}=\mathbf{x}_{p}+r \frac{\mathbf{w}_{o}}{\left\|\mathbf{w}_{o}\right\|}
$$

onde $\mathbf{x}_{p}$ é a projeção normal de $\mathbf{x}$ sobre o hiperplano ótimo e $r$ é a distância algébrica desejada entre $\mathbf{x}$ e o hiperplano. Aplicando em 2.11 e rearranjando temos

$$
r=\frac{g(\mathbf{x})}{\left\|\mathbf{w}_{o}\right\|} .
$$

A questão a ser resolvida aqui é encontrar $\mathbf{w}_{o}$ e $b_{o}$ tal que, aplicados às equações, o hiperplano seja ótimo. O par $\left(\mathbf{w}_{o}, b_{o}\right)$ deve satisfazer as restrições

$$
\begin{aligned}
\mathbf{w}_{o}^{T} \mathbf{x}_{i}+b_{o} \geq 1 & \text { para } y_{i}=+1 \\
\mathbf{w}_{o}^{T} \mathbf{x}_{i}+b_{o} \leq-1 & \text { para } y_{i}=-1 .
\end{aligned}
$$

Os pontos $\left(\mathbf{x}_{i}, y_{i}\right)$ para os quais as equações 2.14 e 2.15 são satisfeitas com o sinal de igualdade são chamados de vetores de suporte. Estes são os pontos que se encontram mais próximos da superfície de decisão do hiperplano. Considerando o vetor de suporte $\mathbf{x}^{(s)}$ para o qual $y^{(s)}=+1$, e lembrando da fórmula apresentada em 2.13, temos 


$$
\begin{aligned}
r & =\frac{g\left(\mathbf{x}^{(s)}\right)}{\left\|\mathbf{w}_{o}\right\|} \\
& = \begin{cases}\frac{1}{\left\|\mathbf{w}_{o}\right\|} & \text { se } y^{(s)}=+1 \\
-\frac{1}{\left\|\mathbf{w}_{o}\right\|} & \text { se } y^{(s)}=-1\end{cases}
\end{aligned}
$$

onde o sinal determina o lado em que o vetor está a partir da divisão do hiperplano ótimo. Considerando que $\rho$ é o valor ótimo da margem de separação entre as duas classes, de 2.16 temos que

$$
\begin{aligned}
\rho & =2 r \\
& =\frac{2}{\left\|\mathbf{w}_{o}\right\|}
\end{aligned}
$$

portanto a maximização da margem de separação equivale a minimizar a norma euclidiana de w. Assim nosso problema, dada a amostra de treinamento, torna-se equivalente a encontrar os valores ótimos de $\mathbf{w}$ e $b$ que satisfaçam as restrições

$$
d_{i}\left(\mathbf{w}^{T} \mathbf{x}_{i}+b\right) \geq 1 \quad \text { para } i=1,2, \ldots, N
$$

e minimizem a função de custo para maximizar a separação das classes. Temos então um problema de otimização que pode ser resolvido usando o método dos multiplicadores de Lagrange (Klein, 2004). Esse método acha valores chamados multiplicadores de Lagrange, e permite que reformulemos o problema, de forma a achar o hiperplano separador em função desses multiplicadores, em conjunto com os vetores de dados de entrada e suas classes reais.

Tendo construído o hiperplano ótimo de separação baseado na amostra de treinamento dada, podemos então inserir padrões de entrada de classes desconhecidas do espaço $D$ dimensional de características e calcular sua distância para o hiperplano. Essa distância determinará o valor da probabilidade a posteriori de pertinência do exemplo à alguma das classes.

Para o caso dos padrões de entrada serem não-linearmente separáveis, o teorema de Cover (Cover, 1965) afirma que é possível formar um novo espaço de características onde os padrões são linearmente separáveis a partir de transformações lineares que transferem os exemplos para um espaço de dimensionalidade maior.

A SVM em sua forma básica é um classificador binário. Porém técnicas já foram desenvolvidas com o intuito de inserir parâmetros e restrições, a fim de estender a SVM permitindo-a separar um número maior de classes (Bredensteiner e Bennett, 1999) (Crammer et al., 2001). Implementações bem sucedidas dessas técnicas já foram apresentadas, embora em geral a formulação do problema o torne um problema complexo, inviável para aplicações com grande número de classes. 


\subsection{Extensão para o Problema Multi-classe}

O caso de classificação binária é um problema já exaustivamente estudado, com um grande número de aplicações implementadas. O problema multi-classe, porém, merece mais cuidado, visto que muitos modelos de treinamento são naturalmente apropriados para a classificação binária (Aly, 2005), além do fato de que a existência de um número maior de classes inerentes ao problema torna-o mais complexo.

Uma abordagem muito utilizada, e com bons resultados, é a de delegar o tratamento do problema multi-classe para um método externo, ao invés de para o treinamento dos classificadores. Dessa forma o problema seria decomposto em vários sub-problemas binários, o que resultaria no treinamento de um classificador para cada sub-problema, e na junção posterior desses resultados. Dentre esses, destacamos os esquemas um-contra-todos e todoscontra-todos.

Além de simples decomposições do problema em problemas binários, ideias mais elaboradas já foram desenvolvidas, porém é sugerido que, com o uso de classificadores com boa capacidade de generalização e bem parametrizados, abordagens mais complexas não apresentam muitos ganhos de desempenho sobre essas abordagens mais simples (Rifkin e Klautau , 2004). Rifkin e Klautau realizaram experimentos com SVMs com parâmetros otimizados, e aplicaram uma série de abordagens para o tratamento de casos multi-classe, e concluíram que, nessas condições, a escolha de um método mais complexo, tanto em sua definição como em sua execução, pode trazer pouca melhora nos resultados.

\subsubsection{Um-Contra-Todos}

Na abordagem um-contra-todos (UCT) (Aly, 2005), para um problema com rótulos $y_{i} \in$ $\left\{y_{1}, y_{2}, \ldots, y_{K}\right\}$ tendo portanto $K$ classes diferentes, construímos $K$ classificadores, um para separar cada classe do resto. Por exemplo, ao criarmos o classificador correspondente à classe $y_{1}$, consideramos que cada exemplo pertencente à classe $y_{1}$ é um exemplo positivo, e todo o resto dos exemplos pertencem à classe negativa. Produzindo um classificador para cada classe, a classe vencedora se torna aquela em que o seu classificador deu resultado positivo com maior confiança.

Dessa forma, os resultados dos classificadores não podem ser somente as classes escolhidas, pois, por exemplo, se o classificador 2 atribuir o exemplo à classe $y_{2}$, e o classificador 5 atribuir o exemplo à $y_{5}$, é necessário existir um grau de confiança dessas decisões para que uma única decisão seja tomada no final. Então, considerando que $f_{i}$ é a função que retorna a saída do classificador para a classe positiva $i$ e x é o padrão de entrada, então uma possível função de decisão do esquema (Oong e Isa, 2012) pode ser dada por

$$
d(\mathbf{x})=\arg \max _{i \in\{1, \ldots, K\}} f_{i}(\mathbf{x}) .
$$




\subsubsection{Todos-Contra-Todos}

No esquema todos-contra-todos (TCT) (Aly, 2005) os classificadores são definidos como representações de cada combinação de duas classes diferentes. Com $K$ classes, construímos então $\frac{K(K-1)}{2}$ classificadores. Para criar o classificador que separa as classes $y_{1}$ e $y_{2}$, por exemplo, usamos somente exemplos pertencentes às classes $y_{1}$ e $y_{2}$ para treinar. A classe vencedora contabiliza o voto para o exemplo classificado. Ao final do processo, o rótulo que possuir mais votos para cada exemplo é escolhido para o exemplo em questão.

No caso do TCT, se os classificadores devolvessem a classe escolhida ao invés do grau de confiança, seria possível simplesmente fazer contagem de votos. Ou seja, quando um classificador separando a classe $y_{4}$ da classe $y_{7}$ escolhe a primeira, então contamos um voto para a classe $y_{4}$. No final, a classe com mais votos é escolhida. Um raciocínio análogo pode ser aplicado se o classificador retornar valores de confiança dentro de um intervalo. Sendo $\mathbf{x}$ os valores de entrada, e $f_{i, j}$ o resultado dado pelo classificador com a classe $y_{i}$ como positiva e a classe $y_{j}$ como negativa, temos a função $d$ de decisão do TCT (Oong e Isa, 2012)

$$
d(\mathbf{x})=\arg \max _{i \in\{1, \ldots, K\}}\left[\sum_{j=i+1}^{K}\left(f_{i, j}(\mathbf{x})\right)+\sum_{j=1}^{i-1}\left(1-f_{j, i}(\mathbf{x})\right)\right] .
$$

\subsection{Avaliação de Desempenho}

A avaliação de desempenho é um aspecto crítico na construção de sistemas de classificação. É necessário que usemos um método formal para medir a qualidade de um classificador, para que este possa ser comparado com outros sistemas de forma justa, e para que seu resultado reflita de fato sua aplicabilidade no mundo real.

O processo escolhido para estimar o desempenho de um classificador deve ser robusto, com o objetivo de minimizar ao máximo qualquer viés proveniente do conjunto de treinamento, do modelo de classificação, ou de qualquer outra etapa do processo. Se isso não for considerado, podemos estar construindo sistemas otimistas que não terão o desempenho esperado ao lidar com dados reais desconhecidos. Por isso, vários procedimentos são desenvolvidos para evitar qualquer tipo de viés na taxa de acerto calculada, e produzir resultados que gerem conclusões confiáveis.

Além de garantir maior relevância dos resultados, é preciso facilitar o máximo possível a visualização do desempenho obtido, de forma a ajudar a comparação entre classificadores.

\subsubsection{Conjunto Treino/Teste}

Tipicamente, usar o conjunto de treinamento para testar o classificador não é uma avaliação muito justa. Após o processo de aprendizado, o classificador estará ajustado aos dados de treinamento. Isso faz com que o classificador apresente taxas de acerto altas que não refletem sua capacidade de generalização. Em geral então é necessária a existência de pelo 
menos dois conjuntos de dados, um para treinamento e outro para teste.

\subsubsection{Validação Cruzada}

Dividir uma base de dados em duas partes aleatoriamente pode trazer alguns problemas. Se determinados padrões forem escolhidos exclusivamente para a base de teste, o classificador não será capaz de classificá-los. É importante garantir que cada classe esteja representada nas duas bases, e diminuir a possibilidade de viés nos resultados provenientes da escolha dos exemplos para base de treino ou de teste.

Um método simples muito usado para avaliação da robustez de um sistema de classificação é a validação cruzada (Duda et al., 2000). A base de dados é dividida em $P$ partes. O algoritmo então passa por $P$ passos, a cada passo separando uma das partes como base de teste, e todas as outras $P-1$ partes como base de treinamento. No final do processo, $P$ resultados são obtidos, dos quais é geralmente calculada a média e o desvio padrão. Com o objetivo de tentar preservar o estado inicial dos dados, cada divisão treino/teste pode ser feita mantendo a distribuição de classes da base original para os dois conjuntos. Isso é chamado de validação cruzada estratificada.

\subsubsection{Matriz de Confusão}

A matriz de confusão é uma forma de mostrar os resultados de um classificador visualmente em uma tabela. Nessa tabela o objetivo é apresentar, para um conjunto de exemplos classificados, as classes reais e as classes preditas em cada caso, permitindo-nos visualizar todos os erros, assim como em que classe ocorreram. É uma ferramenta útil para análise de desempenho de classificadores multi-classe.

As linhas da matriz correspondem às classes reais, e as colunas às classes preditas. A fig. 2.2 apresenta um exemplo de matriz de confusão para três classes, $A, B$ e $C$. A cada exemplo pertencente à classe $B$, e predito pelo classificador para a classe $C$, o número da matriz correspondente à linha $B$ e coluna $C$ é incrementado em um. Por exemplo, na primeira linha e terceira coluna temos o número 1 . Isso quer dizer que, na base de teste, um exemplo pertencente à classe $A$ foi classificado como pertencendo à classe $C$, o que constitui em um erro. Na segunda linha e segunda coluna temos o número 13, que significa que treze exemplos da classe $B$ foram rotulados pelo classificador com a mesma classe $B$. Isso constitui treze acertos. 


\begin{tabular}{c|c|c|c|c|}
\multicolumn{2}{c|}{} & \multicolumn{3}{|c|}{$\begin{array}{c}\text { Classe } \\
\text { Predita }\end{array}$} \\
\cline { 3 - 5 } \multicolumn{2}{c|}{} & A & B & C \\
\hline \multirow{3}{*}{$\begin{array}{c}\text { Classe } \\
\text { Real }\end{array}$} & A & 16 & 1 & 1 \\
\cline { 2 - 5 } & B & 2 & 13 & 3 \\
\cline { 2 - 5 } & C & 0 & 4 & 14 \\
\hline
\end{tabular}

Figura 2.2: Exemplo de matriz de confusão para um problema de 3 classes, $A, B$ e $C$. 


\section{Capítulo 3}

\section{Abordagem Hierárquica de Decomposição do Problema de Classificação}

Um dos principais desafios inerentes ao problema de reconhecimentos de símbolos matemáticos está na grande quantidade de classes. Problemas com muitas classes apresentam uma quantidade maior de padrões de objetos, além de tipicamente apresentarem alguma sobreposição de informação entre eles.

Por esse motivo, uma forma amplamente empregada para aumentar a eficácia dos classificadores é a sub-divisão do problema em problemas menores. Um conjunto de classificadores pode então ser treinado, um para cada sub-problema, e os resultados posteriormente combinados. Essa abordagem segue a ideia de que aprender um grande número de conceitos simples é mais simples e mais útil do que aprender um único conceito complexo global (Kumar e Ghosh, 1999).

Por exemplo, Kumar et al. (2002) propôs uma abordagem hierárquica para construção de uma árvore de classificadores. A cada estágio da recursão o problema corrente é transformado em um problema binário com duas meta-classes. Essas meta-classes formam uma composição disjunta das classes originais do problema. Um classificador é usado em cada nó para dividir o problema nessas duas meta-classes, de forma que elas não compartilhem nenhum exemplo de mesma classe. Ao chegarmos a um estágio onde cada folha possua uma meta-classe correspondendo a uma única classe original, essa classe é retornada. Teremos gerado então uma árvore com $K$ folhas (sendo $K$ o número total de classes).

Algumas outras abordagens de decomposição de problemas também já foram aplicadas ao problema de reconhecimento de símbolos matemáticos. A abordagem de Watt e Xie (2005) utiliza correspondência elástica (Uchida e Sakoe, 2005) para o reconhecimento dos símbolos. Nesse método são definidos modelos relacionados a cada rótulo, e a partir de uma medida de distância encontramos o modelo com forma mais similar à do exemplo desconhecido. Como esse problema pode ser computacionalmente custoso, uma vez que é 
nescessário o cálculo da distância para cada um dos modelos, um conjunto de características extraídas dos exemplos é usado para limitar o espaço de busca. A partir de um conjunto pré-determinado de comparações entre os valores das características dos modelos, é possível diminuir o número de modelos para os quais será nescessário efetuar o cálculo da distância, o que corresponde à sub-divisões do problema completo, mesmo que de maneira manual, já que os valores limites das características são fixados.

Garain et al. (2004) utilizam um esquema de combinação de quatro classificadores para reconhecimento de símbolos matemáticos impressos. O primeiro classificador é usado para reconhecer algumas classes de símbolos com formas mais simples, mas de alta frequência em expressões usuais (Chaudhuri e Garain, 2000). Para as classes determinadas pelo classificador inicial como não-determinadas, uma combinação de três outros classificadores é usada para o reconhecimento dos padrões mais complexos de símbolos. Cada um dos quatro classificadores é diferenciado pelo conjunto de características que são usadas para treiná-los.

Com essas ideias em mente, tentamos definir uma abordagem para sub-divisão do problema utilizando árvores de decisão, aplicando assim uma forma automática de decomposição ao problema de reconhecimento de símbolos matemáticos manuscritos. Diferente da árvore de decisão tradicional, não é nescessário que cada folha apresente exemplos de somente uma classe, precisando apresentar somente um conjunto de dados que forma um problema mais simples do que o inicial.

O processo de divisão de cada nó da árvore acontece em dois passos principais. No primeiro são verificados os critérios de parada da divisão. Caso eles sejam atendidos, a divisão não segue em frente, tornando o nó em questão uma folha na árvore. Caso contrário, a divisão ocorre. Nesse caso, como comentado na seção 2.1.2, é necessário que encontremos a característica que melhor separe o conjunto de dados em questão, assim como o valor ótimo de separação.

\subsection{Critério de Parada}

Sendo o objetivo final melhorar a eficácia do classificador diminuindo o tamanho do problema, é interessante que a divisão seja interrompida no momento em que o conjunto dos desempenhos obtidos pelos classificadores treinados a partir dos dois filhos é inferior ao desempenho obtido pelo classificador treinado pelos exemplos associados ao nó corrente. Dessa forma a decomposição é finalizada quando novas decomposições reduzem o desempenho geral.

Uma forma de realizar isso pode ser a incorporação de uma base de dados para validação durante o treinamento. Para o sistema determinar se uma futura divisão do nó corrente é benéfica, são treinados três classificadores: um para o nó corrente, um para o seu possível filho direito, e outro para o seu possível filho esquerdo, os três a partir de suas respectivas bases de treinamento. Esses três classificadores são aplicados à base de validação referente 
ao nó correspondente (classificador do nó corrente à base de validação corrente, classificador do filho direito à base de validação do filho direito, etc). Duas taxas de acerto são geradas, uma para a aplicação do classificador referente ao nó corrente, e a outra sendo a junção dos resultados obtidos pelos dois filhos. Se a taxa de acerto dos filhos superar a taxa obtida pelo classificador do pai, consideramos que a divisão é benéfica, portanto ela é efetuada. Caso contrário, o algoritmo recursivo atinge seu caso base, e o nó corrente é retornado como folha.

Esse esquema de divisão de um nó é ilustrado na figura 3.1. O conjunto $X_{p}$ representa o conjunto total de exemplos do nó corrente, e $X_{e}$ e $X_{d}$ seus filhos esquerdo e direito respectivamente. As regiões $t$ representam as seções de exemplos de treinamento para cada conjunto, e as regiões $v$ as de validação. Treinando os três classificadores e aplicando-os às respectivas bases de validação, teremos o mesmo número de exemplos de validação em ambos os níveis da árvore, e o número de acertos pode ser então comparado.

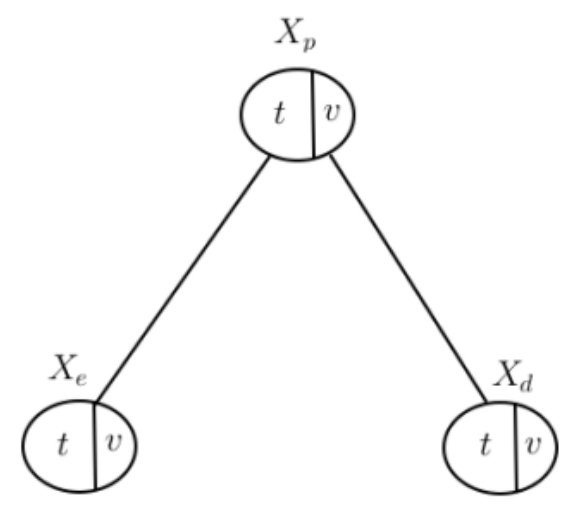

Figura 3.1: Esquema de decomposição de um nó.

Com a taxa de acerto na base de validação sendo o único critério de parada, a árvore pode continuar se expandindo até produzir folhas com uma quantidade menor de classes do que talvez fosse necessário. Por isso, como um critério de parada alternativo, podemos usar um limite ajustável do número máximo de classes que uma folha pode conter, terminando o processo também quando essa quantia for atingida.

\subsection{Preenchimento das Folhas}

A cada etapa de divisão de um nó em dois filhos, o conjunto de dados é divido em duas partes disjuntas com relação a exemplos, mas não disjuntas com relação às classes. Por exemplo, uma situação onde, a partir de 100 exemplos pertencentes à classe referente ao símbolo "a", 50 desses exeplos compõe o filho esquerdo e os outros 50 o filho direito, não é rara. Após sucessivas divisões dessa natureza, é possível que, em algumas folhas da árvore, o número de exemplos pertencentes à determinada classe possa ter diminuído o suficiente para não representar completamente aquele padrão de escrita. 
Uma forma simples de contornar esse problema é preencher as folhas com todos os exemplos disponíveis referentes às classes atribuídas àquela folha. Dessa forma, apesar de cada divisão ser feita analisando-se os exemplos, o resultado final é uma redução de classes. Por exemplo, consideremos que as classes "a", "b" e "c" possuem, respectivamente, 100, 80 e 50 exemplos no total. Consideremos também que a árvore seja construída com somente uma divisão (ou seja, duas folhas), de forma que a primeira receba 60 exemplos de "a" e 80 de "b", e a segunda receba 40 exemplos de "a" e 50 de "c". As classes "b" e "c" foram atribuídas completamente a folhas diferentes, enquanto que a classe "a" foi dividida em duas partes, e está presente em ambas folhas. Como forma de "completar" os dados de treinamento, todos os exemplos de "a" iniciais são atribuídos a ambas as folhas, deixando assim a primeira com 100 exemplos de "a" e 80 de "b", e a segunda com 100 exemplos de "a" e 50 de "c". Dessa forma, repartimos um problema de três classes em dois sub-problemas de duas classes, mas usando todos os exemplos disponíveis para cada classe em cada sub-problema.

É importante notar que a base de validação usada para determinar o critério de parada não é mais necessária uma vez que a folha já está determinada, então ela é simplesmente agregada a base de treinamento para formar um único conjunto de dados para aquela folha.

\subsection{Algoritmo de Treinamento}

A sequência de passos referente ao treinamento da árvore é mostrada a seguir. Denominamos $X_{p, t}$ o conjunto de dados do nó corrente separado para treinamento, assim como $X_{p, v}$ os exemplos para validação (analogamente para $X_{e}$ e $X_{d}$ ).

1. A partir de $X_{p, t}$, encontra-se a melhor divisão para os dois filhos $X_{e}$ e $X_{d}$, utilizando alguma métrica de divisão;

2. calcula-se as taxas de acerto $t_{p}$ (treinando em $X_{p, t}$ e testando em $X_{p, v}$ ) e $t_{f}$ (treinando dois classificadores em $X_{e, t}$ e $X_{d, t}$, testando respectivamente em $X_{e, v}$ e $X_{d, v}$, e agregando os resultados);

3. se $t_{f} \leq t_{p}$ :

(a) retorna o nó corrente como folha com um classificador treinado em $X_{p}$;

4. caso contrário:

(a) executa o algoritmo recursivamente a partir do passo 1 usando $X_{e}$ e $X_{d}$ como novos nós correntes;

(b) associa as duas sub-árvores retornadas ao nó corrente como filhos;

(c) retorna o nó corrente. 


\section{Capítulo 4}

\section{Representação, Coleta e Pré-processamento de Dados}

Uma base de dados a ser usada como entrada de um sistema de reconhecimento de padrões, em geral, é formada por um conjunto de exemplos que representam objetos pertencentes ao domínio do problema. Cada exemplo corresponde às informações extraídas de um único objeto. Essa extração pode ser realizada de várias formas, dependendo do problema em questão e do tipo de sistema a ser construído.

Em relação ao processo de coleta de dados de símbolos manuscritos, podemos classificar a escrita como on-line ou off-line. Símbolos coletados de forma off-line são representados por uma imagem contendo a escrita completa de um símbolo representada em pixels. Esse tipo de dados pode, por exemplo, ser obtido através do uso de um scanner para digitalizar uma sequência escrita. Os símbolos podem então ser segmentados em imagens individuais, para que finalmente informações relevantes referentes à sua forma possam ser extraídas.

Dizer que um símbolo é coletado de forma on-line significa dizer que o dado bruto do símbolo armazenado consiste de um conjunto de pontos sequenciais formando os tracejados realizados pela sua escrita. Essa escrita pode ser feita, por exemplo, em algum tipo de mesa digitalizadora, onde o toque de uma caneta sobre a tela da mesa indica a posição e o momento do ponto a ser coletado, uma vez que a tela é representada computacionalmente como um sistema de coordenadas. A figura 4.1 mostra o conjunto de pontos coletados na escrita de uma letra "a".

É comum também o uso das classificações on-line e off-line para se referir a tipos de reconhecimento. Nesse caso, o reconhecimento on-line ocorre enquanto a escrita está sendo realizada, enquanto que o reconhecimento off-line acontece posteriormente à entrada completa de dados. É importante que seja feita essa distinção, uma vez que dados on-line podem ser usados em reconhecimento tanto on-line como off-line.

Algumas das vantagens de se trabalhar com escrita on-line são:

- possibilidade de implantação do método em um sistema dinâmico de reconhecimento, com resposta imediata; 


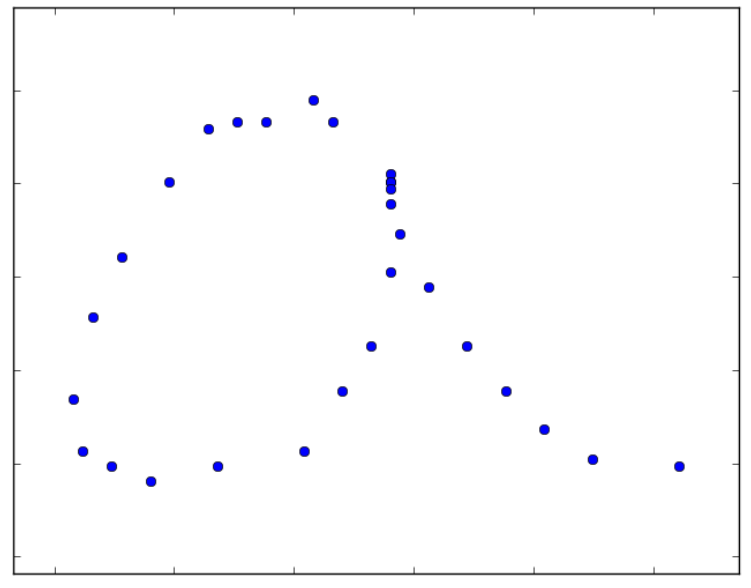

(a) Pontos coletados.

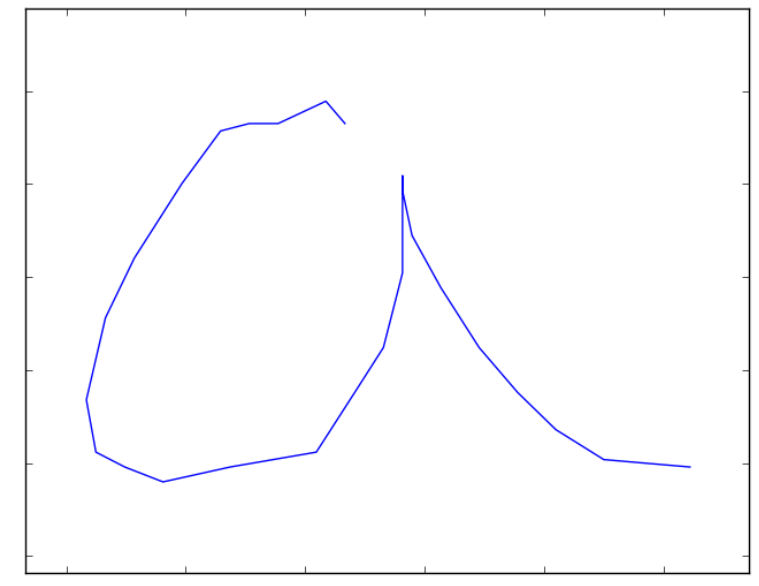

(b) Linhas reproduzindo a sequência de pontos.

Figura 4.1: Sistema de coordenadas com coleta de pontos de uma escrita da letra "a".

- uso em novos dispositivos com tecnologias de telas sensíveis ao toque;

- possibilidade do uso de informações dinâmicas de escrita (como velocidade, direção e número de traços) para o reconhecimento;

- maior facilidade em cálculos de uma série de pré-processamentos e extração de características (pela disponibilidade das informações citadas no item anterior);

- possível maior interação com o usuário durante o processo de reconhecimento (visto que ele pode enxergar os exemplos sendo reconhecidos enquanto os escreve);

- não é limitada à extração de características de dados on-line, uma vez que um conjunto de pontos em um sistema de coordenadas pode ser facilmente impresso em uma malha de pixels, transformando-o em escrita off-line.

A principal desvantagem da escrita on-line é a necessidade do uso de equipamento especial para a escrita. Já existem, porém, muitos dispositivos construídos com o intuito de tornar esse processo mais confortável para o usuário. Equipamentos como pranchetas eletrônicas ou canetas especiais que enviam informações de escrita para um computador permitem que usuários possam digitalizar a escrita mesmo escrevendo em papel.

A coleta dos dados em si pode ser realizada de várias formas. No resto deste texto, consideramos que ela é realizada em um computador com tela sensível ao toque, com o uso de uma caneta especial para esse tipo de equipamento.

\subsection{Representação de Dados}

O suporte (por exemplo, uma região retangular na tela) no qual a escrita é realizada é associado a um sistema de coordenadas discretas. No caso do nosso problema discutido no 
capítulo 1, cada exemplo corresponde a um símbolo. Em um símbolo a estrutura de dados mais básica é o ponto, definido da seguinte forma:

Definição 1. Um ponto $\mathcal{P}$ consiste de três valores $(x, y, t)$, sendo que $x$ e y representam as coordenadas relativas ao sistema de coordenadas adotado, e $t$ o valor temporal no qual a caneta esteve em $(x, y)$.

A partir do momento que a caneta encosta na tela, o estado da coleta muda para iniciar a leitura de pontos que é realizada a uma determinada taxa de frequência dependente do hardware. Os pontos ficarão mais espaçados quando a escrita é mais rápida, e mais próximos quando a escrita é mais lenta.

Dois pontos podem formar um segmento, como definido a seguir:

Definição 2. Chamamos simplesmente de segmento o segmento de reta entre dois pontos $\mathcal{P}_{i}$ e $\mathcal{P}_{j}$, que tem comprimento $\left\|\mathcal{P}_{i} \mathcal{P}_{j}\right\|$ e representação vetorial $\overrightarrow{\mathcal{P}_{i} \overrightarrow{\mathcal{P}}_{j}}$. Uma trajetória $T=\left\{\mathcal{P}_{i}, \mathcal{P}_{j}\right\}$ é uma sequência de segmentos formados por pares de pontos consecutivos que começam no ponto $\mathcal{P}_{i}$ e terminam no ponto $\mathcal{P}_{j}$.

Quando a caneta deixa o contato com a tela, o estado muda novamente e os pontos deixam de ser coletados. Então definimos traço como:

Definição 3. Um traço $\mathcal{T}$ é composto de uma lista de $n$ pontos consecutivos $\left\{\mathcal{P}_{i}=\left(x_{i}, y_{i}, t_{i}\right)\right\}_{i=1}^{n}$, $n>0$, onde o primeiro ponto corresponde ao local e momento em que a caneta que encontravase afastada toca a tela, e o último ponto corresponde ao último ponto coletado antes da caneta se afastar novamente da tela. Em outras palavras, um traço é uma trajetória maximal com respeito ao toque da caneta à tela.

Símbolos contém quantidades variadas de traços. Em alguns casos, é comum até que símbolos iguais tenham representações com número de traços diferentes.

Definição 4. Um símbolo $\mathcal{S}$ corresponde a um conjunto de $n_{t}$ traços $\left\{\mathcal{T}_{i}\right\}_{i=1}^{n_{t}}, n_{t}>0$. Traços são agrupados em símbolos utilizando algum método de segmentação.

Finalmente, uma expressão matemática corresponde a uma sequência de símbolos organizados em alguma forma estrutural definida formalmente por notações matemáticas conhecidas. Este trabalho, porém, trabalha com símbolos isolados, portanto a formação de expressões inteiras não será discutida.

\subsection{Notações}

A partir daqui usaremos uma série de notações para facilitar cálculos. Uma lista delas é apresentada a seguir:

- Como já comentado, $n$ é o número de pontos em um traço, e $n_{t}$ o número de traços em um símbolo; 
- $u_{x}$ e $u_{y}$ são vetores unitários que têm mesma direção que os eixos de coordenada $x$ e $y$ respectivamente, com $u_{y}$ direcionado para baixo;

- $N$ é o número total de pontos em um símbolo;

- $\mathcal{P}_{1}$ e $\mathcal{P}_{N}$ são os pontos iniciais e finais da escrita do símbolo;

- $L_{i, j}$ é o comprimento da trajetória (ou caminho) entre os pontos $\mathcal{P}_{i}$ e $\mathcal{P}_{j}$, definido como

$$
L_{i, j}=\sum_{l=i}^{j-1} \begin{cases}0 & \text { se } \mathcal{P}_{l} \text { é um ponto final de um traço } \\ \left\|\mathcal{P}_{l} \mathcal{P}_{l+1}\right\| & \text { caso contrário }\end{cases}
$$

- dos dois itens anteriores, temos que $L_{1, N}$ é o comprimento total de escrita do símbolo;

- $\mathcal{P}_{m}$ é o ponto médio da trajetória total, que é aproximado encontrando-se o primeiro ponto do símbolo (pela ordem como eles estão armazenados) que obedece a condição $L_{1, m} \geq L_{m, N}$

- $x_{\max }$ é o valor máximo da coordenada $x$ em um símbolo. Analogamente, $x_{\min }, y_{\max } \mathrm{e}$ $y_{\text {min }}$ são os outros valores extremos do símbolo;

- $B$ é a caixa envoltória do símbolo, sendo o retângulo definido por $x_{\max }, x_{\min }, y_{\max } \mathrm{e}$ $y_{\min }$

- $w=x_{\max }-x_{\min }$ é a largura de $B$, e $h=y_{\max }-y_{\min }$ é a altura de $B$. Caso $w$ ou $h$ sejam nulos, atribuímos 1 a esses valores;

- $c=\left(c_{x}, c_{y}\right)$ é o ponto localizado no centro de $B$;

- $\mu=\left(\mu_{x}, \mu_{y}\right)=\frac{1}{N} \sum_{i=1}^{N} \mathcal{P}_{i}$ é o centro de gravidade do conjunto de pontos.

- $\theta_{i}$ é o ângulo de virada entre dois segmentos consecutivos $\mathcal{P}_{i-1} \mathcal{P}_{i}$ e $\mathcal{P}_{i} \mathcal{P}_{i+1}$ (figura 4.2), calculado por

$$
\theta_{i}=\arccos \left(\frac{\overrightarrow{\mathcal{P}_{i-1} \mathcal{P}_{i}} \overrightarrow{\mathcal{P}_{i} \mathcal{P}_{i+1}}}{\left\|\mathcal{P}_{i-1} \mathcal{P}_{i}\right\|\left\|\mathcal{P}_{i} \mathcal{P}_{i+1}\right\|}\right)
$$

\subsection{Segmentação}

Em aplicações reais dificilmente é esperado que os símbolos sejam entrados separadamente. É responsabilidade então do sistema agregar os traços corretamente para formar símbolos. Uma abordagem ingênua para realizar segmentação de símbolos seria simplesmente separar componentes conexas. Isso causaria uma série de problemas, já que, como já foi comentado, vários símbolos, como "i", "=" ou "!", possuem mais de uma componente. Alguns cuidados também são necessários com símbolos que possuem relações espaciais diferenciadas (como $\sqrt{ }$ ou a barra de fração). 


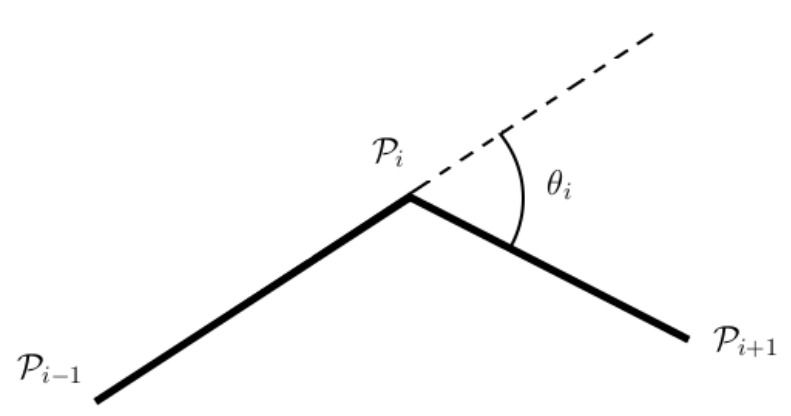

Figura 4.2: Ângulo de virada $\theta_{i}$.

Possivelmente as primeiras soluções apresentadas na literatura para resolver o problema de segmentação usam sinal explícito do usuário. Dessa forma o início e final de cada símbolo são indicados manualmente. Posteriormente começaram a ser usados limites temporais entre os traços, que determinam quando dois traços consecutivos pertencem ao mesmo símbolo, e quando pertencem a símbolos diferentes. Experimentos começaram então a ser feitos combinando indicadores espaciais, temporais, e outras informações calculadas a partir de dados de escrita, para aumentar a taxa de acerto do segmentador. Referências de trabalhos utilizando esses métodos podem ser encontradas em (Tappert et al., 1990).

Smithies et al. (1999) apresentam um algoritmo de agrupamento progressivo de traços. A ideia geral consiste em gerar todos os possíveis agrupamentos de traços da expressão, e então utilizar um classificador vizinho-mais-próximo (Duda et al., 2000) para reconhecer cada símbolo. Algumas heurísticas são usadas para diminuir o espaço de busca dos agrupamentos, como definir um limite máximo $k$ de traços para um mesmo símbolo (no caso $k=4$ ), e assumir que todos os traços que tiverem interseção entre si pertencerão ao mesmo símbolo. O classificador, além de retornar a categoria prevista de cada símbolo, retorna um valor representando o quão confiável é aquela predição. O agrupamento total que apresentar o maior dos menores valores de confiança de cada expressão é escolhido como agrupamento final. Apesar de ser simples e rápido, o método tem necessidade de correção manual de erros, que os autores alegam ser bem simples.

\subsection{Pré-processamento de Dados}

As informações de cada símbolo neste trabalho são representadas por conjuntos de pontos representando traços escritos. Esses pontos, porém, podem apresentar uma série de ruídos. As duas principais fontes de ruídos em coleta de símbolos manuscritos são falhas de hardware e particularidades de formas de escrita específicas.

Falhas de hardware acontecem devido à imprecisão do sistema. Não existe informação prévia sobre, por exemplo, a pressão que o usuário colocará na caneta sobre a tela enquanto 
ele está escrevendo. O grande número de fatores que podem influenciar na coleta de cada ponto pode tornar o sistema inconstante. Dessa inconstância, problemas podem ocorrer. Por exemplo, imprecisão no instante determinado como início ou fim da coleta de pontos para cada traço pode resultar no aparecimento de pequenas curvas que não existiam no traço original.

Exemplos específicos de escritas dos símbolos também podem ter particularidades, tanto em função da forma diferente de escrita de cada usuário (por exemplo, pessoas diferentes podem escrever a letra " $\mathrm{x}$ " ordenando os dois traços diferentemente), como do contexto em que o símbolo estava inserido (por exemplo, dentro de uma mesma expressão, um número "2" pode ser escrito em tamanhos diferentes, por estar dentro de uma raiz ou não). Isso pode fazer com que amostras de mesmos símbolos tenham conjuntos de pontos muito diferentes.

A solução usualmente empregada para tratar esses problemas é usar uma série de técnicas de pré-processamento em cada símbolo, tornando assim esses dados comparáveis.

Para o nosso problema detectamos duas classes principais de pré-processamentos: os que são aplicados a traços separadamente, e os que são usados no símbolo como um todo.

\subsubsection{Pré-processamentos de Traços Individuais}

\section{Remoção de Pontos Duplicados}

A existência de pontos de posições iguais em traços não traz nenhuma informação sobre a escrita do símbolo. Uma forma simples de reduzir redundâncias é a simples eliminação de pontos duplicados. Dessa forma todo ponto $\mathcal{P}_{j}=\left(x_{j}, y_{j}, t_{j}\right)$ para $j \in\{1, \cdots, n\}$, tal que já exista um ponto anterior $\mathcal{P}_{i}=\left(x_{i}, y_{i}, t_{i}\right)$ no qual $x_{j}=x_{i}$ e $y_{j}=y_{i}$, é eliminado.

\section{Suavização}

Suavização de sinais é a substituição de cada valor pela média dos valores ao redor dele. Dado um sinal $x_{1}, x_{2}, \ldots, x_{n}$ e uma largura $k$ da vizinhança a ser considerada, calculamos a média em $x_{i}$ dos $k$ pontos que têm $x_{i}$ como ponto central. Considerando $r=(k-1) / 2$, cada coordenada $x_{i}$ é então atualizada calculando

$$
x_{i}^{*}=\frac{1}{k} \sum_{j=-r}^{r} x_{i+j} .
$$

Para o caso bidimensional, somente repetimos o cálculo analogamente para as coordenadas do eixo $y$.

A média calculada pode também ser ponderada, dando mais ênfase, por exemplo, aos pontos mais próximos a $x_{i}$. Nesse caso diferentes coeficientes $\gamma$ são utilizados para multiplicar as coordenadas, de forma que 


$$
\begin{aligned}
x_{i}^{*} & =\sum_{j=-r}^{r} \gamma_{j} x_{i+j}, \\
y_{i}^{*} & =\sum_{j=-r}^{r} \gamma_{j} y_{i+j},
\end{aligned}
$$

e

$$
\sum_{j=-r}^{r} \gamma_{j}=1
$$

Tapia e Rojas (2003), por exemplo, utilizam uma janela de $k=3$ pontos, com coeficientes $\gamma_{-1}=\gamma_{1}=1 / 4$ e $\gamma_{0}=1 / 2$.

As figuras 4.3a e 4.3b mostram, respectivamente, uma escrita da letra "a" antes e depois do processo de suavização de pontos.

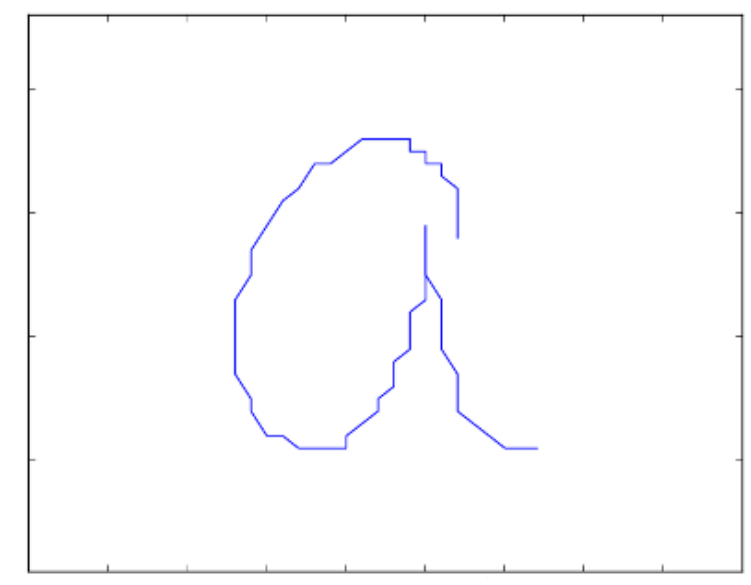

(a) Escrita da letra "a" antes da suavização.

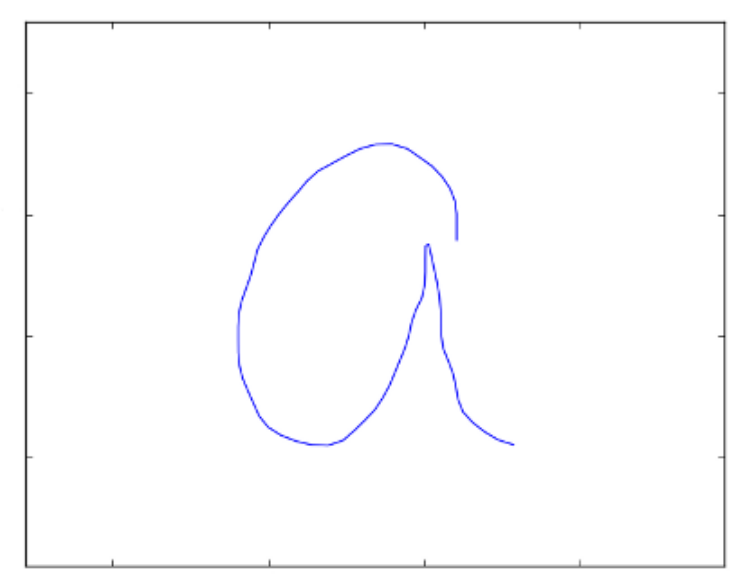

(b) Escrita da letra "a" após a suavização.

Figura 4.3: Exemplo de suavização.

\section{Eliminação de Ganchos}

Ganchos são pequenos desvios bruscos de direção de escrita que podem ocorrer no começo e no final de traços, como mostrado na figura 4.4. Eles geralmente aparecem devido a atrasos na detecção do toque ou separação da caneta com a tela em escritas rápidas.

Em geral, dois aspectos de um conjunto de pontos são verificados para a detecção de ganchos: o quão pequeno é o ângulo $\theta_{i}$ (formado pelos pontos $\mathcal{P}_{i-1}, \mathcal{P}_{i}$ e $\mathcal{P}_{i+1}$ ), e o quão próximo o ponto $\mathcal{P}_{i}$ está de alguma das pontas do traço.

Para a primeira condição, dizemos que o ponto $\mathcal{P}_{i}$ pode ser o início ou fim de um gancho se $\theta_{i}>\theta_{l}$, dado um $\theta_{l}$ pré-estabelecido. 


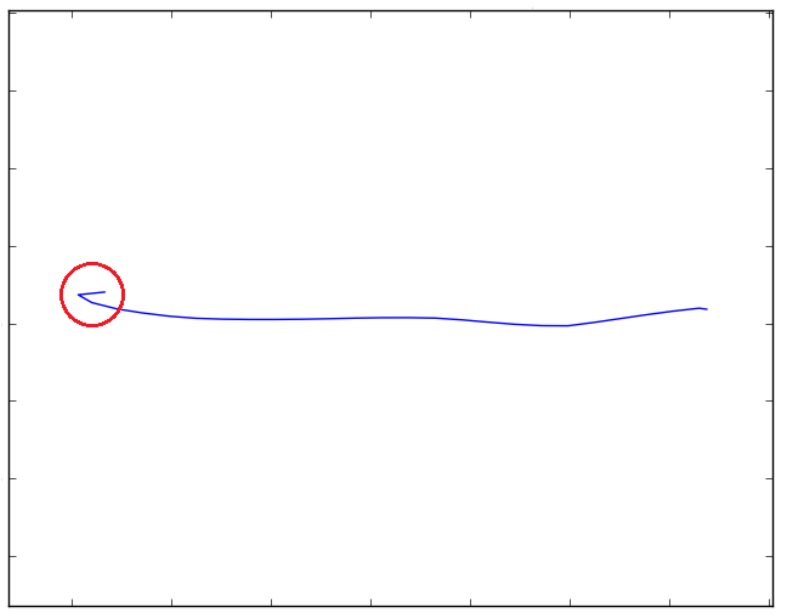

Figura 4.4: Escrita de um símbolo "-" com gancho.

A segunda condição consiste em verificar se a distância entre $\mathcal{P}_{i}$ e a ponta do traço mais próxima é pequena o suficiente, proporcionalmente ao tamanho do traço. Assim é preciso que $\mathcal{P}_{i}$ satisfaça uma das condições

$$
L_{1, i}<\lambda L_{1, n}
$$

$\mathrm{Ou}$

$$
L_{i, n}<\lambda L_{1, n}
$$

tal que $n$ é o número de pontos do traço, $L_{i, j}$ é o comprimento da trajetória entre os pontos $\mathcal{P}_{i}$ e $\mathcal{P}_{j}$, e $\lambda$ é uma constante entre 0 e 1 que representa a proporção máxima de um traço que pode ser considerada como gancho. Se a distância entre $\mathcal{P}_{i}$ e uma das pontas é menor do que essa porção com comprimento do traço, o ponto $\mathcal{P}_{i}$ encontra-se em uma área do traço onde podem existir ganchos.

Tapia (2004) utiliza os valores $\theta_{l}=85$ graus e $\lambda=0.12$.

Na figura 4.5 mostramos o mesmo traço anterior após a aplicação da eliminação de ganchos.

\section{Reamostragem de Pontos}

Como já foi comentado, dependendo da velocidade em que a escrita é realizada, a frequência de pontos coletados muda. Escritas rápidas, por exemplo, geram pontos mais espaçados. Escritas lentas geram pontos mais próximos. Um processamento interessante seria então reamostrar pontos do traço forçando uma distância $d$ (para um dado $d$ ) entre cada par de pontos (Huang et al., 2007).

A partir de um ponto $\mathcal{P}_{i}$, temos duas opções de operação possíveis:

- se $\left\|\mathcal{P}_{i} \mathcal{P}_{i+1}\right\|>d$ : precisamos inserir novos pontos espaçados por $d$ para completar o 


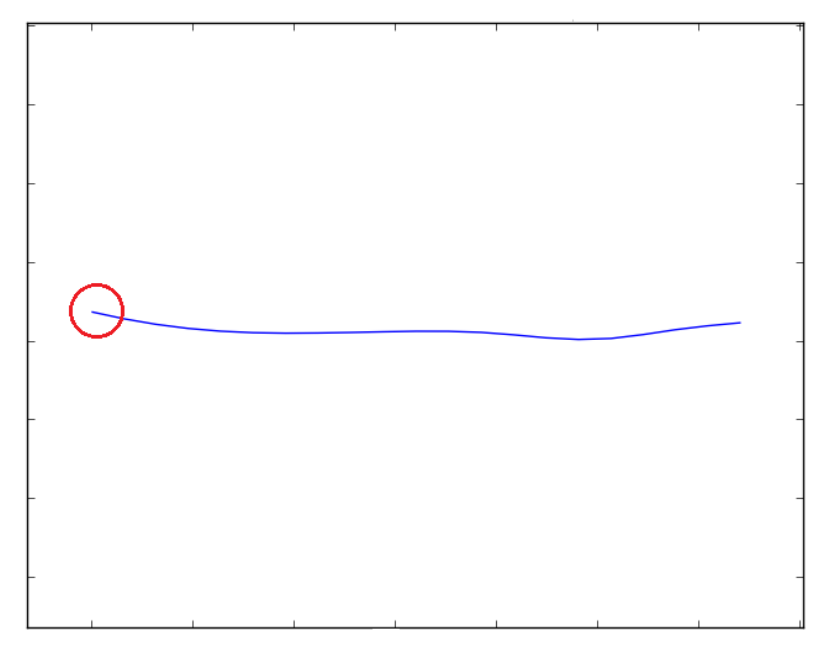

Figura 4.5: Escrita de um símbolo "-" após a eliminação de ganchos.

espaço;

- se $\left\|\mathcal{P}_{i} \mathcal{P}_{i+1}\right\|<d$ : precisamos eliminar pontos até que a distância $d$ seja alcançada.

Para o primeiro caso temos um espaço vazio, e precisamos adicionar novos pontos. Para isso, a partir de $\mathcal{P}_{i}$ e $\mathcal{P}_{i+1}$, calculamos o novo ponto $\mathcal{P}^{*}$ entre os dois usando as regras

$$
\begin{gathered}
x^{*}= \begin{cases}x_{i}+\sqrt{\frac{d^{2}}{k^{2}+1}} & \text { se } x_{i}<x_{i+1} \\
x_{i}-\sqrt{\frac{d^{2}}{k^{2}+1}} & \text { se } x_{i}>x_{i+1} \\
x_{i} & \text { se } x_{i}=x_{i+1}\end{cases} \\
y^{*}= \begin{cases}k x^{*}+y_{i}-k x_{i} & \text { se } x_{i} \neq x_{i+1} \\
y_{i}+d & \text { se } y_{i}<y_{i+1} \text { e } x_{i}=x_{i+1} \\
y_{i}-d & \text { se } y_{i}>y_{i+1} \text { e } x_{i}=x_{i+1}\end{cases}
\end{gathered}
$$

sendo que $k$ representa a inclinação da linha entre $\mathcal{P}_{i}$ e $\mathcal{P}_{i+1}$, calculado por $k=\frac{y_{i+1}-y_{i}}{x_{i+1}-x_{i}}$, quando $x_{i} \neq x_{i+1}$.

No segundo caso, quando $\left\|\mathcal{P}_{i} \mathcal{P}_{i+1}\right\|<d$, procuramos o primeiro ponto $\mathcal{P}_{i+w}$, tal que $\left\|\mathcal{P}_{i} \mathcal{P}_{i+w}\right\|>d$. A partir dele calculamos uma nova distância, chamada $d_{d i f}$, para, a partir de $\mathcal{P}_{i+w-1}$, gerar o próximo ponto. Para que o espaçamento $d$ seja mantido, $d_{d i f}$ é calculado como

$$
d_{d i f}=\left(\sum_{j=i}^{i+w-1}\left\|\mathcal{P}_{j} \mathcal{P}_{j+1}\right\|\right)-d .
$$

Dessa forma utilizamos as regras anteriores $\left(x^{*}\right.$ e $\left.y^{*}\right)$ para gerar um novo ponto com distância $d_{\text {dif }}$ de $\mathcal{P}_{i}$, e todos os pontos $\left\{\mathcal{P}_{i+1}, \cdots, \mathcal{P}_{i+w-1}\right\}$ são descartados.

O processo se repete até que o último ponto do traço é inserido. 
O valor de $d$ é geralmente menor do que a média dos tamanhos de segmentos do traço. Com essa média $L_{m}$ então correspondendo a

$$
L_{m}=\frac{\sum_{i=1}^{n-1}\left\|\mathcal{P}_{i} \mathcal{P}_{i+1}\right\|}{n},
$$

calculamos $d$ multiplicando $L_{m}$ por uma costante $p_{l}$, formando $d=p_{l} L_{m}$. Neste trabalho utilizamos $p_{l}=0.9$.

\section{Padronização da Orientação de cada Traço}

Matsakis (1999) propôs em seu trabalho um pré-processamento para padronização da orientação de escrita dos traços, como uma tentativa de aumentar a normalização entre escritas diferentes de símbolos iguais. A ideia é atribuir a cada traço uma classificação quanto à sua direção, sendo \{vertical, horizontal, diagonal, fechado\} o conjunto de classificações possíveis, e então, baseado nessa informação, padronizar a orientação dos pontos.

Primeiro calculamos as razões

$$
\begin{aligned}
& R_{x}=\frac{\left|x_{n}-x_{1}\right|}{D} \\
& R_{y}=\frac{\left|y_{n}-y_{1}\right|}{D}
\end{aligned}
$$

onde $x_{1}$ e $x_{n}$ são, respectivamente, coordenadas do primeiro e do último pontos do traço, e $D$ é o comprimento da diagonal da caixa envoltória do traço. Essas razões representam a variação de cada coordenada, entre o início e o final do traço.

A partir disso, dado uma constante pré-determinada $\delta$, classificamos cada traço como

- vertical se

$$
R_{x}<\delta \text { e } R_{y} \geq \delta
$$

- horizontal se

$$
R_{x} \geq \delta \text { e } R_{y}<\delta
$$

- diagonal se

$$
R_{x} \geq \delta \text { e } R_{y} \geq \delta
$$

- fechado se

$$
R_{x}<\delta \text { e } R_{y}<\delta
$$

Uma vez classificado o traço, revertemos a ordem dos pontos de traços horizontais se $x_{1}>x_{n}$, e de traços verticais e diagonais se $y_{1}>y_{n}$. Caso essas condições não estejam satisfeitas, ou o traço for identificado como fechado, nenhuma mudança é realizada. No final 
a reversão é feita, dado um traço $\mathcal{T}=\left\{\mathcal{P}_{i}\right\}_{i=1}^{n}$, calculando

$$
\mathcal{T}^{*}=\left\{\mathcal{P}_{n+1-i}\right\}_{i=1}^{n}
$$

Alguns comentários devem ser feitos também com relação à escolha do $\delta$. Se o $\delta$ for grande demais (já que o mesmo $\delta$ é utilizado nas comparações de $R_{x}$ e $R_{y}$ ), uma grande quantidade de exemplos pertencentes à outras classes serão atribuídos à classe "fechado". Por outro lado, se ele for pequeno demais, muitos exemplos poderão ser falsamente atribuídos à classe "diagonal". O trabalho de Matsakis (1999) relatou que $\delta=0.37$ teve uma precisão maior em seus experimentos.

\subsubsection{Pré-processamentos de Símbolos Individuais}

\section{Padronização da Ordenação dos Traços}

Outro pré-processamento sugerido por Matsakis (1999) consiste na padronização na ordenação de traços. Diferentes usuários geralmente apresentam uma grande variação em relação à ordem na qual eles escrevem traços, portanto a reordenação tornaria mais similares instâncias diferentes de símbolos de mesmas classes.

Para isso, atribuímos um valor $\beta_{i}$ para cada um dos traços, e depois reordenamos os traços no símbolo de acordo com $\beta_{i}$, do menor para o maior. $\mathrm{O}$ valor $\beta_{i}$ corresponde ao ângulo formado entre a reta horizontal e o segmento que une o canto superior esquerdo da caixa envoltória e o último ponto do traço $\mathcal{T}_{i}$.

Consideremos o ponto $\mathcal{P}_{T E}=\left(x_{\text {min }}, y_{\text {min }}\right)$ mais ao topo e mais à esquerda da caixa envoltória. Esse ponto, em relação ao ponto $\mathcal{P}_{T D}=\left(x_{\text {max }}, y_{\min }\right)$ mais ao topo e mais à direita, forma a reta $\mathcal{P}_{T E} \mathcal{P}_{T D}$. O mesmo ponto, em relação ao último ponto $\mathcal{P}_{n}$ do traço $\mathcal{T}_{i}$, forma a reta $\mathcal{P}_{T E} \mathcal{P}_{n}$. O ângulo $\beta_{i}$ referente ao traço $\mathcal{T}_{i}$ corresponde então ao ângulo entre as retas $\mathcal{P}_{T E} \mathcal{P}_{T D}$ e $\mathcal{P}_{T E} \mathcal{P}_{n}$, como mostrado na figura 4.6.

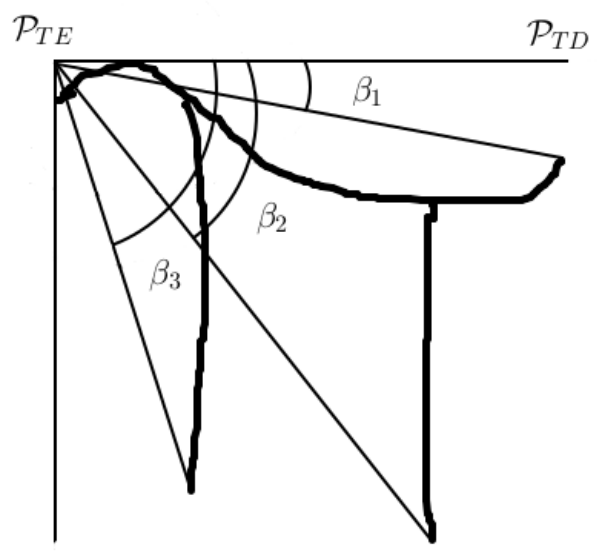

Figura 4.6: Símbolo " $\pi$ " com indicação dos ângulos de cada um de seus três traços. 


\section{Normalização}

Para que símbolos possam ser comparados, um processamento comum é a sua normalização com respeito à posição e a escala. Para isso, fixa-se um quadrado $[0, M] \times[0, M]$ (figura 4.7), e então cada símbolo é "encaixado" nesse quadrado por meio de uma operação de translação seguida pela mudança de escala.

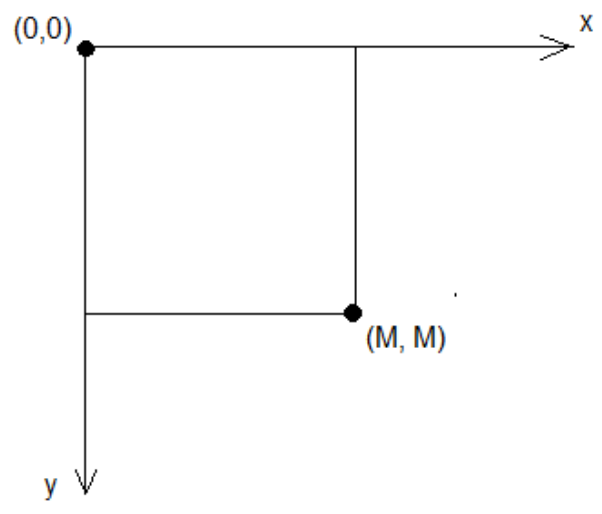

Figura 4.7: Posição do quatrado $M \times M$ no sistema de coordenadas.

Seja $d=\max \{h, w\}$ a maior dimensão da caixa envoltória do símbolo. Enquadra-se o símbolo em um quadrado $d \times d$, de modo que seu centro coincida com o centro da caixa envoltória, como na figura 4.8. A translação é realizada movendo-se o símbolo de forma que o canto superior esquerdo do quadrado $d \times d$ que o envolve coincida com a origem $(0,0)$.

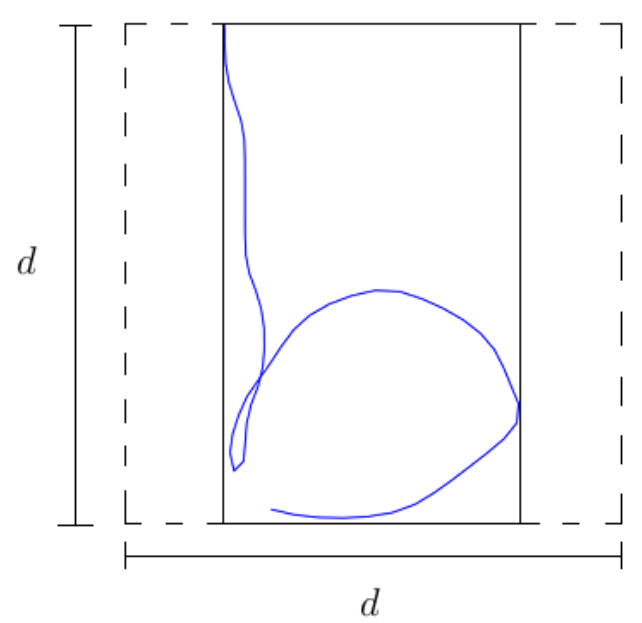

Figura 4.8: Escrita de um "b" com sua respectiva caixa envoltória, e o quadrado $d \times d$ pontilhado.

Em seguida, o símbolo passa por uma mudança de escala para que a dimensão da caixa $d \times d$ coincida com a caixa $M \times M$. Para tanto calcula-se o fator de escala $R=\frac{M}{L}$ e então multiplica-se por $R$ cada coordenada dos pontos que compõem o símbolo. 


\section{Capítulo 5}

\section{Extração de Características}

Neste capítulo são descritas as características propostas no trabalho de Delaye e Anquetil (2013), que são utilizadas na parte experimental deste trabalho. O conjunto de características proposto por eles é chamado HBF49 e é dividido em dois grupos: características dinâmicas e características visuais.

Características dinâmicas têm como objetivo modelar o processo de escrita, tirando vantagem da parte "on-line" das informações, como a direção de escrita, o número de traços escritos, etc. Características visuais são projetadas de forma a não depender do processo de escrita, e sim da aparência do símbolo escrito, como o comprimento da trajetória completa da caneta, o ângulo diagonal da caixa envoltória, etc.

A ideia proposta pelos autores consiste na construção de um conjunto de características que possa ser utilizado em problemas gerais de reconhecimento de escrita on-line, sem dependências de particularidades de um problema específico.

São 49 características no total, e elas serão identificadas aqui por $f_{i}$, tal que $i \in\{1, \cdots, 49\}$.

\subsection{Características Dinâmicas}

Pontos iniciais e finais do símbolo: Apesar da variação de escrita entre usuários, pontos iniciais e finais de símbolos geralmente apresentam posições estáveis, sobretudo em símbolos mais simples, como símbolos de um único traço. Para representar esses pontos, seja $M=\max (h, w)$, de forma que $[0, M] \times[0, M]$ forme um quadrado centrado em $c=\left(c_{x}, c_{y}\right)$. Então calculamos características para o ponto inicial

$$
\boldsymbol{f}_{\mathbf{1}}=\frac{x_{1}-c_{x}}{M}+\frac{1}{2}, \quad \boldsymbol{f}_{\mathbf{2}}=\frac{y_{1}-c_{y}}{M}+\frac{1}{2}
$$

e para o ponto final

$$
\boldsymbol{f}_{\mathbf{3}}=\frac{x_{N}-c_{x}}{M}+\frac{1}{2}, \quad \boldsymbol{f}_{\mathbf{4}}=\frac{y_{N}-c_{y}}{M}+\frac{1}{2} .
$$

Vetor do primeiro para o último ponto: 
As informações sobre a direção entre o primeiro e o último ponto do símbolo também são importantes para a caracterização da dinâmica da escrita. A partir do vetor $v=\overrightarrow{\mathcal{P}_{1} \mathcal{P}_{n}}$, calculamos a sua norma, assim com o seno e o cosseno do seu ângulo formado com a linha horizonal, gerando as três características

$$
\boldsymbol{f}_{5}=\|v\|, \quad \boldsymbol{f}_{6}=\frac{\vec{v} \cdot \overrightarrow{u_{x}}}{\|v\|}, \quad \boldsymbol{f}_{7}=\frac{\vec{v} \cdot \overrightarrow{u_{y}}}{\|v\|} .
$$

Quando a norma de $v$ é muito pequena, os valores de seno e cosseno calculados podem ser instáveis. Por esse motivo, caso $\|v\|$ seja menor que um limite pré-estabelecido $d_{\text {min }}$, atribuímos zero às características $f_{6}$ e $f_{7}$. Neste trabalho usamos $d_{\min }=\max (h, w) / 4$, pois é o valor utilizado por Delaye e Anquetil (2013).

\section{Fecho:}

Um valor que pode ser usado para diferenciar padrões de escritas fechados (como laços e círculos) de padrões alongados (como barras e integrais) é denominado fecho, é dado pela razão entre a norma do vetor $v$ citado anteriormente e o comprimento total $L_{1, N}$, pela equação

$$
f_{8}=\frac{\|v\|}{L_{1, N}}
$$

\section{Ângulo do vetor inicial:}

Como usado na implementação de Delaye e Anquetil (2013), ao calcular um vetor $\vec{s}$ da direção inicial de escrita do símbolo, é útil considerar o primeiro e o terceiro ponto no lugar dos dois primeiros. Dessa forma temos $s=\overrightarrow{\mathcal{P}_{1} \mathcal{P}_{3}}$. A partir desse vetor, como anteriormente, calculamos o cosseno e seno

$$
\boldsymbol{f}_{\mathbf{9}}=\frac{\vec{s} \cdot \overrightarrow{u_{x}}}{\|s\|}, \quad \boldsymbol{f}_{\mathbf{1 0}}=\frac{\vec{s} \cdot \overrightarrow{u_{y}}}{\|s\|} .
$$

A estabilidade dessas medidas é garantida pelo fato de os pontos do símbolo terem sido reamostrados com espaçamento igual. Dessa forma não corremos o risco de termos o valor de $\|s\|$ muito pequeno.

\section{Inflexões:}

Características úteis para distinguir diferentes traços em formas de "u" (como "u" e "n" por exemplo) são chamadas inflexões, e são calculadas diferenciando-se o ponto médio $\mathcal{P}_{m}$ da média dos pontos inicial e final do símbolo. Assim, calculamos

$$
\boldsymbol{f}_{\mathbf{1 1}}=\frac{1}{w}\left(x_{m}-\frac{x_{1}+x_{N}}{2}\right), \quad \boldsymbol{f}_{\mathbf{1 2}}=\frac{1}{h}\left(y_{m}-\frac{y_{1}+y_{N}}{2}\right) .
$$

Delaye e Anquetil (2013) comentam que Willems e Niels (2008) apresentam características mais complexas para fornecer esse tipo de informação, mas que as descritas acima são 
preferíveis por sua simplicidade.

\section{Proporção da trajetória de traços direcionados para baixo:}

Segundo Anquetil e Lorette (1997), a proporção do comprimento da escrita que é direcionada para baixo na sequencia de pontos fornece uma importante percepção da forma do símbolo. Como o sistema de coordenadas usual para representação gráfica é formado pela coordenada $x$ direcionada para a direita e a coordenada $y$ direcionada para baixo, um segmento de traço orientado para baixo corresponde a um segmento de traço no qual a coordenada $y$ de seus pontos aumenta.

Para detectar quais desses segmentos têm de fato um aumento no $y$, considerando uma trajetória $T=\left\{\mathcal{P}_{i}, \mathcal{P}_{j}\right\}$, é preciso que sejam satisfeitas as seguintes condições:

- Toda a trajetória $T$ pertence a um único traço;

- $D=\sum_{k=i}^{j-1} \max \left(0, y_{k+1}-y_{k}\right)$ é a distância cumulativa de segmentos orientados para baixo, e é menor que um limite $\mathcal{L}_{1}$;

- a trajetória $T$ não contém nenhuma subsequência de pontos $\mathcal{P}_{p} \ldots \mathcal{P}_{q}$ tal que a distância cumulativa de segmentos orientados para cima $U=\sum_{k=p}^{q-1} \max \left(0, y_{k}-y_{k+1}\right)$ seja superior a um limite $\mathcal{L}_{2}$.

Para uma normalização de tamanho 128, os valores limites sugeridos por Delaye e Anquetil (2013) são $\mathcal{L}_{1}=2$ e $\mathcal{L}_{2}=5$.

A característica corresponde a

$$
\boldsymbol{f}_{13}=\frac{\sum L_{i, j}}{L_{1, N}}
$$

sendo que $i$ e $j$ são os limites extremos de todas as trajetórias detectadas. O denominador na fração correspondente ao comprimento total do símbolo foi inserido para normalizar a soma calculada. Considerando o exemplo ilustrativo de dois símbolos apresentados na figura 5.1, temos os traços orientados para baixo marcados com uma linha mais grossa, e temos seus respectivos comprimentos. Se a característica fosse somente o acúmulo das distâncias direcionadas para baixo, esses dois símbolos apresentariam o mesmo valor. Como o valor é normalizado, as características $\boldsymbol{f}_{\mathbf{1 3}}$ de cada um desses símbolos são drasticamente diferentes.

\section{Número de traços:}

Muito embora seja verdade que diferentes autores possam escrever um mesmo símbolo usando números diferentes de traços, símbolos de forma mais complexa têm a tendência de serem escritos com mais traços. Além disso, existe uma série de símbolos (como "!" ou ":") que não podem ser escritos utilizando um único traço. O número de traços $n_{t}$ do símbolo 

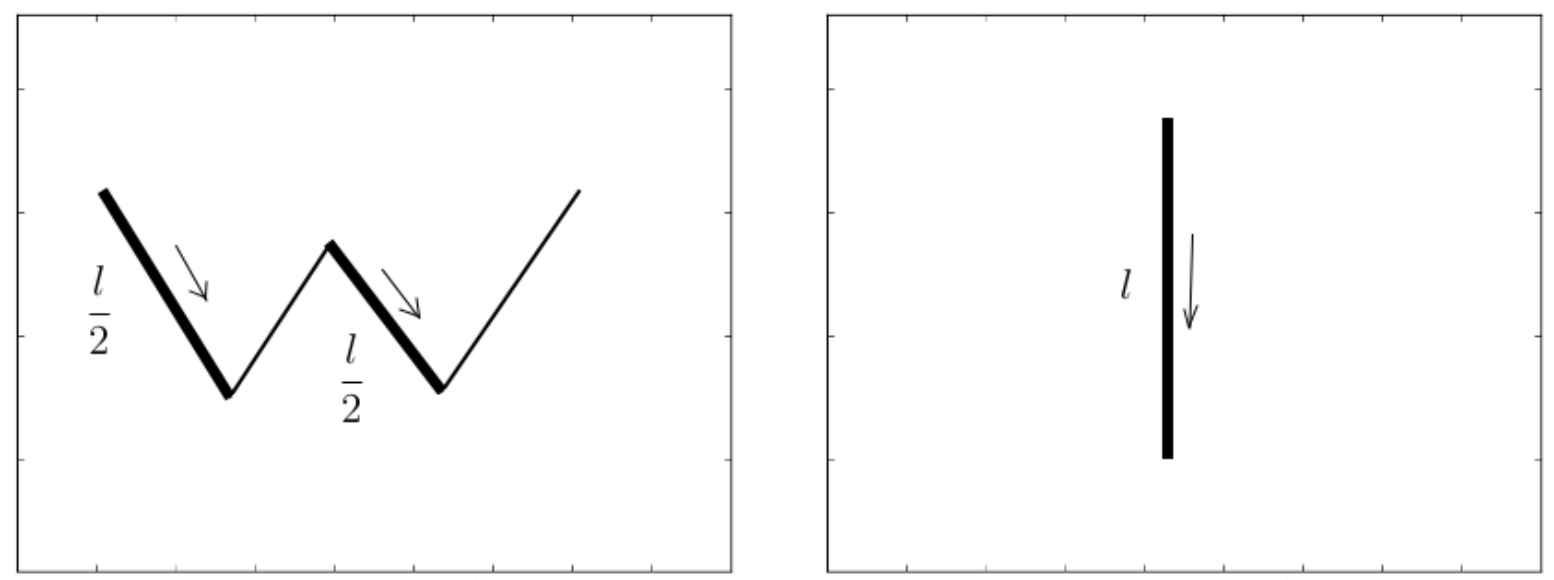

Figura 5.1: Exemplo ilustrativo de símbolos com marcações em suas trajetórias direcionadas para baixo.

então por si só é considerado uma informação importante para a caracterização de várias classes de símbolos. Dessa forma temos

$$
\boldsymbol{f}_{14}=n_{t}
$$

\subsection{Características Visuais}

\section{Ângulo da diagonal da caixa envoltória:}

O ângulo entre a diagonal da caixa que envolve o símbolo e a linha horizontal (Rubine, 1991) é medido através de

$$
\boldsymbol{f}_{15}=\arctan \frac{h}{w}
$$

\section{Comprimento da trajetória:}

O comprimento total da trajetória de escrita também é uma informação importante, já que fornece um meio simples de diferenciar símbolos curtos e simples de símbolos mais longos e complexos.

$$
\boldsymbol{f}_{16}=L_{1, N}
$$

Além disso, símbolos distintos que possuem caixas envoltórias de dimensões similares também podem ser diferenciados com facilidade se relacionarmos a altura e largura do símbolo com o seu respectivo comprimento total, calculando

$$
\boldsymbol{f}_{\mathbf{1 7}}=\frac{w+h}{L_{1, N}}
$$




\section{Desvio:}

Outra característica independente de orientação de escrita pode ser obtida calculando a média das distâncias entre cada ponto e o centro de gravidade $\mu=\left(\mu_{x}, \mu_{y}\right)$ do símbolo, obtendo assim o desvio médio.

$$
\boldsymbol{f}_{\mathbf{1 8}}=\frac{1}{N} \sum_{i=1}^{N}\left\|\mu \mathcal{P}_{i}\right\|
$$

\section{Média da direção de escrita:}

A média das direções de escrita de cada segmento do símbolo é um descritor usado para representar de forma integral as variações de direção em uma trajetória, e é definido por

$$
\boldsymbol{f}_{\mathbf{1 9}}=\frac{1}{N-1} \sum_{i=1}^{N-1} \arctan \left(\frac{y_{i+1}-y_{i}}{x_{i+1}-x_{i}}\right)
$$

\section{Curvatura e perpendicularidade:}

Sabemos que $\theta_{i}$ corresponde ao ângulo de virada formado pelos dois segmentos consecuti$\operatorname{vos} \mathcal{P}_{i-1} \mathcal{P}_{i}$ e $\mathcal{P}_{i} \mathcal{P}_{i+1}$. Somando todos os $\theta_{i}$ calculados em um símbolo obtemos sua curvatura. Somando o quadrado dos senos desses mesmos $\theta_{i}$ obtemos sua perpendicularidade.

$$
\boldsymbol{f}_{\mathbf{2 0}}=\sum_{i=2}^{N-1} \theta_{i}, \quad \boldsymbol{f}_{\mathbf{2 1}}=\sum_{i=2}^{N-1} \sin ^{2} \theta_{i}
$$

Curvaturas são úteis para diferenciar linhas retas de formas curvilíneas. Perpendicularidade é útil para detectar mudanças abruptas de direção em uma sequência de pontos.

\section{k-Perpendicularidade e k-ângulo:}

Outra forma interessante de utilizar a ideia de ângulos entre segmentos é aumentando o espaçamento entre os pontos dos segmentos. Considerando então um valor $k$, os ângulos $\theta_{i}^{k}$ são calculados entre os segmentos $\overrightarrow{\mathcal{P}_{i-k} \mathcal{P}_{i}}$ e $\overrightarrow{\mathcal{P}_{i} \mathcal{P}_{i+k}}$ (onde os três pontos em questão pertencem ao mesmo traço) por

$$
\theta_{i}^{k}=\arccos \left(\frac{\overrightarrow{\mathcal{P}_{i-k} \mathcal{P}_{i}} \overrightarrow{\mathcal{P}_{i} \mathcal{P}_{i+k}}}{\left\|\mathcal{P}_{i-k} \mathcal{P}_{i}\right\|\left\|\mathcal{P}_{i} \mathcal{P}_{i+k}\right\|}\right)
$$

A partir desses valores então, analogamente às características anteriores, calculamos as k-perpendicularidades dos símbolos, assim como o $\theta_{i}^{k}$ máximo de cada um, chamado de k-ângulo

$$
\boldsymbol{f}_{\mathbf{2 2}}=\sum_{i=k+1}^{N-k} \sin ^{2} \theta_{i}^{k}, \quad \boldsymbol{f}_{\mathbf{2 3}}=\max _{i=k+1}^{N-k} \theta_{i}^{k}
$$

Dada a utilização do tamanho 128 na normalização, Delaye e Anquetil (2013) relatam 
que fixar $k=2$ traz bons resultados.

\section{Histograma de ângulos absolutos:}

Histogramas são representações gráficas de distribuições de frequências muito utilizadas em várias aplicações. No caso do histograma angular, são representadas frequências da ocorrência de ângulos. No nosso caso, cada ângulo absoluto $\alpha_{i}$ é formado pelo vetor $\overrightarrow{\mathcal{P}_{i} \mathcal{P}_{i+1}}$ com o eixo horizontal.

Definimos um espaço angular com oito regiões, nomeadas de $h_{1}$ a $h_{8}$, e a cada região $h_{j}$ associamos o respectivo vetor central $v_{j}$ como na figura 5.2 .

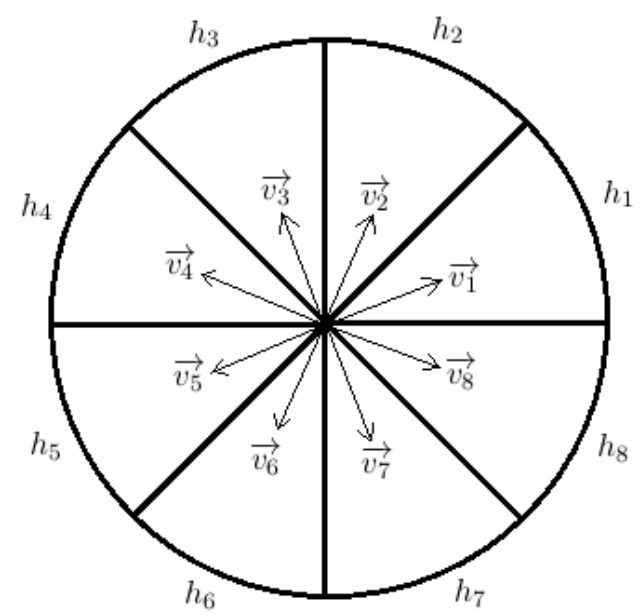

Figura 5.2: Espaço angular de ângulos absolutos com suas oito regiões e vetores centrais.

Supondo que o segmento se encontre dentro da região $h_{p}$, e a outra região mais próxima seja a região $h_{q}$, o método proposto adiciona a contagem desse segmento às duas regiões $h_{p}$ e $h_{q}$. As adições são calculadas com base na distância angular entre $\overrightarrow{\mathcal{P}_{i} \mathcal{P}_{i+1}}$ e o vetor central da região em questão.

Seja $\xi$ o ângulo entre $\overrightarrow{\mathcal{P}_{i} \mathcal{P}_{i+1}}$ e $v_{p}$. $\grave{A} h_{p}$, adicionamos então o valor

$$
\varphi_{p}=1-\frac{\xi}{\pi / 4}
$$

Analogamente para $h_{q}$, como a soma $\varphi_{p}+\varphi_{q}$ deve equivaler à uma contagem, temos

$$
\varphi_{q}=1-\varphi_{p}
$$

Adicionando esses valores para cada segmento no símbolo, temos os valores finais de $h_{1}$ a $h_{8}$. Sabemos que para cada traço o número de segmentos é igual ao número de pontos menos um, e que temos $n_{t}$ traços, então o número total de segmentos é $n_{s}=N-n_{t}$. Sabemos também que cada contagem correspondente a um segmento foi adicionada a duas regiões.

Agrupando regiões angularmente opostas e normalizando pelo número de segmentos, 
temos então

$$
\boldsymbol{f}_{\mathbf{2 4}}=\frac{h_{1}+h_{5}}{n_{s}}, \quad \boldsymbol{f}_{\mathbf{2 5}}=\frac{h_{2}+h_{6}}{n_{s}}, \quad \boldsymbol{f}_{\mathbf{2 6}}=\frac{h_{3}+h_{7}}{n_{s}}, \quad \boldsymbol{f}_{\mathbf{2 7}}=\frac{h_{4}+h_{8}}{n_{s}} .
$$

\section{Histograma de ângulos relativos:}

O histograma de ângulos relativos é calculado de maneira similar ao histograma de ângulos absolutos, porém utilizando uma média ponderada dos ângulos $\theta_{i}$ e $\theta_{i}^{k}$ (como definido na equação 5.15) usando

$$
\psi_{i}^{k}=\gamma \theta_{i}+(1-\gamma) \theta_{i}^{k}
$$

$\operatorname{com} \gamma=0.25$ e $k=2$.

Como $\theta_{i}$ e $\theta_{i}^{k}$ são distâncias angulares entre segmentos, e não entre um segmento e um eixo de coordenada, os ângulos $\psi_{i}^{k}$ pertencem ao intervalo $[0, \pi]$. Portanto o histograma terá quatro regiões ( $h_{1}$ a $h_{4}$, como na figura 5.3).

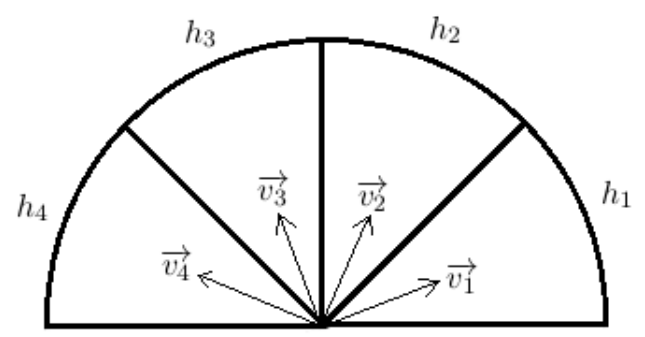

Figura 5.3: Espaço angular de ângulos relativos com suas quatro regiões e vetores centrais.

Calculamos então as contribuições de cada ângulo para cada região utilizando as fórmulas usadas anteriormente, encontrando as regiões mais próximas utilizando $\psi_{k}^{i}$ ao invés de $\alpha_{i}$, e com $\xi$ correspondendo à diferença absoluta entre $\psi_{i}^{k}$ e o ângulo formado pelo vetor central mais próximo com o eixo horizontal. Por fim temos as características

$$
\boldsymbol{f}_{\mathbf{2 8}}=\frac{h_{1}}{n_{s}}, \quad \boldsymbol{f}_{\mathbf{2 9}}=\frac{h_{2}}{n_{s}}, \quad \boldsymbol{f}_{\mathbf{3 0}}=\frac{h_{3}}{n_{s}}, \quad \boldsymbol{f}_{\mathbf{3 1}}=\frac{h_{4}}{n_{s}} .
$$

\section{Histograma 2D:}

Além do histograma de ângulos, podemos ter também histogramas de posições dos pontos $\mathcal{P}_{i}$. A ideia é repartir o espaço de pontos em uma grade $3 \times 3$, e então contabilizar as ocorrências de pontos em cada uma das nove regiões. O trabalho de Delaye e Anquetil (2013) propõe essa característica utilizando a caixa envoltória do símbolo como espaço de pontos. Isso traz certos problemas em alguns casos, uma vez que símbolos podem ter uma das 
dimensões (altura ou largura) igual a, ou próximo a zero. Por esse motivo decidimos utilizar como espaço de pontos o menor quadrado que envolve o símbolo, usando assim somente a maior das dimensões dos símbolo para delimitar a dimensão do quadrado, e mantendo uma região equivalente para todos os símbolos normalizados.

A partir então do quadrado $[0, M] \times[0, M]$ que engloba a caixa envoltória do símbolo (tal que $M=\max \{h, w\}$ ), definimos nove regiões na forma de uma grade $3 \times 3$.

Cada uma dessas regiões possui um ponto central, denominado $c_{p q}$ (onde $1 \leq p \leq 3$ corresponde à linha e $1 \leq q \leq 3$ corresponde à coluna). Como nos outros histogramas, cada ponto contribui com graus de pertinência ao invés de contagens simples.

Para cada ponto $\mathcal{P}_{i}$ determina-se as quatro regiões mais próximas, baseado nas distâncias $\left\|c_{p q} \mathcal{P}_{i}\right\|$. Definimos por $\Omega$ o conjunto das quatro posições mais próximas a $\mathcal{P}_{i}$. Supondo que para dado ponto, os centros mais próximos sejam $c_{12}, c_{13}, c_{22}$ e $c_{23}$, ou seja, $\Omega=$ $\{12,13,22,23\}$, os valores de contribuição serão calculadas então da forma

$$
\begin{aligned}
\varphi_{12} & =\frac{1}{\left\|c_{12} \mathcal{P}_{i}\right\|} \\
\varphi_{13} & =\frac{1}{\left\|c_{13} \mathcal{P}_{i}\right\|} \\
\varphi_{22} & =\frac{1}{\left\|c_{22} \mathcal{P}_{i}\right\|} \\
\varphi_{23} & =\frac{1}{\left\|c_{23} \mathcal{P}_{i}\right\|} .
\end{aligned}
$$

Para obter um fator de divisão para que os valores sejam normalizados calculamos a soma de todas essas contribuições através de

$$
\Phi=\varphi_{12}+\varphi_{13}+\varphi_{22}+\varphi_{23}
$$

Para as contribuições finais temos então

$$
\begin{aligned}
\eta_{12}\left(\mathcal{P}_{i}\right) & =\frac{\varphi_{12}}{\Phi} \\
\eta_{13}\left(\mathcal{P}_{i}\right) & =\frac{\varphi_{12}}{\Phi} \\
\eta_{22}\left(\mathcal{P}_{i}\right) & =\frac{\varphi_{12}}{\Phi} \\
\eta_{23}\left(\mathcal{P}_{i}\right) & =\frac{\varphi_{23}}{\Phi} .
\end{aligned}
$$

Considera-se $\eta_{p q}\left(\mathcal{P}_{i}\right)=0$ se $c_{p q}$ não é um dos quatro centros mais próximos.

Generalizando então temos que

$$
\varphi_{p q}=\left\{\begin{array}{cc}
\frac{1}{\left\|c_{p q} \mathcal{P}_{i}\right\|} & \text { se } p q \in \Omega \\
0 & \text { caso contrário; }
\end{array}\right.
$$




$$
\begin{gathered}
\Phi=\sum_{p=1}^{3} \sum_{q=1}^{3} \varphi_{p q} \\
\eta_{p q}\left(\mathcal{P}_{i}\right)=\frac{\varphi_{p q}}{\Phi} .
\end{gathered}
$$

Calculando $\eta_{p q}$ para todos os pontos, geramos então as características finais somando todas as contribuições

$$
\begin{array}{lll}
\boldsymbol{f}_{\mathbf{3 2}}=\frac{1}{N} \sum_{i=1}^{N} \eta_{11}\left(\mathcal{P}_{i}\right), & \boldsymbol{f}_{\mathbf{3 3}}=\frac{1}{N} \sum_{i=1}^{N} \eta_{12}\left(\mathcal{P}_{i}\right), & \boldsymbol{f}_{\mathbf{3 4}}=\frac{1}{N} \sum_{i=1}^{N} \eta_{13}\left(\mathcal{P}_{i}\right), \\
\boldsymbol{f}_{\mathbf{3 5}}=\frac{1}{N} \sum_{i=1}^{N} \eta_{21}\left(\mathcal{P}_{i}\right), & \boldsymbol{f}_{\mathbf{3 6}}=\frac{1}{N} \sum_{i=1}^{N} \eta_{22}\left(\mathcal{P}_{i}\right), & \boldsymbol{f}_{\mathbf{3 7}}=\frac{1}{N} \sum_{i=1}^{N} \eta_{23}\left(\mathcal{P}_{i}\right), \\
\boldsymbol{f}_{\mathbf{3 8}}=\frac{1}{N} \sum_{i=1}^{N} \eta_{31}\left(\mathcal{P}_{i}\right), & \boldsymbol{f}_{\mathbf{3 9}}=\frac{1}{N} \sum_{i=1}^{N} \eta_{32}\left(\mathcal{P}_{i}\right), & \boldsymbol{f}_{\mathbf{4 0}}=\frac{1}{N} \sum_{i=1}^{N} \eta_{33}\left(\mathcal{P}_{i}\right) .
\end{array}
$$

\section{Momentos $\mathrm{Hu}$ :}

Momentos Hu são um conjunto de sete características calculadas a partir de momentos de inércia que apresentam invariância à deformações como escala, rotação e translação (Hu, 1962). Esses valores, como foram usados neste trabalho, são chamados de momentos centrais de $\mathrm{Hu}$, por serem calculados utilizando o centro de gravidade $\mu=\left(\mu_{x}, \mu_{y}\right)$ do símbolo. Os momentos de inércia centrais são definidos por

$$
m_{p q}=\sum_{i=1}^{N}\left(x_{i}-\mu_{x}\right)^{p}\left(y_{i}-\mu_{y}\right)^{q} \quad \text { para } 0 \leq p, q \leq 3 .
$$

Esses valores são então normalizados com respeito ao número de pontos do símbolo pela fórmula

$$
v_{p q}=\frac{m_{p q}}{m_{00}^{\gamma}} \quad \operatorname{com} \gamma=1+\frac{p+q}{2}
$$


Como descrito em (Hu, 1962), as características são então calculadas

$$
\begin{aligned}
\boldsymbol{f}_{\mathbf{4 1}}= & v_{02}+v_{20} \\
\boldsymbol{f}_{\mathbf{4 2}}= & \left(v_{20}-v_{02}\right)^{2}+4 v_{11}^{2} \\
\boldsymbol{f}_{\mathbf{4 3}}= & \left(v_{30}-3 v_{12}\right)^{2}+\left(3 v_{21}-v_{03}\right)^{2} \\
\boldsymbol{f}_{\mathbf{4 4}}= & \left(v_{30}+v_{12}\right)^{2}+\left(v_{21}+v_{03}\right)^{2} \\
\boldsymbol{f}_{\mathbf{4 5}}= & \left(v_{30}-3 v_{12}\right)^{2}\left(v_{30}+v_{12}\right)\left[\left(v_{30}+v_{12}\right)^{2}-3\left(v_{21}+v_{03}\right)^{2}\right] \\
& +\left(3 v_{21}-v_{03}\right)\left(v_{21}+v_{03}\right)\left[3\left(v_{30}+v_{12}\right)^{2}-\left(v_{21}+v_{03}\right)^{2}\right] \\
\boldsymbol{f}_{\mathbf{4 6}}= & \left(v_{20}-v_{02}\right)\left[\left(v_{30}+v_{12}\right)^{2}-\left(v_{21}+v_{03}\right)^{2}\right]+4 v_{11}\left(v_{30}+v_{12}\right)\left(v_{21}+v_{30}\right) \\
\boldsymbol{f}_{\mathbf{4 7}}= & \left(3 v_{21}-v_{03}\right)\left(v_{30}+v_{12}\right)\left[\left(v_{30}+v_{12}\right)^{2}-3\left(v_{21}+v_{03}\right)^{2}\right] \\
& -\left(v_{30}-3 v_{12}\right)\left(v_{21}+v_{03}\right)\left[3\left(v_{30}+v_{12}\right)^{2}-\left(v_{21}+v_{03}\right)^{2}\right]
\end{aligned}
$$

\section{Casco convexo:}

Um jeito de gerar uma representação de um conjunto de pontos com respeito à forma geométrica que eles compõem é calculando seu casco convexo (Preparata e Shamos, 1985). O casco convexo de um conjunto de pontos corresponde ao sub-conjunto desses pontos que forma um polígono convexo, de forma que todos os pontos interno são eliminados. Um exemplo de conjunto de pontos é mostrado na figura 5.4a, e na figura 5.4b seu respectivo casco convexo, formado pelos pontos que estão ligados por traços.
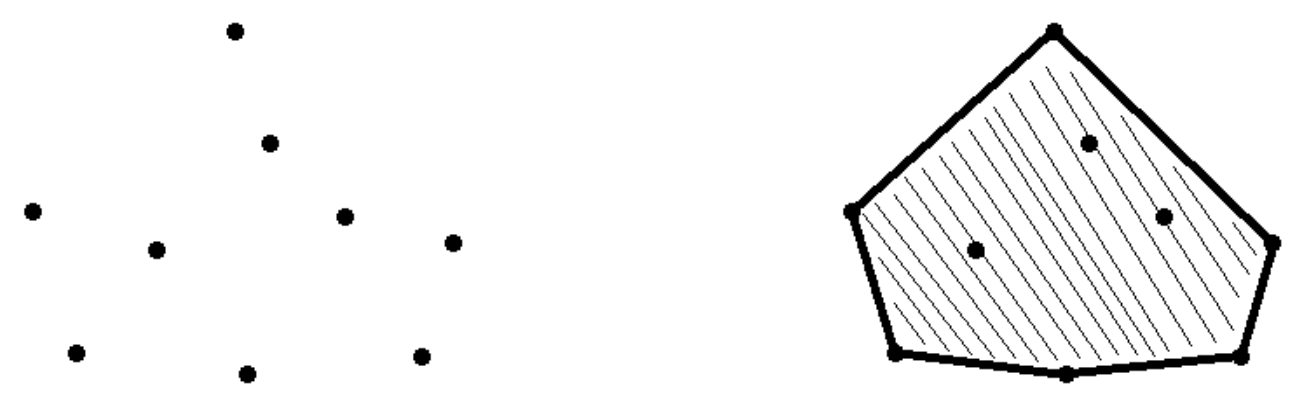

(a) Conjunto de pontos.

(b) Delimitação de seu casco convexo.

Figura 5.4: Exemplo de um conjunto de pontos e seu casco convexo.

O conjunto de pontos $H$ que forma o casco convexo de um símbolo é obtido usando o algoritmo de Graham (Graham, 1972).

O algoritmo consiste de três passos principais:

1. achar um ponto $P$ qualquer que se encontre no espaço interior do casco convexo;

2. ordenar os pontos pelo ângulo formado com a linha horizontal, tendo $P$ como ponto 
de origem;

3. eliminar os pontos que não pertencem ao casco convexo.

O primeio passo pode ser realizado encontrando três pontos consecutivos não-coolineares e calculando o ponto $P$ médio do triângulo formado pelos pontos encontrados (como exemplificado na figura 5.5), através das médias das coordenadas $x$ e $y$. Dessa forma sabemos que o ponto $P$ é interno ao espaço formado pelo casco convexo do símbolo.

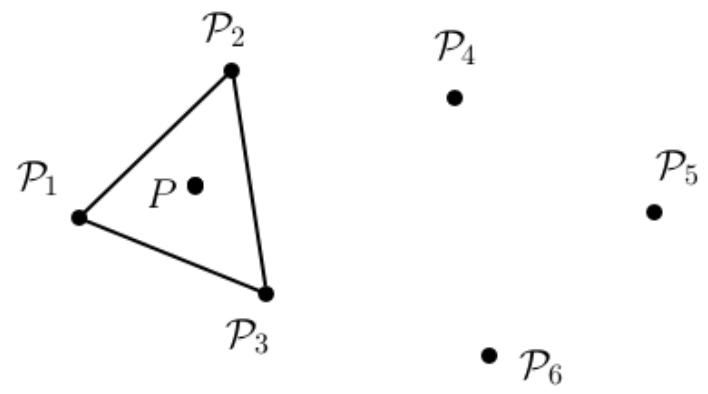

Figura 5.5: Exemplo de cálculo de $P$ a partir de três pontos não-coolineares.

Para realizar o segundo passo representamos os pontos do símbolo como coordenadas polares. Sendo o ponto $P$ a origem do sistema de coordenadas, representaremos o conjunto de pontos $\left\{\mathcal{P}_{1}, \mathcal{P}_{2}, \ldots, \mathcal{P}_{N}\right\}$ na forma $\left\{\left(r_{1}, \Theta_{1}\right),\left(r_{2}, \Theta_{2}\right), \ldots,\left(r_{N}, \Theta_{N}\right)\right\}$, onde $r_{i}$ é a distância euclidiana entre $\mathcal{P}_{i}$ e $P$, e $\Theta_{i}$ é a distância angular do eixo horizontal até o vetor formado pelo ponto $\mathcal{P}_{i}$ a partir da origem. A partir dessa representação, os pontos são ordenados de forma crescente pelos valores $\Theta_{i}$. A figura 5.6 mostra um exemplo da obtenção do $r$ e do $\Theta$ para um ponto, dado um conjunto de pontos e um ponto $P$.

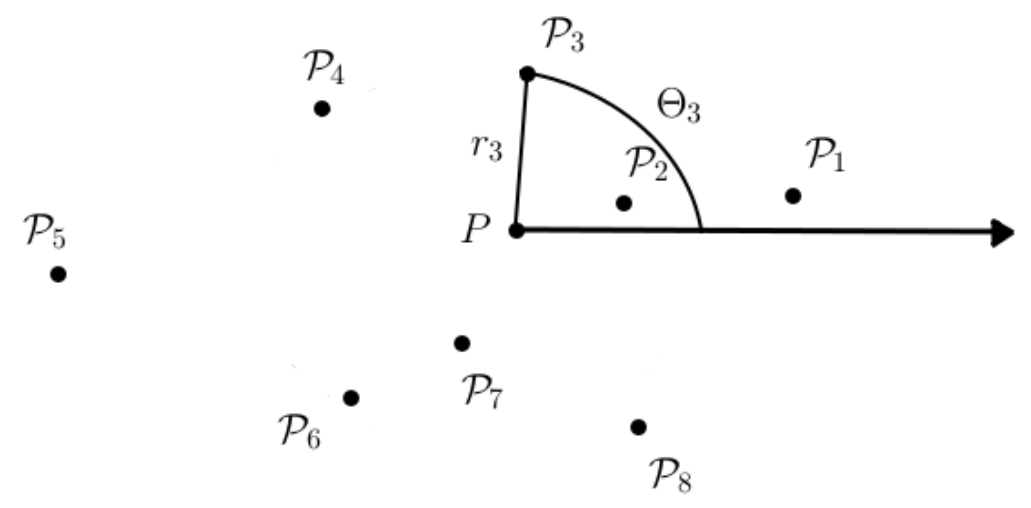

Figura 5.6: Obtenção dos valores de $r$ e $\Theta$ para o ponto $\mathcal{P}_{3}$.

Algumas regras são utilizadas para eliminar alguns pontos que sabemos que não pertencem ao casco convexo. Pontos que possuem $r_{i}=0$ tem a mesma posição de $P$, que é um 
ponto que sabemos ser interno, portanto esses podem ser eliminados. Se dois ou mais pontos tiverem o mesmo ângulo $\Theta_{i}$, sabemos que dentre eles os mais internos são internos também ao casco convexo, então o único ponto mantido é o mais externo (com maior $r_{i}$ ).

A partir do conjunto de pontos resultante, considerando três pontos consecutivos $\mathcal{P}_{i}$, $\mathcal{P}_{i+1}$ e $\mathcal{P}_{i+2}$, calculamos os ângulos $\alpha$ e $\beta$ como na figura 5.7. Existem duas possibilidades:

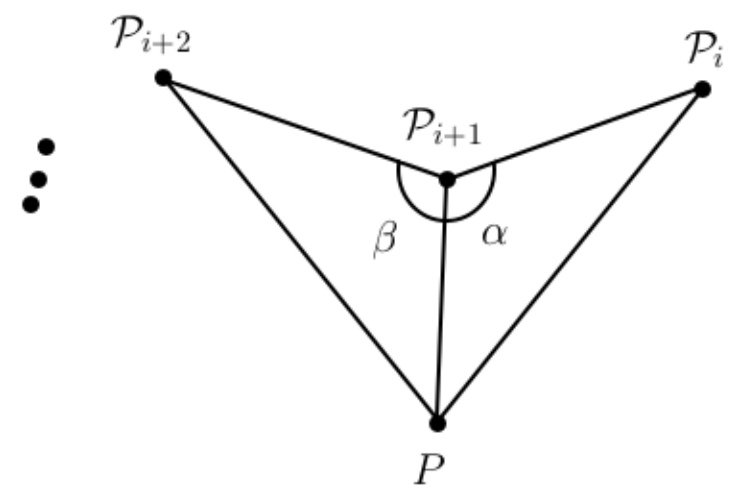

Figura 5.7: Cálculo dos ângulos $\alpha$ e $\beta$ a partir de três pontos consecutivos.

- se $\alpha+\beta \geq \pi$, então $\mathcal{P}_{i+1}$ não pode ser um ponto externo do símbolo $\mathcal{S}$, então o eliminamos. Os próximos três pontos consecutivos a serem analisados serão $\mathcal{P}_{i-1}, \mathcal{P}_{i}$ e $\mathcal{P}_{i+2}($ com o índice $i$ sendo módulo $N$ );

- se $\alpha+\beta<\pi$, então todos os três pontos pertencem ao casco convexo. Analisamos então os próximos três pontos consecutivos $\mathcal{P}_{i+1}, \mathcal{P}_{i+2}$ e $\mathcal{P}_{i+3}$ (também com $i$ módulo $N)$.

Ao final desse processo (quando todos os trios de pontos consecutivos foram analisados), os pontos restantes formam o casco convexo $H$ do símbolo. Dado o casco convexo $H=$ $\left\{\mathcal{P}_{i}\right\}_{i=1}^{p}$, e denotando por $\mathcal{P}_{i, x}$ a coordenada $x$ do ponto $\mathcal{P}_{i}$, a área de $H$ é dada por

$$
A_{H}=\frac{1}{2}\left|\sum_{i=1}^{p}\left(\mathcal{P}_{i, x} \mathcal{P}_{i+1, y}-\mathcal{P}_{i+1, x} \mathcal{P}_{i, y}\right)\right|
$$

com $i$ sendo módulo $p$.

A partir desse valor podemos calcular as duas últimas características do conjunto, que são a área do casco normalizada pela área da caixa envoltória, e a razão do quadrado do comprimento da trajetória total pela área $A_{H}$ (Willems e Niels, 2008)

$$
\boldsymbol{f}_{\mathbf{4 8}}=\frac{A_{H}}{w h}, \quad \boldsymbol{f}_{\mathbf{4 9}}=\frac{L_{1, n}^{2}}{A_{H}} .
$$




\section{Capítulo 6}

\section{Experimentos}

Neste capítulo serão apresentados e discutidos os resultados obtidos através de experimentos realizados utilizando os métodos apresentados. O objetivo principal desses experimentos é a análise comparativa do comportamento de cada método aplicado à classificação de símbolos matemáticos manuscritos, a fim de um maior entendimento de possíveis formas de resolver esse problema.

Todos os métodos usados nos experimentos podem ser vistos como uma forma diferente de combinação de classificadores. O um-contra-todos (UCT) e o todos-contra-todos (TCT) combinam um conjunto de classificadores base que se diferenciam pelos rótulos associados aos exemplos de treinamento, transformando um problema multi-classe em vários problemas binários. A abordagem hierárquica (chamada aqui de DAD - Decomposição por Árvore de Decisão) utiliza uma árvore de decisão para distribuir os exemplos na estrutura de uma árvore, e posteriormente construir um classificador multi-classe para o conjunto de exemplos associado a cada uma das folhas.

A seguir são apresentados todos os resultados obtidos pelos experimentos realizados, e observações formuladas a partir desses resultados.

\subsection{Descrição dos Dados Usados}

Nesta seção estão descritos os dados usados nos experimentos, e como eles são processados.

\subsubsection{Classes Presentes no Problema}

Grande parte dos trabalhos referentes ao reconhecimento de expressões matemáticas utiliza expressões como um todo, já que o contexto em que os símbolos estão inseridos fornece várias informações relevantes para o problema. Para esse caso faz sentido que, por exemplo, funções matemáticas como cos, lim e arg sejam representadas como classes específicas de objetos. 
O nosso trabalho, porém, trata de reconhecimento de símbolos isolados, portanto um exemplo do símbolo cos não tem distinção de um conjunto consecutivo de símbolos $c$, o e $s$.

Além disso, um caso particular de classe de símbolos que merece atenção é o "."(ponto). Um usuário pode escrevê-lo como de fato um único ponto na tela, o que faz com que o símbolo tenha ambas as dimensões (largura e altura) igual a zero, requerendo então cuidados especiais na implementação dos processamentos dos símbolos. Por outro lado, o usuário pode escrever um "." como traços circulares bem próximos, ou um único traço muito pequeno. Nesse caso o processamento acontece como em qualquer símbolo comum, porém a normalização de escala pode transformar o símbolo em uma figura pouco característica de um ".", o que dificulta a classificação quando informações de contexto não estão disponíveis. A figura 6.1 mostra diferentes formas que exemplos de símbolos da classe "." podem assumir após a normalização.

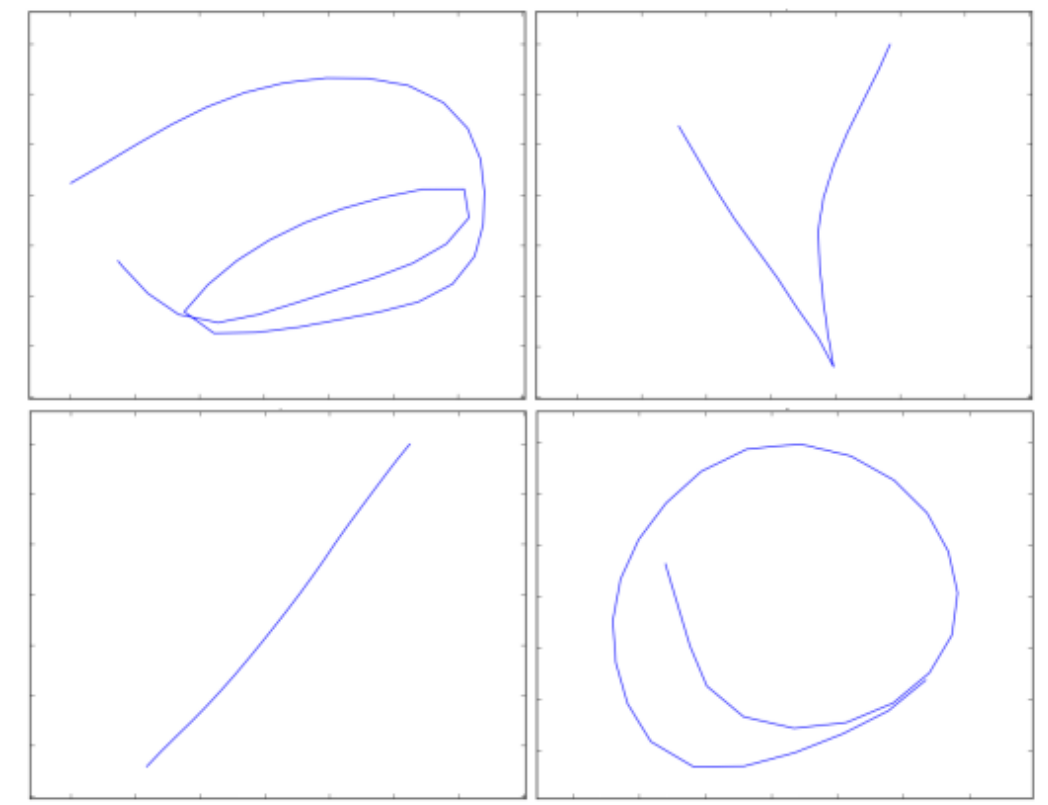

Figura 6.1: Exemplos de símbolos da classe ". " após aplicação dos pré-processamentos.

Dessa forma, como primeira forma de simplicar o problema, eliminamos das bases de dados (a origem dos dados é detalhada no apêndice B) todos os exemplos da classe ".", assim como todos símbolos que são formados por letras posicionadas sequencialmente. Símbolos como "=", por exemplo, também são formados por um conjunto de mais de um símbolo já existente (dois "-"), porém é importante sintaticamente, em relação à expressão, que cada um deles seja considerado como um todo. Ou seja, dado nosso exemplo, não existe forma válida de posicionar dois símbolos "-" em uma expressão de forma a construir um "=". A tabela 6.1 mostra todos os símbolos que foram eliminados.

Também como consequência do uso de símbolos isolados, não dispomos de informação de contexto para auxiliar a classificação. Tendo, por exemplo, duas categorias diferentes para os símbolos "s" e "S", a única forma de discriminar os dois seria usando informações externas referentes à expressão, ou usando a informação de escala, uma vez que os símbolos são visual- 
Tabela 6.1: Categorias de Simbolos Eliminadas

\begin{tabular}{l|r|r|r|r|r}
\hline $\lim$ & $\sin$ & $\cos$ & $\tan$ & $\log$ & . \\
\hline
\end{tabular}

mente idênticos. Em reconhecimento de símbolos isolados, porém, geralmente normalizamos a escala dos símbolos para que símbolos da mesma classe se tornem mais compatíveis entre si, diminuindo dependências de dispositivo e escritor. Por isso, uma segunda forma lógica de simplificar o problema seria agrupar símbolos com representação visual equivalente como pertencentes a uma mesma categoria.

A tabela 6.2 mostra as conversões de categorias realizadas.

Tabela 6.2: Conversões de Rótulos

\begin{tabular}{cccc}
\hline De & Para & De & Para \\
\hline$\frac{0}{0}$ (traço fração) & - (traço subtração) & $\epsilon$ & $\in$ \\
C & $\mathrm{c}$ & $\mathrm{W}$ & $\mathrm{w}$ \\
$\mathrm{K}$ & $\mathrm{k}$ & $\omega$ & $\mathrm{w}$ \\
O (o maiúsculo) & $\mathrm{o}$ & $\mathrm{X}$ & $\mathrm{x}$ \\
0 (zero) & $\mathrm{o}$ & $\times$ & $\mathrm{x}$ \\
V & $\mathrm{v}$ & $\mathrm{Z}$ & $\mathrm{Z}$ \\
$\mathrm{S}$ & $\mathrm{S}$ &, &, \\
$\mathrm{P}$ & $\mathrm{p}$ & & \\
$\mathrm{U}$ & $\mathrm{u}$ & $\ldots$ (reticências centrais) & $\ldots$. (reticências) \\
\hline
\end{tabular}

A simplificação do problema cria algumas limitações com relação à usabilidade da solução. Problemas reais de reconhecimento de símbolos matemáticos podem conter qualquer tipo de classe válida na sintaxe matemática. O objetivo porém é, em trabalhos futuros, usando a solução do problema simplificado em conjunto com uma solução para a análise estrutural de expressões como um todo, tratar essas limitações na solução final.

Após as simplificações, o problema resultante apresenta 115 classes, com suas distribuições de exemplos apresentadas na tabela 6.3 (onde $C$ representa a classe em questão e $N_{e}$ representa seu número de exemplos).

\subsubsection{Pré-processamento de Símbolos e Extração de Características}

Todos os dados brutos originados de diferentes fontes, escritos por diferentes usuários, precisam ser pré-processados a fim de eliminar possíveis variações provenientes de modos de escrita ou hardware específico. Portanto, todos os pré-processamentos descritos no capítulo 4 são aplicados ao conjunto de dados.

Primeiro os pontos duplicados são removidos e os traços são reamostrados, com o objetivo de normalizar a amostragem de pontos em coletas de origens diferentes. Depois disso, para os traços que possuem no mínimo três pontos (por causa de restrições impostas pelo algoritmo), é aplicada a suavização e a eliminação de ganchos (métodos que eliminam ou alteram a 
Tabela 6.3: Distribuição Final de Classes

\begin{tabular}{cccccccccccccc}
\hline$C$ & $N_{e}$ & $C$ & $N_{e}$ & $C$ & $N_{e}$ & $C$ & $N_{e}$ & $C$ & $N_{e}$ & $C$ & $N_{e}$ & $C$ & $N_{e}$ \\
\hline$!$ & 161 & $:$ & 45 & $\mathrm{Q}$ & 68 & $\gamma$ & 148 & $\neq$ & 170 & \{ & 231 & $\mathrm{~m}$ & 509 \\
( & 3978 & $;$ & 54 & $\mathrm{R}$ & 227 & $\geq$ & 227 & $\nexists$ & 49 & \} & 231 & $\mathrm{n}$ & 2290 \\
) & 3972 & $<$ & 176 & $\mathrm{~T}$ & 147 & $\in$ & 112 & $\notin$ & 69 & ] & 352 & $\mathrm{o}$ & 2014 \\
$*$ & 96 & $=$ & 3707 & $\mathrm{Y}$ & 154 & $\infty$ & 378 & $\partial$ & 114 & $\mathrm{a}$ & 2487 & $\mathrm{p}$ & 721 \\
+ & 5464 & $>$ & 122 & {[} & 352 & $\int$ & 665 & $\phi$ & 132 & $\mathrm{~b}$ & 1610 & $\mathrm{q}$ & 320 \\
, & 900 & $\mathrm{~A}$ & 317 & $\%$ & 90 & $\lambda$ & 74 & $\pi$ & 498 & $\mathrm{c}$ & 1268 & $\mathrm{r}$ & 498 \\
- & 8051 & $\mathrm{~B}$ & 279 & $\Delta$ & 101 & $\cdots$ & 166 & \pm & 231 & $\mathrm{~d}$ & 1074 & $\mathrm{~s}$ & 469 \\
$/$ & 272 & $\mathrm{D}$ & 70 & $\Phi$ & 47 & $\leq$ & 297 & $\prod$ & 61 & $\mathrm{e}$ & 474 & $\mathrm{t}$ & 677 \\
1 & 6237 & $\mathrm{E}$ & 181 & $\alpha$ & 389 & $\mathbb{C}$ & 39 & $\psi$ & 48 & $\mathrm{f}$ & 692 & $\mathrm{u}$ & 402 \\
2 & 6224 & $\mathrm{~F}$ & 204 & $\approx$ & 58 & $\mathbb{I}$ & 39 & $\rho$ & 47 & $\mathrm{~g}$ & 328 & $\mathrm{v}$ & 480 \\
3 & 2489 & $\mathrm{G}$ & 133 & $\beta$ & 305 & $\mathbb{N}$ & 47 & $\sigma$ & 101 & $\mathrm{~h}$ & 307 & $\mathrm{w}$ & 274 \\
4 & 1645 & $\mathrm{H}$ & 146 & $\delta$ & 47 & $\mathbb{Q}$ & 47 & $\sqrt{ }$ & 1815 & $\mathrm{i}$ & 986 & $\mathrm{x}$ & 6039 \\
5 & 1013 & $\mathrm{I}$ & 114 & $\div$ & 241 & $\mathbb{R}$ & 47 & $\sum$ & 625 & $\mathrm{j}$ & 311 & $\mathrm{y}$ & 1800 \\
6 & 806 & $\mathrm{~J}$ & 66 & $\equiv$ & 36 & $\mathbb{Z}$ & 47 & $\theta$ & 545 & $\mathrm{k}$ & 690 & $\mathrm{z}$ & 1162 \\
7 & 759 & $\mathrm{~L}$ & 175 & $\eta$ & 47 & $\mu$ & 93 & $\rightarrow$ & 329 & $\mathrm{l}$ & 158 & $\mid$ & 448 \\
8 & 739 & $\mathrm{M}$ & 147 & $\exists$ & 74 & $\nabla$ & 76 & $\varepsilon$ & 47 & & & & \\
9 & 739 & $\mathrm{~N}$ & 174 & $\forall$ & 76 & $\neg$ & 54 & $\varphi$ & 48 & & & & \\
\hline
\end{tabular}

posição de pontos), e então uma nova reamostragem, para uniformizar o espaçamento entre pontos após essas alterações.

Posteriormente são usados os métodos de padronização da orientação e da ordenação de traços, e por fim a normalização de posição e escala, acompanhada de uma nova reamostragem. Ao normalizarmos a escala de um símbolo aumentando seu tamanho, podemos obter pontos muito espaçados. Da mesma forma, normalizando um símbolo diminuindo o seu tamanho pode resultar em pontos muito próximos. Então para evitar alguns problemas no cálculo posterior das características uma última reamostragem após a normalização se mostrou necessária.

Alguns símbolos, como "|" e "-" por exemplo, podem possuir uma das dimensões de sua caixa envoltória igual a zero. Pela forma com que a normalização de escala e posição é feita (ver seção 4.4.2), esse caso não traz nenhum problema, uma vez que é somente a maior das duas dimensões que é usada para representar o espaço que envolve o símbolo a ser normalizado.

Os conjuntos de pontos pré-processados podem ser usados como entrada para o treinamento de um classificador, porém em muitos casos é interessante que sejam utilizadas características mais sofisticadas, calculadas a partir dos dados brutos das posições dos pontos. As características descritas no capítulo 5 são então extraídas de cada exemplo. As constantes utilizadas nos métodos de extração foram definidas por Delaye e Anquetil (2013), e são válidas assumindo a normalização em relação a um quadrado de lado igual a 128. 


\subsection{Treinamento e Teste de Classificadores}

\subsubsection{Classificador Base}

Como modelos para treinar os classificadores base decidimos usar SVMs, por registros de seu uso em estudos do problema de reconhecimento de símbolos matemáticos em literatura recente (Keshari e Watt, 2008) (Malon et al., 2008), assim como evidências em alguns experimentos preliminares que mostraram que as SVMs, em comparação às redes neurais, apresentaram melhor desempenho com tempo menor de treinamento, além de menor necessidade da calibração de parâmetros.

Para a criação das SVMs, foi usada uma biblioteca chamada libsvm (Chen et al., 2005) (apêndice A). Usando as estruturas dessa biblioteca, os nós de treinamento são criados com as características de cada exemplo como dados de entrada. A arquitetura do modelo escolhida foi a C-SVC com o kernel polinomial (Bishop, 2006). O parâmetro $C$ intrínseco a SVM, responsável por controlar a complexidade do ajuste do modelo, foi definido como $C=8$. O grau $d$ do polinômio calculado no kernel foi escolhido como 3. Todas as escolhas relacionadas à configuração da SVM foram definidas baseadas em resultados preliminares, e mantidas posteriormente por todo o trabalho.

\subsubsection{Validação dos Classificadores}

Cada resultado apresentado neste capítulo é calculado como a média das cinco taxas de acerto obtidas a partir de uma validação cruzada estratificada (mantendo as proporções de classe originais) de cinco partes do método em questão, geralmente acompanhada do desvio padrão. A escolha dos exemplos que formam cada uma das cinco partes foi fixada, para uma melhor comparação dos resultados obtidos.

Para os resultados de tempo de processamento, também são calculadas médias dos cinco tempos de treinamento e teste.

\subsection{Um-contra-todos e Todos-contra-todos Aplicados ao Problema Completo}

Primeiramente medimos o desempenho dos métodos UCT e TCT, usando SVMs como classificador base, aplicados ao problema completo. Como problema completo definimos o problema de classificação contendo todas as 115 classes aqui definidas.

Este experimento foi realizado em duas partes: a primeira aplicando ambos os métodos ao treinamento da base completa; e a segunda usando-os em um conjunto de dados com distribuição uniforme de classes, com o intuito de observar seus comportamentos quando cada classe é representada pelo mesmo número de exemplos. 


\subsubsection{Conjunto Completo de Exemplos}

A tabela 6.4 mostra as médias (e desvios padrões) das taxas de acerto dos métodos UCT e TCT aplicados ao conjunto total de dados em cada uma das cinco divisões treino-teste definidas pela validação cruzada. Para efeito de comparação, mostramos também o resultado obtido usando o método de vizinhos-mais-próximos, com $k=1$ (chamado de 1-NN), e o método de árvore de decisão (AD), usando as métricas entropia e twoing.

Tabela 6.4: 1-NN, AD, UCT e TCT - Taxas de Acerto

\begin{tabular}{cc}
\hline & Média de Acerto (Desvio Padrão) \\
\hline 1-NN & $91.31 \%(0.13 \%)$ \\
AD-entropia & $83.76 \%(0.18 \%)$ \\
AD-twoing & $83.13 \%(0.12 \%)$ \\
UCT & $92.96 \%(0.16 \%)$ \\
TCT & $92.51 \%(0.16 \%)$ \\
\hline
\end{tabular}

Vemos então que os métodos superam o classificador 1-NN por até por volta de $1.6 \%$, e apresentam taxas de acerto entre $92.5 \%$ e 93\%. As árvores de decisão apresentaram taxas de acerto inferiores $(83.76 \%$ e $82.13 \%$ ), e estruturas de profundidade máxima de até 28, com milhares de folhas. Um possível sobre-ajuste no treinamento das árvores pode ser a causa do maior tamanho nas estruturas e da menor taxa de acerto. Nesse caso poderiam ser utilizadas heurísticas para poda das árvores, em uma tentiva de melhorar os resultados. O uso da métrica gini resultou em um número muito maior de divisões, que se aproximaram da capacidade computacional disponível, portanto os testes com essa métrica não foram finalizados.

Os valores baixos de desvio padrão indicam que houve pouca variação na taxa de acerto de cada conjunto treino-teste, o que sugere pequena dependência na escolha do sub-conjunto de dados usado para treino.

Com relação à eficiência, é importante ressaltar o número de classificadores utilizados em cada método. No UCT, são treinados 115 classificadores, cada um com o conjunto inteiro de dados, somente renomeando os rótulos para separar uma classe do resto. O TCT faz a combinação de todas as classes duas a duas, treinando então $\frac{115(115-1)}{2}=6555$ classificadores. No caso do TCT, embora seja verdade que o tempo total de treinamento seja reduzido pelo fato de que, apesar da maior quantidade de classificadores, cada classificador será treinado a partir de exemplos de somente duas classes, o tempo de teste aumenta quando comparado com o UCT, já que o número de exemplos de teste para cada classificador é o mesmo para ambos os métodos, portanto o tempo se torna proporcional somente ao número de classificadores usados para a tomada de decisão. 


\subsubsection{Conjunto de Exemplos com Distribuições Equivalentes de Classe}

Neste teste aplicamos novamente os métodos UCT e TCT, comparados ao 1-NN, porém igualando a distribuição de exemplos por classe na base de treinamento. A base de teste é mantida com as distribuições originais de classes para que a comparações com os resultados anteriores seja possível. A classe $\equiv$ possui a menor quantidade de representantes no conjunto de dados, totalizando 36, com por volta de 28 separados para treinamento, portanto cada um dos conjuntos de exemplos de outras classes na base de treinamento precisa ser reduzido para o total de 28 (ou 29, dependendo da fase da validação cruzada em execução, uma vez que não é possível dividir o conjunto de 36 exemplos em 5 partes iguais). Isso é feito selecionando aleatoriamente o número de exemplos determinado de cada classe, da base de treinamento.

Como existem classes com uma quantidade de exemplos de treinamento significativamente maior que 28, a escolha de exemplos específicos pode fazer considerável diferença no resultado. Por isso foram realizados cinco testes diferentes para cada um dos métodos, diferenciando-os pela escolha dos exemplos utilizados em cada um. A tabela 6.5 mostra os resultados deste experimento, nomeando como $T i$ cada um dos testes realizados, onde $1 \leq i \leq 5$. É importante ressaltar que a linha correspondente ao teste $T i$ indica que é o $i$-ésimo teste realizado com cada um dos métodos, mas não sugere que ambos os métodos na mesma linha foram aplicados ao mesmo conjunto de dados.

Tabela 6.5: 1-NN, UCT e TCT Com Distribuição Uniforme de Classes - Taxas de Acerto

\begin{tabular}{cccc}
\hline & 1-NN & UCT & TCT \\
\hline T1 & $71.11 \%(0.93 \%)$ & $76.26 \%(0.83 \%)$ & $74.86 \%(0.55 \%)$ \\
T2 & $71.45 \%(0.79 \%)$ & $76.30 \%(1.04 \%)$ & $74.24 \%(1.15 \%)$ \\
T3 & $70.84 \%(0.76 \%)$ & $76.16 \%(0.74 \%)$ & $74.17 \%(0.97 \%)$ \\
T4 & $71.37 \%(1.00 \%)$ & $76.94 \%(0.82 \%)$ & $74.02 \%(0.93 \%)$ \\
T5 & $71.14 \%(0.41 \%)$ & $76.65 \%(1.38 \%)$ & $74.05 \%(0.79 \%)$ \\
\hline Média (Desvio Padrão) & $71.18 \%(0.22 \%)$ & $76.46 \%(0.29 \%)$ & $74.27 \%(0.31 \%)$ \\
\hline
\end{tabular}

Por esses resultados pudemos observar a diminuição clara da taxa de acerto dos métodos (cerca de 16\% para o UCT e 18\% para o TCT) devido provavelmente à redução de informação presente no conjunto de dados. Em comparação, o 1-NN também teve grande perda de desempenho, ficando perto de $3 \%$ abaixo do TCT e 5\% abaixo do UCT. Apesar disso, as taxas de acerto em testes diferentes se mantiveram relativamente próximas, sugerindo que escolhas de poucos exemplos para representar classes com muitos dados resultaram em desempenhos parecidos, mesmo descartando uma grande parte das informações necessárias para reconhecer essas classes. 


\subsection{Degradação do Desempenho com o Aumento do Nú- mero de Classes}

Uma das principais ideias deste trabalho é a de que o aumento no número de classes de um problema aumenta sua complexidade, o que, em geral, pode provocar uma diminuição na taxa de acerto do classificador treinado. Assumindo a veracidade dessa afirmação, podemos concluir que dividir de maneira eficaz o problema total em sub-problemas com menor número de classes pode aprimorar o desempenho do classificador.

Uma forma interessante de observar essa degradação de desempenho com o aumento do número de classes é treinar e testar classificadores em conjuntos incrementais de classes.

Dessa forma, estabelecemos um incremento de 10 classes por teste, a partir de um conjunto inicial também de 10. A cada novo teste, o conjunto de dados utilizado para treinar e testar o classificador apresenta todos os exemplos pertencentes às classes usadas no teste anterior, mais os exemplos correspondentes às 10 novas classes selecionadas. Por exemplo, para o teste referente à 50 classes, utilizamos as 40 classes presentes no teste anterior, mais 10 novas classes escolhidas a partir das classes restantes no conjunto total de 115 . A tabela 6.6 mostra os 11 conjuntos (denominados $C_{i}$, onde $i$ é o índice do conjunto) de 10 classes adicionados a cada passo do algoritmo, cobrindo o intervalo de 10 a 110 classes.

Tabela 6.6: Classes Inseridas a Cada Teste

\begin{tabular}{ccccccccccc}
\hline$C_{1}$ & $C_{2}$ & $C_{3}$ & $C_{4}$ & $C_{5}$ & $C_{6}$ & $C_{7}$ & $C_{8}$ & $C_{9}$ & $C_{10}$ & $C_{11}$ \\
\hline$\notin$ & $\mathrm{N}$ & $\neg$ & $\psi$ & $\mathrm{H}$ & $\leq$ & $\nexists$ & $\varepsilon$ & 6 & $:$ & $<$ \\
- & $\Phi$ & $\mathrm{c}$ & $\rho$ & $\mathrm{A}$ & $\mathrm{M}$ & $\mathrm{b}$ & $\mathbb{C}$ & $\gamma$ & $\sum$ & $\geq$ \\
$\mathrm{R}$ & $\mathrm{u}$ & ) & $\mathrm{s}$ & $=$ & $\mathbb{I}$ & $\equiv$ & $\mathrm{n}$ & $\mathrm{i}$ & $\exists$ & $\mathbb{Q}$ \\
3 & $\Delta$ &, & $\mathrm{B}$ & $\infty$ & $\mathrm{L}$ & $\mathrm{f}$ & $\mathrm{x}$ & $\theta$ & 4 & $\lambda$ \\
$\varphi$ & $\mathrm{Q}$ & $\mathrm{a}$ & $\mathrm{v}$ & + & $\sqrt{ }$ & $>$ & 1 & $\nabla$ & $\mathbb{N}$ & $*$ \\
$\mathrm{E}$ & $\mathrm{T}$ & $\mathrm{h}$ & $\mathrm{k}$ & $\div$ & $\mathrm{t}$ & $\rightarrow$ & 8 & $\mathrm{q}$ & $\mathrm{y}$ & \{ \\
$/$ & $\mathrm{l}$ & $\mathcal{1}$ & $\beta$ & $\%$ & 9 & ( & 2 & $\mathrm{~F}$ & $\approx$ & $\partial$ \\
$\mathrm{m}$ & $\in$ & $\mathrm{r}$ & $\mathrm{D}$ & $\mathrm{o}$ & $\mathbb{R}$ & $\neq$ & $\mathrm{I}$ & $\mathrm{g}$ & $\mathrm{z}$ & $\mathrm{d}$ \\
$\mathrm{e}$ & $\delta$ & $\forall$ & {[} & \} & $;$ & $\phi$ & $\mathrm{G}$ & $\prod$ & $\mathrm{Y}$ & $\pi$ \\
5 & $\mu$ & $\mathrm{w}$ & $\mathrm{p}$ & ] & $\mathrm{j}$ & 7 & $\alpha$ & $\mathbb{Z}$ & $\cdots$ & $!$ \\
\hline
\end{tabular}

A figura 6.2 mostra a evolução das taxas de acerto obtidas através dos métodos UCT e TCT com o aumento do número de classes.

A observação mais clara a ser feita a partir do gráfico mostrado é a constante diminuição da taxa de acerto dos classificadores, quanto maior o número de classes presentes no problema. Com exceção da passagem de 40 para 50 classes, todos as outras mostraram degradação de desempenho em ambos os métodos. O aumento da taxa de acerto em ambos os métodos na passagem para o conjunto de 50 classes pode ser explicado pela adição de classes como "+", "=" e "o", que possuem formas relativamente simples e grande quantidades de exemplos. 


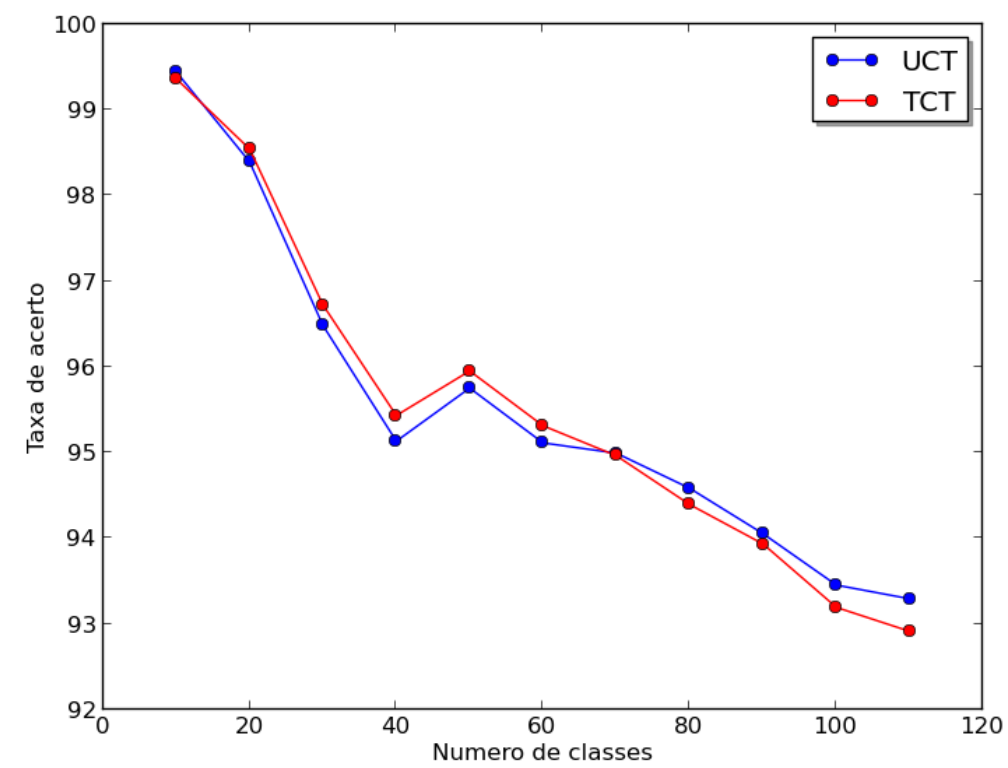

Figura 6.2: Gráfico mostrando a progressão do desempenho do UCT e do TCT com o aumento do número de classes.

Observamos também que o TCT mostra uma certa vantagem nos primeiros testes, porém no ponto correspondente às 70 classes ocorre uma troca, e a partir dela o UCT passa a apresentar resultados melhores. Com isso é possível fazer um paralelo com nosso último resultado, de que com a limitação de dados o TCT tem uma perda maior, e observar também que com o aumento da complexidade do problema, a partir do aumento do número de classes, o TCT perde acurácia com mais velocidade que o UCT.

A figura 6.3 apresenta o mesmo experimento da figura 6.2, só que com distribuição uniforme de classes. Além de mostrar uma progressão de taxas de acerto mais inconstante, ela mostra uma perda ainda maior de desempenho do TCT em relação ao UCT com essa limitação na quantidade de exemplos, que se torna cada vez mais evidente com o aumento do número de classes.

A velocidade com que esse desempenho cai à medida que se aumentam o número de classes, particularmente quando comparados os testes iniciais (10, 20 classes) com os testes finais (100, 110 classes), também parece sugerir que a taxa de acerto passe a diminuir menos com novos aumentos do número de classes. Porém, um experimento com um problema com mais classes, e consequentemente mais passos do algoritmo, poderia revelar isso com mais clareza.

Analisando ambos os métodos em termos de eficiência, foram gerados os dois gráficos apresentados na figura 6.4. Ambos os gráficos mostram a progressão do tempo de processamento medido para cada um dos onze testes, o da esquerda mostrando os tempos de treinamento e o da direita os de teste.

Como comentado na seção 6.3.1, apesar de no TCT serem treinados uma quantidade maior de classificadores, o tamanho menor do conjunto de dados utilizado para treinar 


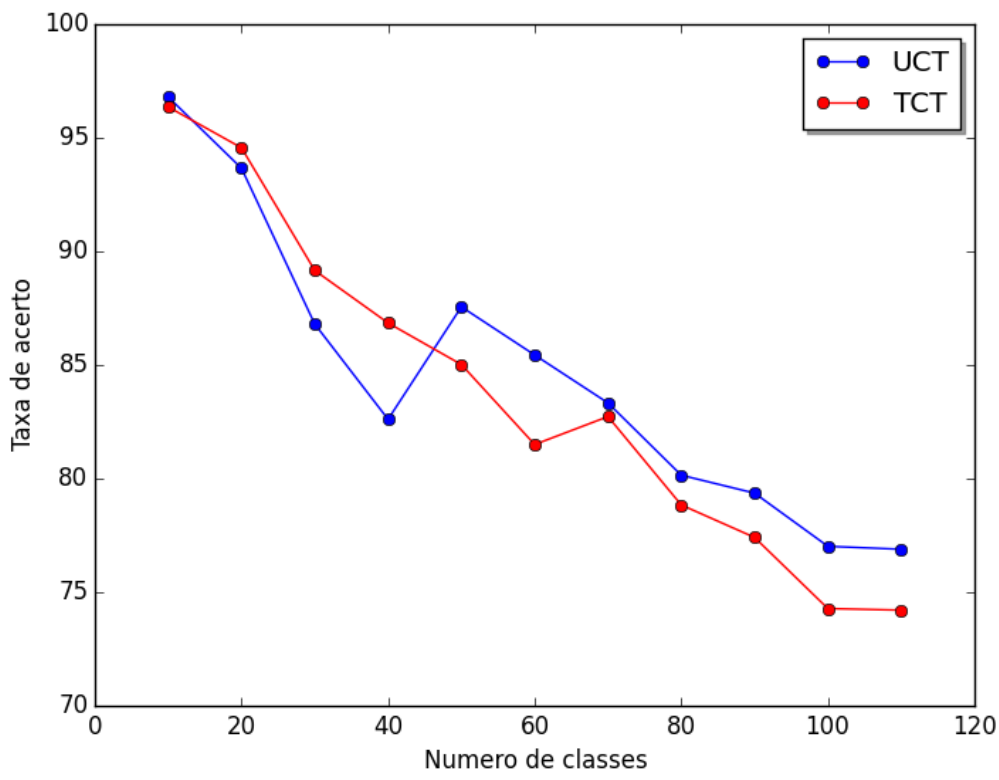

Figura 6.3: Gráfico mostrando a progressão do desempenho do UCT e do TCT com o aumento do número de classes e distribuição de classes uniforme.

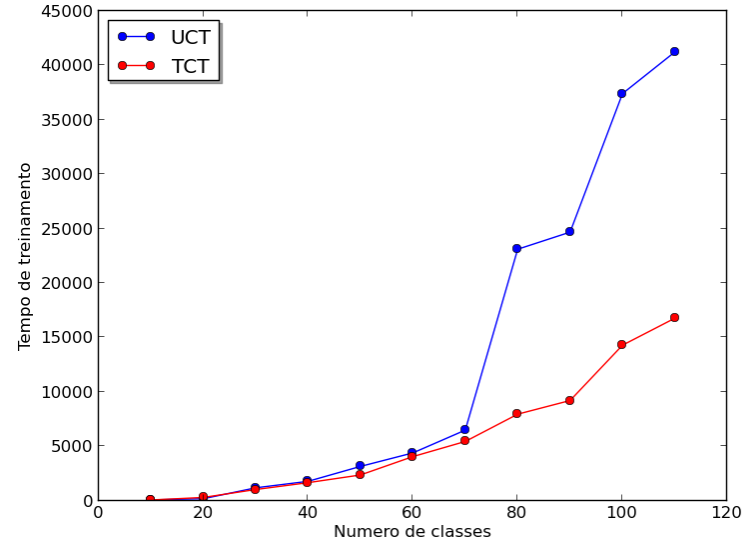

(a) Tempos de treinamento.

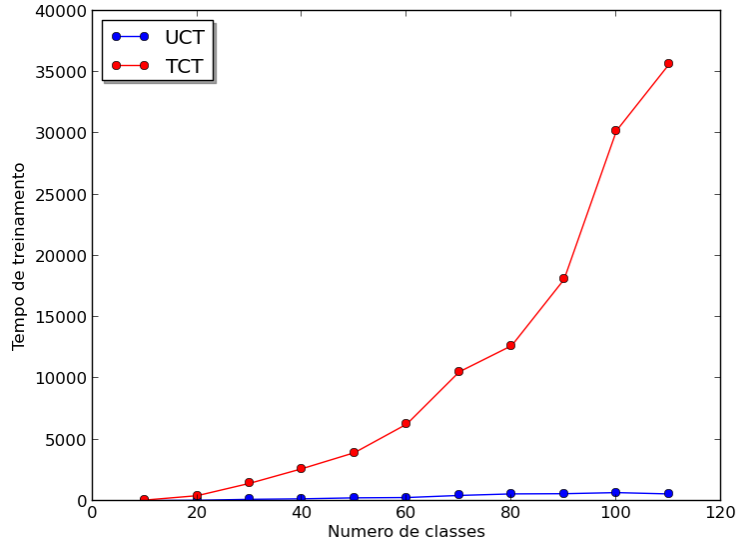

(b) Tempos de teste.

Figura 6.4: Progressão dos tempos de treinamento e teste do UCT e do TCT com o aumento do número de classes.

cada classificador diminui o tempo total consideravelmente, comparado com o UCT. Em problemas com poucas classes a diferença não é tão perceptível, porém à medida que o número de classes aumenta, o tempo de treinamento de cada classificador do UCT aumenta, enquanto que o tempo de cada classificador no TCT se mantêm similar, com somente um aumento no número de classificadores treinados. O crescimento íngreme que acontece no gráfico de tempos de treinamento no UCT entre 70 e 80 classes provavelmente ocorre devido a inserção da segunda, terceira e quarta classes com mais exemplos do conjunto de dados, "1", "2" e "x".

Olhando para os tempos de teste podemos observar que a situação se inverte. Com 
os modelos de classifição de cada SVM já definidos na fase de treinamento, o número de exemplos usados para treinar o classificador já não faz mais diferença. Supondo tempo constante para avaliar cada exemplo, o tempo total é então proporcional ao número de classificadores envolvidos. Portanto, como mostrado no gráfico da direita, o tempo de teste do UCT cresce a uma taxa muito menor do que o tempo de teste do TCT.

Além disso, é possível afirmar que o UCT requer menos memória que o TCT, já que o número de modelos que precisam ser armazenados é menor. Por esses motivos faz sentido concluir que o UCT seja um método mais apropriado para problemas com grande número de classes em aplicações destinadas a dispositivos com poder computacional e de armazenamento limitados.

\subsection{Método de Separação de Classes Aplicado ao Pro- blema Completo}

Para observar o desempenho do método DAD detalhado no capítulo 3, em comparação com os resultados iniciais alcançados, repetimos então o primeiro experimento utilizando o método citado. Como classificador multi-classe para cada folha da árvore, foram experimentados tanto o classificador 1-NN quanto a abordagem UCT, com SVMs como classificador base.

\subsubsection{Comparação de Taxas de Acerto}

A tabela 6.7 mostra a taxa de acerto obtida pelo teste com a aplicação do método DAD ao conjunto completo de dados, em comparação com as taxas de acerto obtidas no experimento da seção 6.3.1. Experimentos foram realizados com o DAD, usando como métrica tanto o ganho de informação por entropia quanto o twoing.

A métrica gini também foi experimentada, porém não mostrou sucesso na decomposição dos dados. Pelo fato de o método não conseguir encontrar uma característica capaz de discriminar a base de dados isolando a classe mais frequente do resto, poucos exemplos são atribuídos a um dos lados da divisão. Dessa forma, por causa do critério de parada, o método sempre julga a primeira decomposição como infrutífera, consequentemente não construindo a árvore.

Podemos ver então que o método DAD, usando tanto entropia como twoing, não superou em taxa de acerto os métodos UCT e TCT. Construindo a árvore usando o 1-NN ao invés do UCT de SVMs como classificador multi-classe para cada folha obtemos um resultado ligeiramente maior se comparado com o 1-NN puro, mas que continua inferior ao UCT e o TCT. 
Tabela 6.7: 1-NN, AD, UCT, TCT e DAD - Taxas de Acerto

\begin{tabular}{cc}
\hline & Média de Acerto (Desvio Padrão) \\
\hline 1-NN & $91.31 \%(0.13 \%)$ \\
AD-entropia & $83.76 \%(0.18 \%)$ \\
AD-twoing & $83.13 \%(0.12 \%)$ \\
UCT & $92.96 \%(0.16 \%)$ \\
TCT & $92.51 \%(0.16 \%)$ \\
DAD-1-NN-entropia & $91.33 \%(0.13 \%)$ \\
DAD-1-NN-twoing & $91.35 \%(0.13 \%)$ \\
DAD-UCT-entropia & $92.96 \%(0.15 \%)$ \\
DAD-UCT-twoing & $92.97 \%(0.10 \%)$ \\
\hline
\end{tabular}

\subsubsection{Estruturas das Árvores}

Durante o processo de validação cruzada de cinco partes, classificadores são treinados cinco vezes, portanto, em cada análise de um método são construídas cinco árvores. Como as árvores são construídas a partir do conjunto de treinamento em questão, as cinco árvores produzidas usando a mesma métrica podem ter estruturas diferentes. Observando os números de folhas em cada árvore construída por cada método tivemos, para o DAD-UCT-entropia $\{1,4,1,1,3\}$ (média 2) e para o DAD-UCT-twoing $\{2,32,2,2,2\}$ (média 8). Quando temos árvores com uma única folha significa que nenhuma divisão foi realizada, portanto o classificador se torna equivalente ao classificador multi-classe base aplicado ao conjunto completo de dados.

O fato de o método, usando a métrica twoing, gerar árvores em geral maiores pode significar que ela seja uma métrica mais apropriada para o problema. Como a geração dos novos filhos de um nó depende do quanto os classificadores dos filhos superam o do pai em desempenho, árvores maiores sugerem que mais dessas divisões foram encontradas.

Observamos também a discrepância entre o número de folhas da árvore treinada (no DAD-UCT-twoing) utilizando a segunda parte (32) do número de folhas do resto (2), mostrando que o conjunto de dados escolhido para treinar a árvore, dentro de um mesmo problema, pode influenciar bastante na estrutura que essa árvore terá.

Tivemos também para o DAD-1-NN-entropia os números de folhas $\{1,4,4,1,1\}$ (média 2.2), e para o DAD-1-NN-twoing $\{2,49,2,2,2\}$ (média 11.4).

\subsubsection{Taxa de Divisão}

Um outro aspecto da análise de desempenho das árvores é a capacidade da árvore de decisão de atribuir os exemplos de teste à folhas capazes de classificá-lo. Por exemplo, se um exemplo da classe ">" for atribuído a uma dada folha da árvore que possui exemplos de treinamento das classes "a", "1" e "+", a classificação correta desse exemplo é impossível. Nesse caso o erro é intrínseco à estrutura da árvore. Podemos então considerar um tipo 
diferente de taxa de acerto, onde o acerto já é considerado se o exemplo for atribuído a uma folha onde sua classe esteja entre as classes dos exemplos de treinamento. A tabela 6.8 mostra essas taxas (chamadas aqui de taxas de divisão), ao lado das taxas de acerto já mostradas de ambas as versões do DAD.

Tabela 6.8: DAD - Taxas de Acerto e Taxas de Divisão

\begin{tabular}{ccc}
\hline & Média de Acerto (Desvio Padrão) & Média de Divisão (Desvio Padrão) \\
\hline DAD-UCT-entropia & $92.96 \%(0.15 \%)$ & $99.99 \%(0.02 \%)$ \\
DAD-UCT-twoing & $92.97 \%(0.10 \%)$ & $99.98 \%(0.03 \%)$ \\
\hline
\end{tabular}

Podemos ver aqui que as taxas de divisão foram bem próximas de $100 \%$ para ambos os métodos. Mesmo a segunda árvore do DAD-UCT-twoing, que foi construída com 32 folhas, e portanto estaria mais sujeito a erros dessa natureza, mostrou taxa de divisão $99.93 \%$.

\subsubsection{Tempos de Processamento}

Olhando para a tabela 6.9 da comparação de médias aproximadas dos tempos (em segundos) de treinamento e teste entre os métodos 1-NN, AD, UCT, TCT, e DAD, observamos a relação entre a construção da árvore e um menor tempo de aplicação do método a novos exemplos.

Tabela 6.9: 1-NN, AD, UCT, TCT e DAD - Tempos de Treinamento e Teste

\begin{tabular}{ccc}
\hline & Treinamento & Teste \\
\hline 1-NN & $0 \mathrm{~s}$ & $23725 \mathrm{~s}$ \\
AD-entropia & $4646 \mathrm{~s}$ & $1 \mathrm{~s}$ \\
AD-twoing & 1590 & $1 \mathrm{~s}$ \\
UCT & $44489 \mathrm{~s}$ & $752 \mathrm{~s}$ \\
TCT & $17773 \mathrm{~s}$ & $38944 \mathrm{~s}$ \\
DAD-1-NN-entropia & $37100 \mathrm{~s}$ & $22694 \mathrm{~s}$ \\
DAD-1-NN-twoing & $42480 \mathrm{~s}$ & $21829 \mathrm{~s}$ \\
DAD-UCT-entropia & $100755 \mathrm{~s}$ & $407 \mathrm{~s}$ \\
DAD-UCT-twoing & $132630 \mathrm{~s}$ & $386 \mathrm{~s}$ \\
\hline
\end{tabular}

O método DAD-UCT-twoing, que construiu árvores de maior estrutura, teve maior tempo de treinamento mas menor tempo de teste, já que as comparações de características que ocorrem em cada nó da árvore são mais rápidas que aplicações de modelos de classificação. Além disso, é esperado que para cada decomposição realizada por um nó da árvore, o número de modelos necessários para treinar cada partição diminua. Isso quer dizer que, quanto maior o custo proveniente do tipo de modelo na predição de novos exemplos, maior é o ganho com o uso da árvore.

Podemos observar também que a árvore de decisão teve tempo de treinamento baixo, e tempo de teste quase instantâneo, porém apresentou os piores resultados com relação a taxa 
de acerto. O método DAD-UCT se igualou ao UCT puro em taxa de acerto, superando o $\mathrm{AD}$, ao mesmo tempo que diminuindo o tempo de teste do UCT em quase metade.

O método DAD-1-NN tem seu tempo de treinamentos aumentado devido à construção da árvore (que envolve também treinamento e teste de classificadores para o cálculo do critério de parada). A presença da estrutura hierárquica da árvore e a diminuição do tamanho do conjunto de dados para cada folha contribuem para que exista alguma diminuição no tempo de teste, mas essa diferença não é tão significativa.

\subsubsection{Variação do Número Máximo de Classes Para Cada Folha}

Observando as árvores contruídas por cada método, vemos que em uma das árvores obtida a partir do método DAD-UCT-twoing, muitas folhas foram finalizadas com uma única classe, delegando o trabalho de classificação para a própria árvore de decisão. Como uma tentativa de podar essa árvore pode ser instalado um novo parâmetro usado como critério de parada, no caso o número máximo de classes para um nó já ser considerado como folha. Por exemplo, se esse parâmetro tem valor 5, quando um nó é formado com cinco ou menos classes, ele já é determinado como folha, antes da verificação da taxa de acerto na base de validação em seus filhos. A tabela 6.10 mostra os números de folhas árvores obtidas variando esse parâmetro de um em um. Cada coluna mostra o teste realizado para um número máximo diferente de classes, com adições incrementais de 1 . O valor inicial é de 1, que é equivalente ao teste sem a utilização desse parâmetro.

Tabela 6.10: DAD - Variação do Parâmetro de Quantidade de Classes - Estruturas das Árvores

\begin{tabular}{cc}
\hline & DAD-UCT-twoing \\
\hline 1 & $\{2,32,2,2,2\}$ \\
2 & $\{2,15,2,2,2\}$ \\
3 & $\{2,9,2,2,2\}$ \\
4 & $\{2,8,2,2,2\}$ \\
5 & $\{2,6,2,2,2\}$ \\
\hline
\end{tabular}

Analisando a figura 6.5 correspondente à estrutura completa da árvore inicial de 32 folhas, vemos que a árvore é desbalanceada.

O primeiro nó se divide já em uma folha e outro nó interno, de forma que essa folha possua exemplos de 106 classes, somente 9 a menos que o problema original. As próximas três divisões ocorrem de maneira semelhante gerando folhas de 90 classes, 40 classes e 17 classes, consecutivamente. A próxima sub-divisão à esquerda leva a uma sub-árvore mais populosa, que sofre novas divisões até cada folha ter no máximo 3 classes.

É importante observar que, da quantidade total de exemplos de teste classificados por essa árvore, por volta de $33 \%$ foram atribuídos à folha de 106 classes, $43 \%$ à folha de 90 classes, $15 \%$ à folha de 40 classes, e $1 \%$ à folha de 17 classes. Os $8 \%$ restantes são classificados na sub-árvore seguinte. 


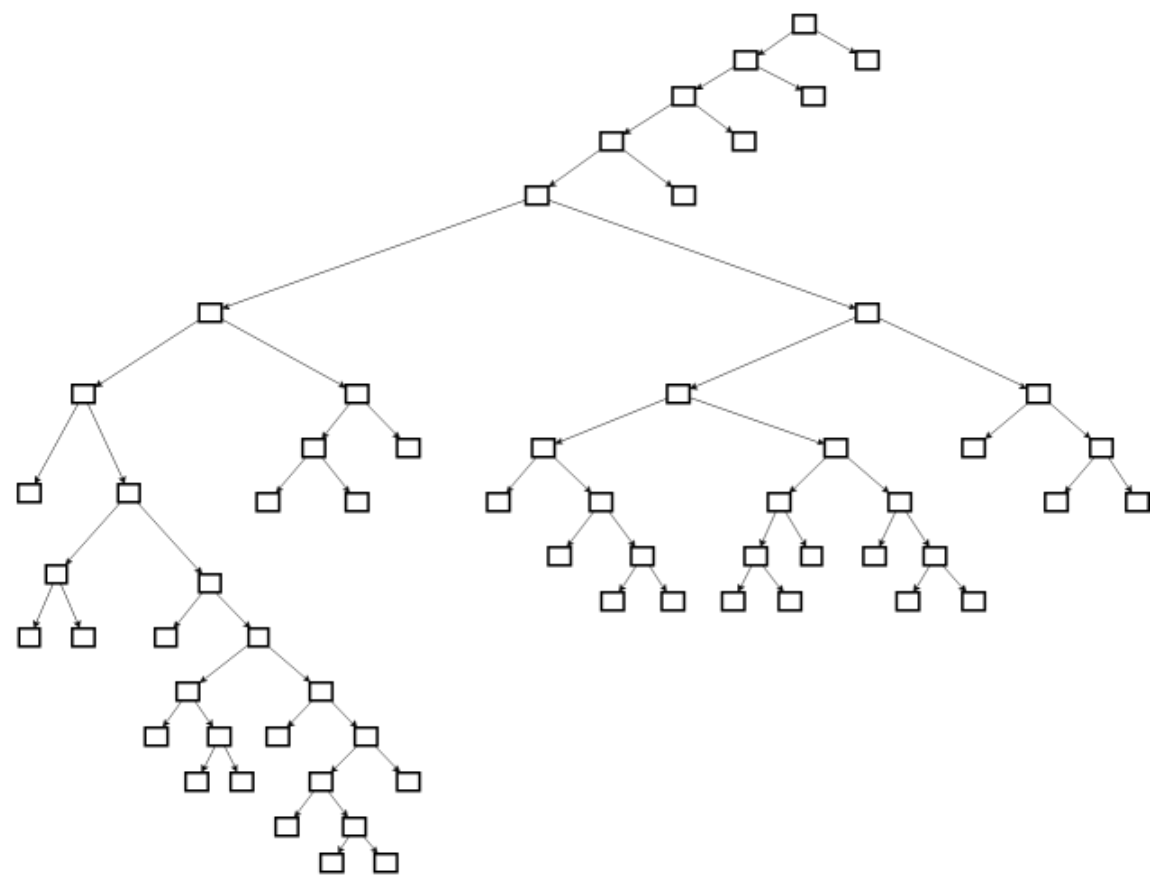

Figura 6.5: Estrutura completa da árvore de 32 folhas.

Para observar a mudança na estrutura dessa árvore a partir da variação do parâmetro, vemos na figura 6.6 a estrutura da árvore correspondente ao segundo caso da tabela.

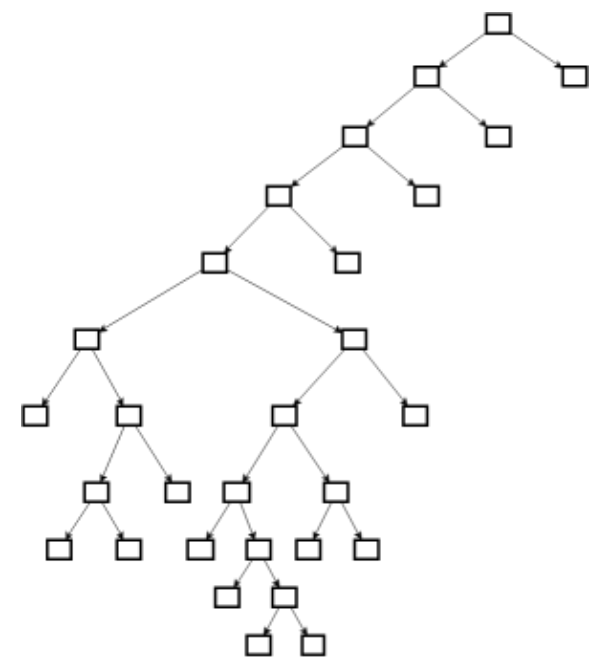

Figura 6.6: Estrutura completa da árvore de 15 folhas.

Vemos então, como esperado, que estabelecendo um número máximo de 2 classes por folha não resulta em nenhuma alteração na parte superior da árvore, porém a sub-árvore inferior sofre várias reduções em sua estrutura.

Vemos também que o mesmo efeito se repete a cada incremento no parâmetro, reduzindo o número de folhas da árvore para 9 (figura 6.7), 8 (figura 6.8), e finalmente para 6 (figura 6.9), onde a sub-árvore que anteriormente tinha estrutura maior é reduzida até uma única divisão, gerando uma folha de 4 classes e outra de 5 . 


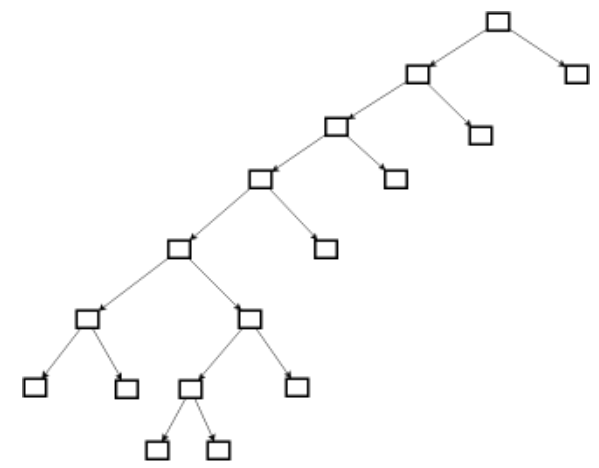

Figura 6.7: Estrutura completa da árvore de 9 folhas.

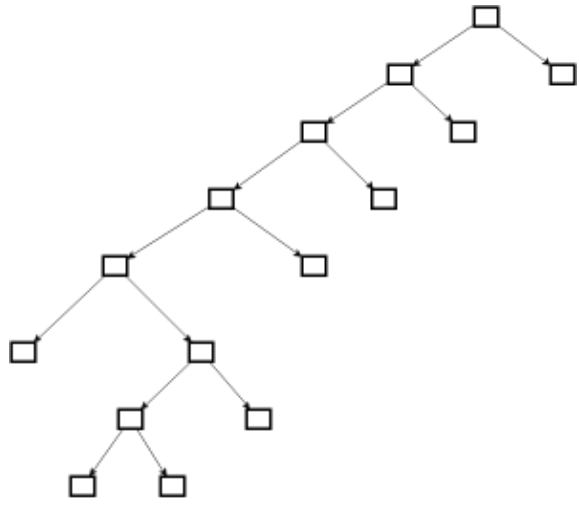

Figura 6.8: Estrutura completa da árvore de 8 folhas.

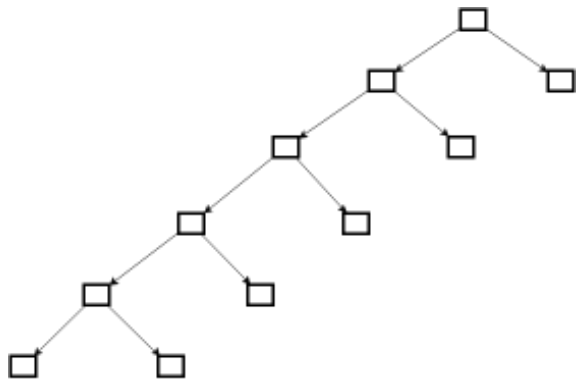

Figura 6.9: Estrutura completa da árvore de 6 folhas.

\subsection{Erros por Classe}

Observar os erros por classe para cada classificador pode fornecer informações importantes sobre possíveis formas de melhorar sua eficácia. Entender quais são as classes que mais contribuem para o erro dos classificadores nos dá meios de trabalhar diretamente nos aspectos do classificador que terão mais chances de resultar em melhoras.

Nesta seção comparamos resultados dos cinco classificadores treinados em cada parte da validação cruzada, para cada um dos quatro métodos principais (UCT, TCT, DAD-UCTentropia e DAD-UCT-twoing), totalizando em vinte classificadores. O erro de uma dada classe A é calculado como a razão entre os exemplos de A que foram classificados como outra classe e o número total de exemplos de A na base de teste. A única classe a aparecer entre as dez com maior erro em todos os vinte classificadores foi a classe "Y". Observando as 
classes que apareceram entre os dez primeiros em pelo menos quinze dos vinte classificadores, obtemos o conjunto \{"Y", ",", " /", ";", "l", "П"\}. Olhando dessa vez para os vinte primeiros pertencentes a todos os vinte classificadores ao mesmo tempo obtemos o mesmo conjunto anterior, substituindo somente a classe "/" pela classe "|".

Observamos que a maior parte dos erros relacionados à classe "Y" acontecem quando ela é classificada como a classe "y". Esse pode ser então um dos casos de classes similares que requerem o uso de informações de contexto para sua diferenciação correta. Também é o caso de "|" e "/", que também tem formas similares, e apresentam vários erros entre si, além de serem confundidos com a classe "," (que pode apresentar forma similar após normalização de escala), e a classe "1". A vírgula por sua vez também é frequentemente classificada como "(" ou ")".

Muitas das classes que aparecem entre os maiores erros de cada classificador tem uma quantidade menor de exemplos, já que o erro é calculado com base no número total de exemplos de cada classe, portanto classes com menor número total estão sujeitas a erros maiores. Obtendo então as classes com número mínimo de exemplos de teste igual a 100, observamos as dez primeiras que aparecem em todos os vinte classificadores, e obtemos então o conjunto $\{" k "$, "z", "t", ","\}.

Erros da classe "k" variaram entre 10 e 20\%, e das classes "z" e "t" entre 15 e 25\%. A classe "t" teve a maior parte de erros atribuídos à classe "+", a classe "z" à classe "2", e a classe "k" teve erros distribuídos entre classes diversas.

\subsection{Seleção de Características}

Uma das contribuições deste trabalho está no uso do conjunto de características HBF49 no problema de reconhecimento de símbolos matemáticos manuscritos. Por esse motivo, um resultado interessante é a definição de quais características são mais relevantes para o problema.

O teste realizado visando tal avaliação também usa validação cruzada de cinco partes, porém, ao invés de separar quatro para treinamento e uma para teste, são separadas três para treinamento, uma para validação e uma para teste. O experimento é dividido em três partes: primeiramente a base de treinamento é usada para avaliar as características e colocálas em ordem de relevância; na segunda parte, as características são selecionadas uma a uma na ordem estabelecida, e então avaliada na base de validação; finalmente, o número ótimo de características determinado na segunda parte é selecionado para avaliação na base de teste.

Para as primeiras duas partes, por uma questão de eficiência, foram usadas somente 60 classes. Para a avaliação final no conjunto de teste, foram utilizadas todas as 115 classes.

Para realizar a ordenação das características, utilizamos um sistema chamado WEKA (Hall et al., 2009) (apêndice C). Nesse sistema um dos métodos implementados usa o treinamento de uma SVM de kernel linear para avaliação do conjunto de características, se 
baseando na grandeza dos coeficientes na equação do hiperplano para colocar as características em ordem de relevância. Esse método é usado então para ordenar as 49 características usando o conjunto de treinamento (para cada um dos cinco passos).

Para encontrar um tamanho ótimo do conjunto de características, realizamos um teste com incremento gradual de características a partir da ordem obtida no primeiro passo. No primeiro teste o conjunto de treinamento, com somente a primeira característica da sequência selecionada, é usado para treinar o UCT, que então avalia a base de validação. No segundo teste são selecionadas as duas primeiras características, no terceiro as três primeiras, e então analogamente até o último teste com todas as 49. O gráfico 6.10 mostra a progressão do erro obtido na base de validação com a inserção de cada característica (para comparação foi apresentado também a progressão do erro na base de treinamento).

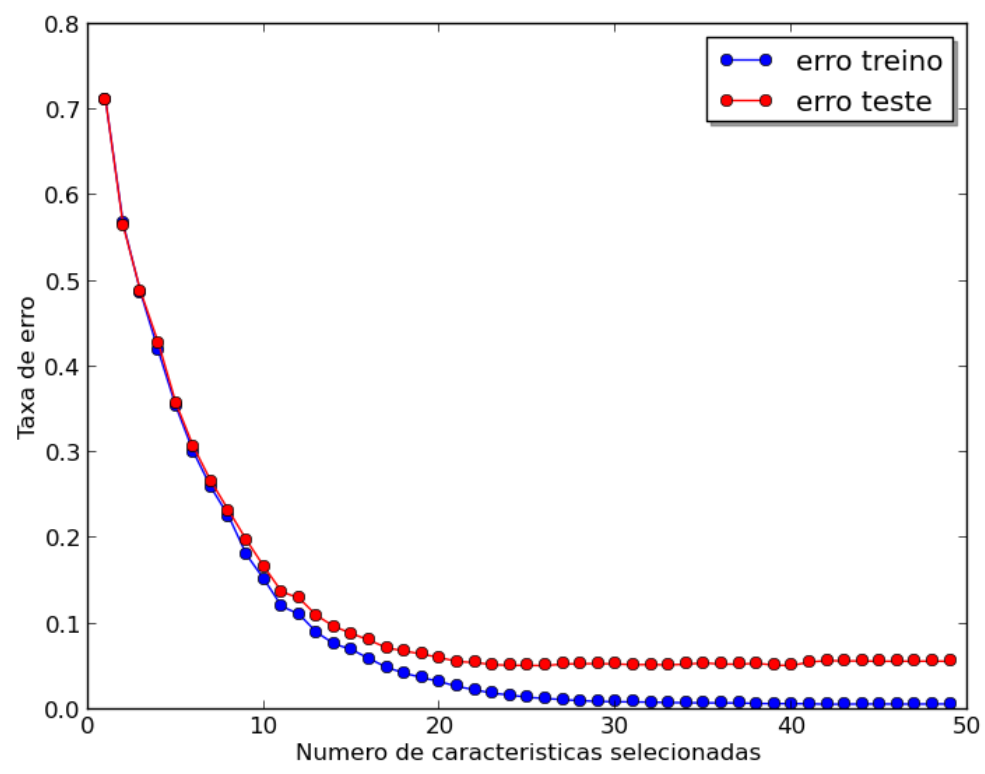

Figura 6.10: Gráfico com progressão do erro com a inserção gradual de características.

Vemos então que o erro diminui gradualmente, até a região próxima à metade do conjunto total, onde o erro se estabiliza e se mantêm aproximadamente o mesmo até a última inserção. Isso quer dizer que as novas características adicionadas a partir desse momento não adicionaram informações importantes para a resolução desse problema reduzido.

Observando os cinco gráficos obtidos em cada um dos passos da validação cruzada, o valor 26 para o tamanho do conjunto de características se situou consistentemente na região estabilizada. Essa quantia foi escolhida então como valor ótimo do tamanho do conjunto.

Usando agora ambas as bases de treinamento e validação para treinamento, e a de teste para avaliação (dessa vez utilizando todas as 115 classes), avaliamos a taxa de acerto final após a seleção das 26 primeiras características, de acordo ainda com a ordem obtida usando o algoritmo do WEKA. Calculando a média das taxas de acerto finais das cinco partições da validação cruzada obtivemos $\mathbf{9 2 . 6 2 \%}$ (com $0.09 \%$ de desvio padrão). Vemos então que, 
utilizando pouco mais que metade do conjunto de características, e avaliando as características selecionadas em um conjunto de dados de somente 60 classes, obtivemos um resultado somente por volta de $0.4 \%$ menor do que o resultado do UCT utilizando o conjunto de dados completo.

Observamos que 14 das 49 características foram comuns a todos os cinco conjuntos de 26 características selecionadas. Essas 14 foram:

f7 : componente vertical do vetor do primeiro ao último ponto;

f8 : fecho;

f14 : número de traços;

f15 : ângulo da diagonal da caixa envoltória;

f16 : comprimento da trajetória total;

f17 : soma da altura e largura, dividido pela trajetória total;

f20 : curvatura;

f22 : k-perpendicularidade;

f28 : primeira região do histograma de ângulos relativos;

f35 : quarta região do histograma 2D;

f37 : sexta região do histograma 2D;

f40 : nona região do histograma 2D;

f41 : primeiro característica referente aos momentos $\mathrm{Hu}$;

f42 : segunda características referente aos momentos $\mathrm{Hu}$.

Vemos que, de forma geral, as características escolhidas estão entre as mais simples, com informações mais gerais sobre o símbolo. É importante também resssaltar a presença das duas regiões do histograma 2D, que neste trabalho teve uma mudança na implementação, passando a usar um quadrado minimal que contém o símbolo para delimitar as regiões, ao invés da área retangular correspondente à caixa envoltória. 


\section{Capítulo 7}

\section{Conclusão}

Neste trabalho tivemos como objetivo realizar uma análise empírica de métodos de classificação aplicados ao problema de reconhecimento de símbolos matemáticos manuscritos. Foram analisados os desempenhos de abordagens clássicas da literatura para resolução do problema multi-classe, em conjunto com um método que usa árvores de decisão para decomposição do problema de classificação. Também foi avaliada a relevância do conjunto de características extraídas dos dados.

\subsection{Resumo do Trabalho Realizado}

Para trabalhar com um problema mais completo, com maior número de classes e maior número de exemplos, foi realizada uma coleta de novos dados, complementando bases já existentes provenientes de outros trabalhos (apêndice B). Esses dados são armazenados no formato de uma sequência de pontos em um sistema de coordenadas que descrevem a escrita realizada para cada símbolo.

Foram implementados uma série de métodos de pré-processamento de sinais, apropriados para o uso nesse tipo de dados, com o objetivo de normalizar e padronizar as formas dos símbolos, assim como eliminar possíveis ruídos provenientes de imprecisão do hardware. Os métodos de pré-processamento usados neste trabalho foram tirados principalmente de (Tapia, 2004), (Matsakis, 1999) e (Huang et al., 2007).

A partir do trabalho de Delaye e Anquetil (2013), foram implementados também métodos para a extração de um conjunto de 49 características chamado HBF49. Essas características foram propostas com o objetivo de servir como um conjunto base para problemas gerais de reconhecimento de símbolos manuscritos on-line.

Para a aplicação dos métodos de reconhecimento, foram implementadas as abordagens um-contra-todos e todos-contra-todos, que fazem uma combinação de classificadores binários para resolver um problema multi-classe. O algoritmo para construção da árvore de decisão foi também implementado, de forma a ser usado, tanto em combinação com os outros métodos citados como sendo um classificador completo. As SVMs (que correspondem aos classifica- 
dores binários usados com o UCT e o TCT) foram criadas utilizando a biblioteca libsvm.

Os métodos descritos foram então experimentados em dois contextos: aplicando-os ao conjunto completo de dados (1-NN, AD, UCT, TCT e DAD); e aplicando-os a conjuntos incrementais de classes (UCT e TCT), verificando assim seus comportamentos com o aumento do número de classes.

O sistema WEKA foi utilizado também para avaliar o uso do conjunto de características no nosso problema. As características foram ordenadas a partir do valor de seu coeficiente no hiperplano da SVM treinada, em um problema reduzido de 60 classes, e então adicionadas uma a uma nessa ordem ao classificador a ser avaliado. Por fim, as características escolhidas são selecionadas para avaliação do classificador no problema completo de 115 classes.

\subsection{Conclusões}

Com relação ao teste com conjuntos incrementais de classes, é interessante observar o comportamento dos métodos UCT e TCT conforme o conjunto de classes considerado aumenta de tamanho. Aplicando esse teste ao problema, tanto utilizando todos os dados disponíveis como limitando a base de treinamento para somente por volta de 28 exemplos por classe, observamos a constante degradação no desempenho dos classificadores com o aumento do número de classes. Foi observado também como o TCT perde eficácia com uma velocidade maior do que o UCT na situação dos conjuntos de exemplos limitados.

Através de gráficos foram mostradas também as relações entre o UCT e o TCT em termos de eficiência. Vimos que o TCT apresenta menor tempo de treinamento por construir cada classificador com menor quantidade de exemplos, e que, considerando os tempos de teste, essa vantagem se inverte, já que o número de classificadores no TCT cresce mais rapidamente, e cada classificador é aplicado a um mesmo número de exemplos no conjunto de teste, para ambos os métodos.

As abordagens UCT e TCT foram também experimentadas usando o conjunto completo de dados de 115 classes. Como referência de comparação para os dois métodos, testamos também o 1-NN e a AD no mesmo conjunto. Foi mostrado então que o UCT e o TCT superaram o 1-NN em até por volta de $1.6 \%$, com a maior vantagem referente ao UCT. Executando os mesmos testes (usando 1-NN, UCT e TCT) com o conjunto de dados com distribuição uniforme de classes observamos a grande queda de desempenho, devido à limitação dos dados.

Comparando os resultados com o desempenho obtido usando a abordagem de separação de classes, vimos que não houve significativo ganho na taxa de acerto. Apesar disso, verificamos que o uso da métrica twoing, em um dos casos de árvore construída, resultou em mais divisões que o uso da métrica de entropia, usando como critério de parada a avaliação dos classificadores treinados a partir dos exemplos do pai e dos filhos, aplicados à base de validação. Isso resultou em um tempo de treinamento das árvores constrúidas com twoing 
um pouco maior, assim como um tempo de teste um pouco menor.

Observamos também que a árvore maior construída utilizando a métrica twoing realizou divisões até que existam folhas com uma única classe, dessa forma delegando o trabalho de classificação para a árvore de decisão. Como forma de regular a distribuição desse trabalho entre a estrutura da árvore e os classificadores nas folhas, sugerimos um parâmetro que estabelece um número máximo de classes para o qual um nó pode ser considerado folha.

Foram analisados brevemente alguns dos erros mais comuns entre os classificadores experimentados. A causa para a maioria dos maiores erros parece ser ainda a dificuldade de diferenciação entre símbolos de formas visuais similares, como por exemplo entre "t" e "+", "z" e "2", "/" e "|", "Y" e "y", etc, sobretudo considerando a forma que cada símbolo assume após sua normalização.

Ao avaliar a inserção gradual de características em ordem de relevância, vimos que, ao atingir por volta de pouco mais da metade do conjunto de características, o desempenho se estabiliza. A avaliação final selecionando características (26 de 49) reduziu o resultado final em somente por volta de $0.4 \%$.

\subsection{Trabalhos Futuros}

Um fator importante relacionado a SVMs que não foi abordado neste trabalho é a calibração de parâmetros e escolha de kernel. Ajustar o kernel e os valores dos parâmetros ao problema em questão é um meio de melhorar o desempenho da SVM, ajustando o classificador para o problema em questão. (Rifkin e Klautau, 2004) descrevem uma abordagem para calibração dos parâmetros da SVM para problemas multi-classe usando as abordagens UCT e TCT que resultou em bons resultados. Na base de treinamento de cada fase da validação cruzada são realizadas novas validações cruzadas como forma de avaliar a eficácia de cada conjunto de parâmetros. Cada parâmetro é otimizado separadamente, ou seja, quando um parâmetro é variado, os outros são fixados.

O problema tratado aqui é uma versão reduzida do problema completo de reconhecimento de símbolos matemáticos, por ainda não conter dados suficientes para representar todos os símbolos possíveis. É esperado que, a partir daqui, cada vez mais dados sejam coletados, sempre visando aproximar o problema resolvido ao conjunto de classes total que representa a sintaxe matemática.

Além disso, o problema com o qual lidamos aqui é também reduzido se comparado com os dados já disponíveis. Isso acontece devido à impossibilidade de segregar certas classes utilizando somente informações do símbolo isolado. Dois caminhos parecem mais óbvios para levar esse conceito adiante. Primeiramente, podemos acoplar um método de reconhecimento de símbolos isolados a um método de análise estrutural. Dessa forma, ambos os métodos trabalhariam simultaneamente aliando informações da forma do símbolo e informações do contexto da expressão em que ele está contido para determinar tanto a classe do 
símbolo quanto seu lugar na expressão. Entre trabalhos recentes relacionados à análise estrutural de expressões matemáticas podemos citar (Vuong et al., 2008), (Rhee e Kim, 2009), (Álvaro et al., 2014) e (Awal et al., 2014).

A segunda possibilidade de caminho seria a inserção de informação de contexto da expressão no próprio classificador de símbolos isolados. Isso poderia ser feito extraindo novas características da forma do símbolo relativas ao resto da expressão. Por exemplo, poderia ser calculada a proporção de escala do símbolo, em relação com a média de escalas dos outros símbolos na mesma expressão. Esse tipo de característica pode auxiliar o sistema de reconhecimento a diferenciar classes que de outra forma poderiam não ter distinção clara. Um trabalho interessante a ser realizado nessa vertente seria propor um conjunto de características dessa natureza, acrescentá-las ao conjunto existente, e verificar a relevância das novas características num contexto geral.

É importante ressaltar que, para seguir o trabalho considerando expressões como um todo, é necessário que todos os símbolos sejam coletados como parte de uma expressão matemática, e que todas as expressões definidas tenham estrutura e conjunto de símbolos usuais na literatura matemática, para que as informações de contexto tenham relevância ao tratar problemas de dados reais.

Dois caminhos também parecem claros para a continuação da pesquisa relacionada à abordagem hierárquica descrita no trabalho. Um deles buscaria modificar o método apresentado tentando obter melhores resultados. uma forma de fazer isso é, por exemplo, experimentar novas métricas de divisão, com o objetivo de encontrar a mais apropriada para esse problema de decomposição da base de dados. Diversos trabalhos, como (Mingers, 1989), (Buntine e Niblett, 1992) e (Berzal et al., 2003) realizam comparações de regras diferentes de divisão de nós. Outra tentativa de melhorar o desempenho do método pode ser a modificação da forma com que a divisão é realizada. Como trabalhamos com um algoritmo comum de árvore de decisão, uma divisão é realizada simplesmente por comparações do valor de uma característica. Métodos mais complexos podem ser experimentados para a divisão da base de dados nos grupos que formarão os filhos do nó corrente.

A pesquisa de formas eficientes para decompor problemas de classificação multi-classe pode ser continuada também com a proposta de novos métodos, e futura comparação deles com o método aqui proposto. Como o nosso método é conceitualmente relativamente simples, ele pode ser usado como resultado base para comparação com novas futuras abordagens. Além disso, essa comparação pode ser realizada em diversos aspectos, como taxa de acerto final, qualidade da divisão de dados, estrutura hierárquica formada, tempo de treinamento e teste, etc. 


\section{Apêndice A}

\section{LibSVM}

A libsvm (Chen et al., 2005) é a biblioteca usada neste trabalho para treinar e testar SVMs. A implementação usada aqui foi escrita em $\mathrm{C}++$, e apresenta várias opções de modelos, parâmetros, e abordagens de execução. A biblioteca também fornece scripts em Python com modos de uso prontos do sistema, porém aqui utilizamos direto as funções do código fonte.

Utilizando as funções da biblioteca, sistemas de treinamento e teste de um modelo de SVM foram implementados. Para representar um conjunto de dados é usada uma estrutura chamada svm_problem. Para representar um conjunto de parâmetros, usamos uma estrutura chamada svm_param.

Todos os dados de treinamento são inseridos na estrutura svm_problem. Dentro dela existe um vetor x onde são inseridos elementos do tipo svm_node, onde são guardados os valores das características. Existe também um vetor y onde são armazenadas as informações de classe.

Na estrutura svm_param são encontradas uma série de variáveis, cada uma correspondente a um dos parâmetros da SVM. Essas variáveis são preenchidas com os valores desejados de cada parâmtro. Listando parte dos parâmetros existentes, temos:

- svm_type : tipo da SVM usada;

- kernel_type : tipo do kernel usado;

- degree : grau na função de kernel;

- gamma : parâmtro gamma da função de kernel;

- coefo : coeficiente na função de kernel;

- C : parâmtro presente nos tipos de SVM C-SVC, epsilon-SVR e nu-SVR;

- nu : parâmetro presente nos tipos de SVM nu-SVC, one-class SVM e nu-SVR;

- eps : epsilon usado na função de perda; 
- cache_size : tamanho da memória cache usada;

- p : parâmtro usado em regressão;

- shrinking : determina se será usada heurística de shrinking;

- weight : determinação de pesos para o parâmtro $C$;

- probability : determina se serão calculadas as estimativas de probablidades.

O modelo (do tipo svm_model) é então criado usando a função svm_train, passando como parâmetros os objetos das estruturas svm_problem e svm_param. Uma vez construído o modelo, ele pode ser salvo em um arquivo para futura referência, e os objetos criados podem ser devidamente desalocados de memória.

Para realizar o teste de novos exemplos, é criado um vetor de estruturas svm_node, uma para cada instância da base de teste. O modelo treinado é recuperado novamente para a estrutura svm_model. A partir dessas duas informações, a função svm_predict_probability é chamada. Originalmente essa função calcula as probabilidades a posteriori de pertinência de cada exemplo a cada uma das duas classes, e retorna a classe resultante encontrando a maior probabilidade encontrada. Como precisamos de valores de confiança para o uso das abordagens um-contra-todos e todos-contra-todos, a função foi alterada levemente para retornar as próprias probabilidades calculadas, ao invés das classes.

Esse resultado é então retornado para o método externo, que fará uso desses valores para calcular o resultado final. 


\section{Apêndice B}

\section{Natureza dos Dados Utilizados no Trabalho}

\section{B.1 Formato dos Dados Armazenados}

Os dados utilizados aqui estão armazenados em arquivos InkML (Ink ). Cada um desses arquivos contém informações sobre uma expressão matemática inteira escrita por um único usuário. O arquivo nos fornece informações para o reconhecimento da expressão como um todo, mas como aqui estamos interessados no reconhecimento de símbolos, destacamos apenas as duas partes do arquivo InkML relevantes para obter dados referentes a símbolos, usando como exemplo o conteúdo do arquivo InkML correspondente à expressão $x=r \cos \theta$ :

Conjunto numerado de traços:

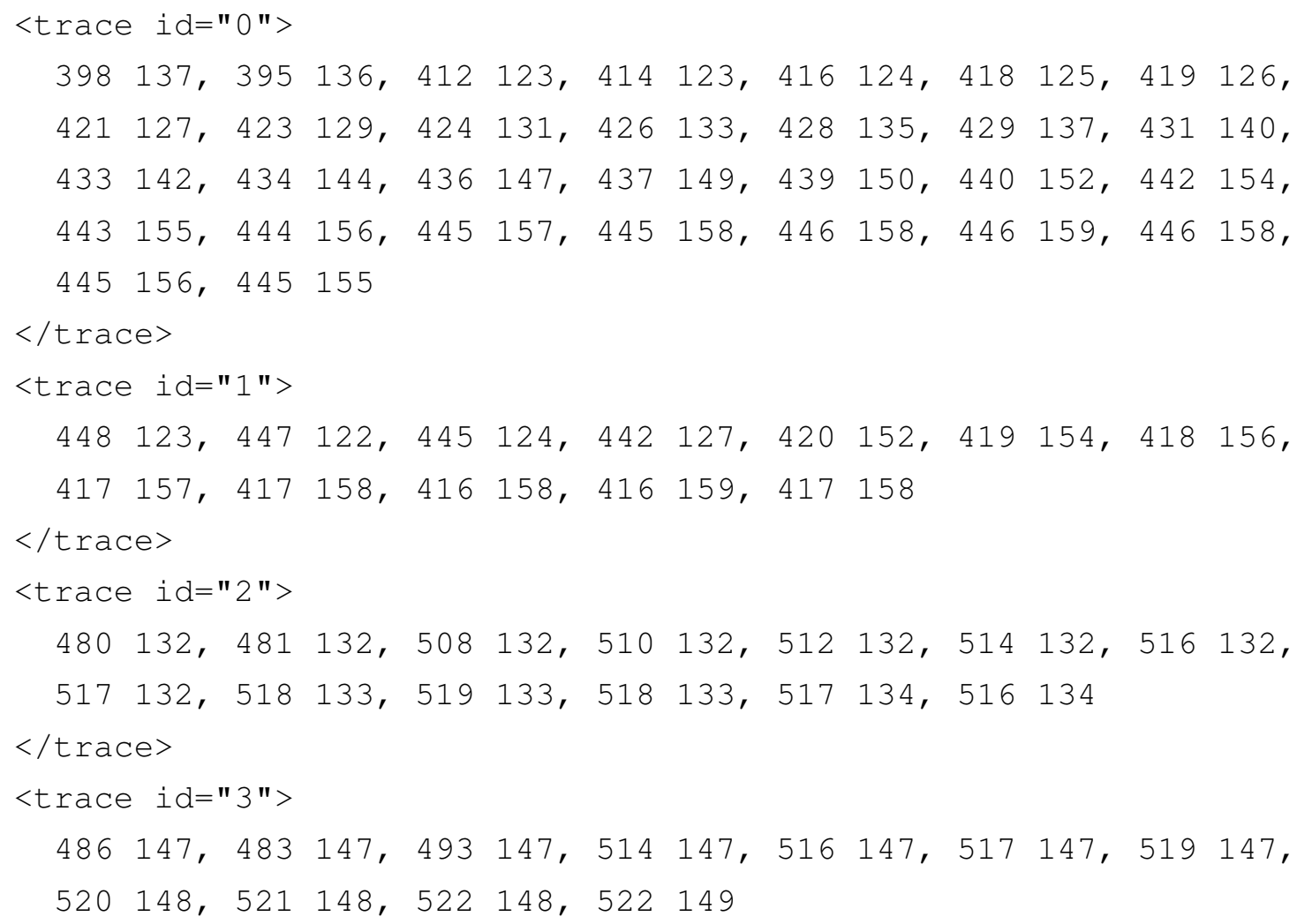


$</$ trace $>$

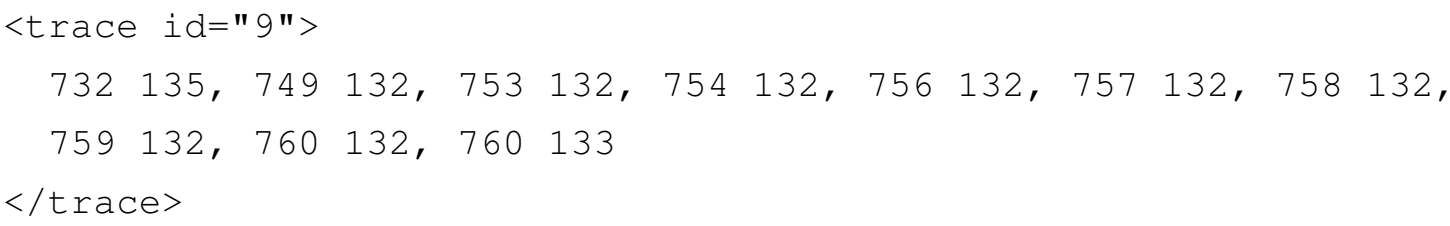

Informações reais de segmentação de traços e rótulos de cada símbolo:

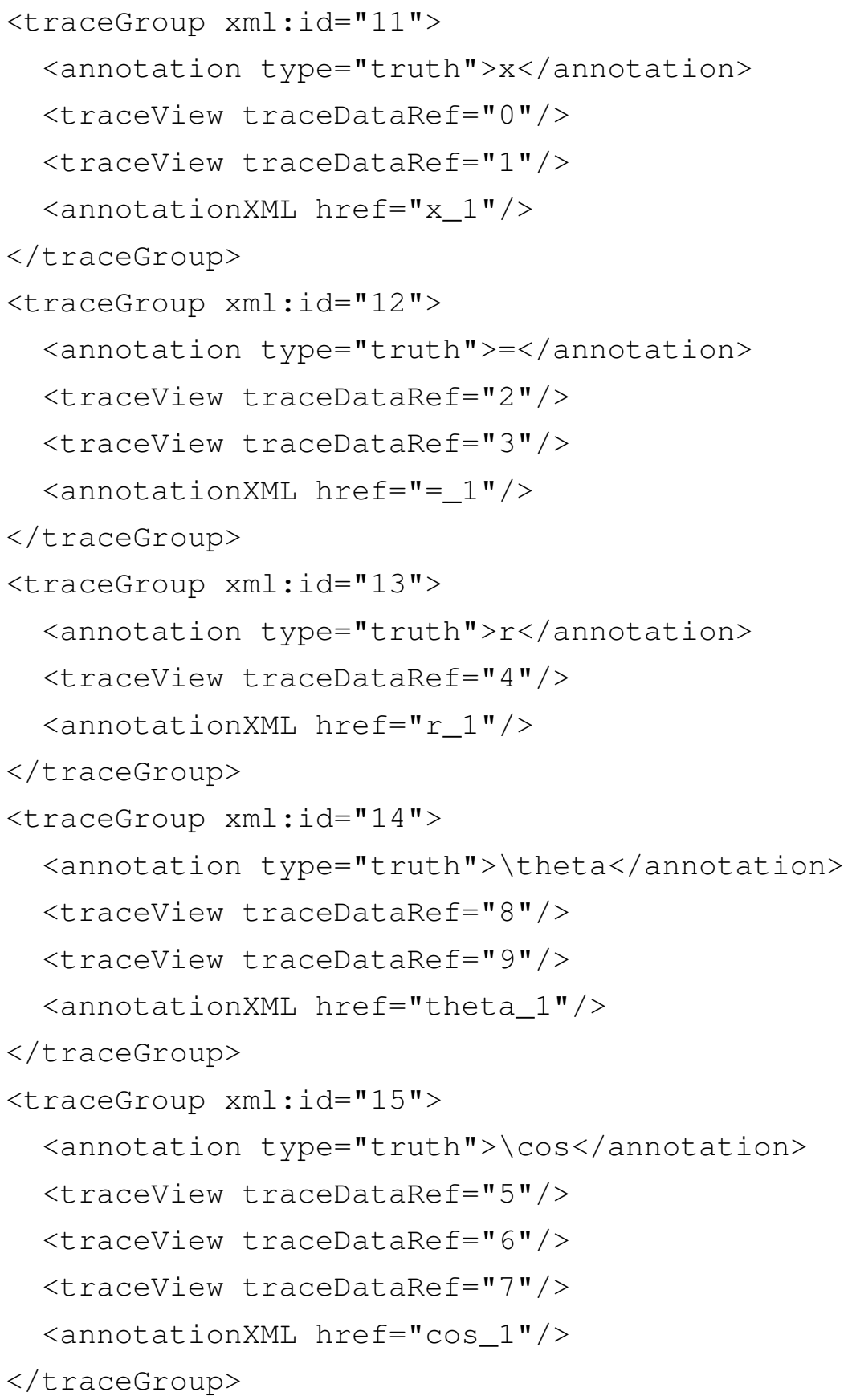


Cada seção "trace" indica um traço e enumera as coordenadas $(x, y)$ dos pontos que fazem parte do traço.

Cada seção "traceGroup" da segunda parte corresponde a um dos símbolos na expressão. Ele é acompanhado do seu respectivo rótulo (annotation type="truth") e dos índices de cada um de seus traços (traceView traceDataRef).

\section{B.2 Bases de Dados}

Bases de dados públicas de expressões matemáticas ainda são escassas (Lapointe, 2008). Além disso, grande parte dos trabalhos nessa área utilizam dados próprios. Isso motivou, por exemplo, a criação do padrão InkML explicado anteriormente, pois dados usando essa representação podem ser aglomerados com mais facilidade.

Outra consequência do problema de dados não unificados é a dificuldade na comparação de resultados. Isso motivou a criação de uma competição de reconhecimento de expressões matemáticas manuscritas chamada CROHME (Competition on Recognition of Online Handwritten Mathematical Expressions) (Mouchere et al., 2011). Seu objetivo é reunir pesquisadores interessados na área para submeter seus sistemas de reconhecimento para que possam ter seus desempenhos analisados usando o mesmo conjunto de dados. A partir disso, a ideia é eventualmente convergir para um método estado da arte que sirva de base para novas pesquisas.

Com essa proposta, alguns grupos de pesquisa contribuíram com suas bases de dados para utilização na competição. Neste trabalho também as usaremos em nossos experimentos, portanto uma breve descrição sobre cada uma delas é apresentada a seguir.

\section{B.2.1 MathBrush}

O sistema MathBrush (Labahn et al., 2008) foi construído com o objetivo de auxiliar estudantes no aprendizado de matemática. Ele recebe expressões matemáticas manuscritas e reconhece os símbolos escritos e a estrutura da expressão, oferecendo também interação com o usuário para possível correção de erros. Uma vez reconhecida a expressão, o sistema estabelece uma comunicação com um sistema externo que, por exemplo, resolve a equação e retorna o resultado.

Para a criação da base de dados, estudantes foram requisitados a transcreverem expressões matemáticas durante uma hora. As expressões a serem transcritas são geradas aleatoriamente, e então apresentadas impressas para o usuário. Detalhes sobre a geração automática de expressões modelo e rotulação automática das expressões transcritas podem ser encontrados em (MacLean et al., 2011) 


\section{B.2.2 HAMEX}

Outro dos conjuntos de dados usados na competição CROHME se chama HAMEX (Handwritten and Audio Dataset of Mathematical Expressions) (Quiniou et al., 2011). Ele foi criado seguindo a ideia de armazenar, além dos dados de escrita, dados de audio correspondentes à fala da expressão. Essa informação a mais pode ser de grande auxílio durante a segmentação e reconhecimento de símbolos, por exemplo, ao tentar classificar um "y"parecido com um "g". As escritas podem ser similares, mas as inflexões da voz durante a fala serão bem diferentes.

Para determinar as expressões que entrarão na base de dados, expressões foram extraídas de artigos da Wikipedia (Wik ), pela preferência por expressões reais usadas em documentos matemáticos comuns. Além disso, para a parte mais simples do conjunto de dados, algumas expressões foram geradas aleatoriamente formando estruturas simples e contendo símbolos simples. Dessa forma o conjunto completo é formado de três sub-conjuntos diferenciados por complexidade de expressão (o sub-conjunto gerado a partir da Wikipedia é dividido em dois).

Tendo definidas as expressões a serem coletadas, uma ferramenta foi implementada para aleatoriamente selecionar expressões do conjunto completo, e mostrá-las na tela. Com as expressões em vista, o usuário pode reescrevê-las a mão, inserindo também seu nome, idade, sexo e se é destro ou canhoto.

Cada uma dessas expressões então é armazenada em um arquivo InkML. De forma análoga à coleta de escrita, cada usuário recebe uma lista de expressões para reproduzir pela fala, e as gravações são armazenadas.

\section{B.2.3 $M \operatorname{MrDB}$}

Também como forma de cobrir a escassez de bases de dados de expressões matemáticas, a fim de avançar uma pesquisa em reconhecimento voltado à análise estrutural, foi desenvolvida uma aplicação Web de coleta de expressões que auxiliou na produção da base de dados MfrBD (Stria et al., 2012). A aplicação foi implementada visando simplificar o processo de aquisição de dados, uma vez que ela estaria disponível em qualquer lugar, e poderia ser usada por vários usuários simultaneamente.

Uma vez que a aplicação é aberta, o usuário escreve seu nome, e em seguida uma série de fórmulas matemáticas. Fica a critério do usuário que a fórmula escrita seja uma transcrição da fórmula impressa pela aplicação, ou alguma outra fórmula qualquer. Os dados entrados são então manualmente analisados, sendo então descartadas fórmulas sintaticamente incorretas, triviais e de qualidade muito pobre.

O primeiro passo para a rotulação e segmentação dos símbolos é converter as expressões para o formato MathML (Mat ). Caso o usuário tenha simplesmente repetido a expressão que lhe foi apresentada, é simplesmente copiada a estrutura MathML da expressão usada. Caso contrário a aplicação Math Control Panel do Microsoft Windows 7 é chamada com 
os traços da expressão como parâmetros. A estrutura da expressão então continua sendo reconhecida pela aplicação, enquanto pequenas correções são feitas manualmente. Por fim, com a estrutura da expressão em mãos, os rótulos dos símbolos são manualmente inseridos.

\section{B.2.4 ExpressMatch}

De todos os conjuntos de dados anteriores, usamos os exemplos fornecidos publicamente pelo CROHME. Porém, para aumentar nossa massa de dados e nosso número de classes, cobrindo categorias de símbolos que ainda não estavam disponíveis, utilizamos o sistema de coleta ExpressMatch, proposto em (Aguilar e Hirata, 2012). A ideia por trás desse sistema consiste em uma maior automatização da coleta de expressões matemáticas manuscritas. A escassez de bases de dados rotuladas desse domínio motivou a implementação de um sistema que torne a entrada de novos exemplos de expressões menos monótona e menos suscetível a erros. Para isso, são definidas expressões modelo, cujos símbolos serão rotulados manualmente. Depois disso, cada novo usuário terá a chance de reescrever um sub-conjunto das expressões modelo. Cada uma dessas novas instâncias terá seus símbolos rotulados automaticamente, com o uso de um algoritmo que calcula a correspondência de um símbolo na expressão de usuário ao símbolo correspondente na expressão modelo (Hirata e Honda , 2011).

Esta base de dados retoma a técnica usada por ichi Hanaki et al. (1976) de separação temporal para coletar símbolos matemáticos manuscritos (Aguilar e Hirata, 2012). Embora essa técnica introduza restrições ao processo de coleta, Aguilar e Hirata (2012) comentam que usuários do sistema não relataram dificuldade de adaptação da maneira de escrita às restrições no processo de coleta do sistema.

\section{Processo da Coleta}

O ExpressMatch consiste de basicamente seis componentes:

- Segmentador: Uma vez que a caneta desfaz o contato com a tela, o tempo final do traço é marcado. Caso o início do próximo traço ocorra antes de uma diferença de tempo pré-estabelecida, partindo do tempo marcado, o próximo traço é agrupado ao anterior sendo agregado ao mesmo símbolo. Caso contrário, um novo símbolo é criado.

- Capturador de Modelos: Fornece as funções para inserção de modelos, incluindo, principalmente, a tela para escrita e as áreas onde os rótulos de cada símbolo serão inseridos manualmente.

- Capturador de Instâncias: Apresenta alguma expressão modelo previamente inserida, e fornece uma tela para que essa expressão seja transcrita pelo usuário. 
- Rotulador Baseado em Correspondência de Expressões: É responsável por corresponder cada símbolo de uma instância inserida ao seu respectivo símbolo no modelo.

- Editor de Rótulos: Possibilita a edição de rótulos que tenham sido erroneamente atribuídos durante a correspondência automática.

- Importador/Exportador: Importa e exporta os dados em formatos diferentes.

Existem dois tipos de usuários do sistema, chamados de administrador e escritor. O administrador interage com o capturador de modelos, para inserir os modelos e rotular cada um dos símbolos. Um exemplo da tela de escrita para entrada de modelos é mostrado na figura B.1.

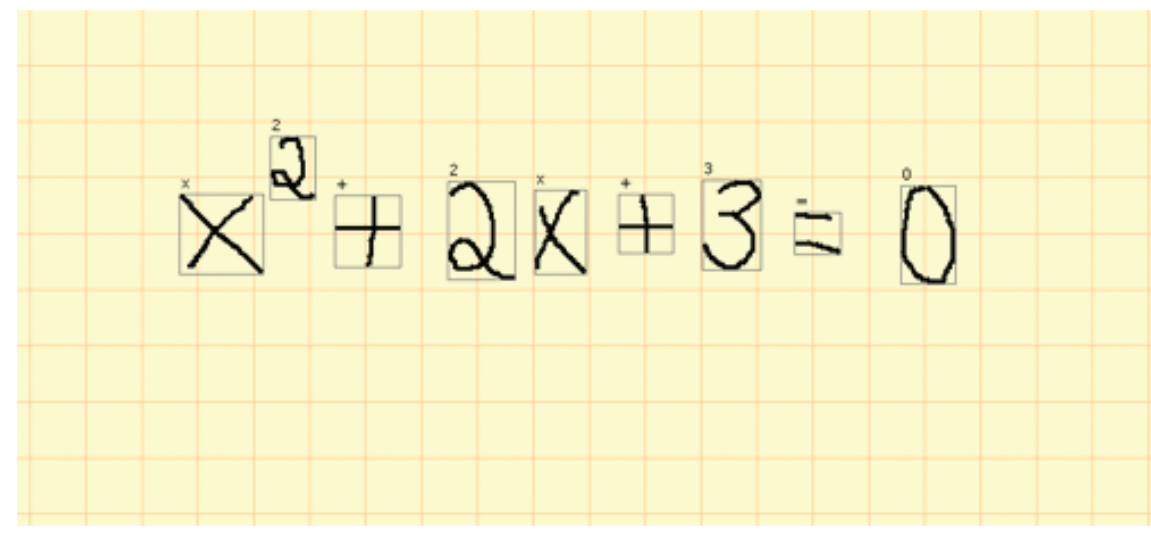

Figura B.1: Exemplo de entrada de um modelo de expressão com rotulação manual.

O escritor interage com o capturador de instâncias para transcrever modelos existentes, criando instâncias que serão rotuladas automaticamente. A tela do sistema para a transcrição de instâncias está exemplificada na figura B.2.

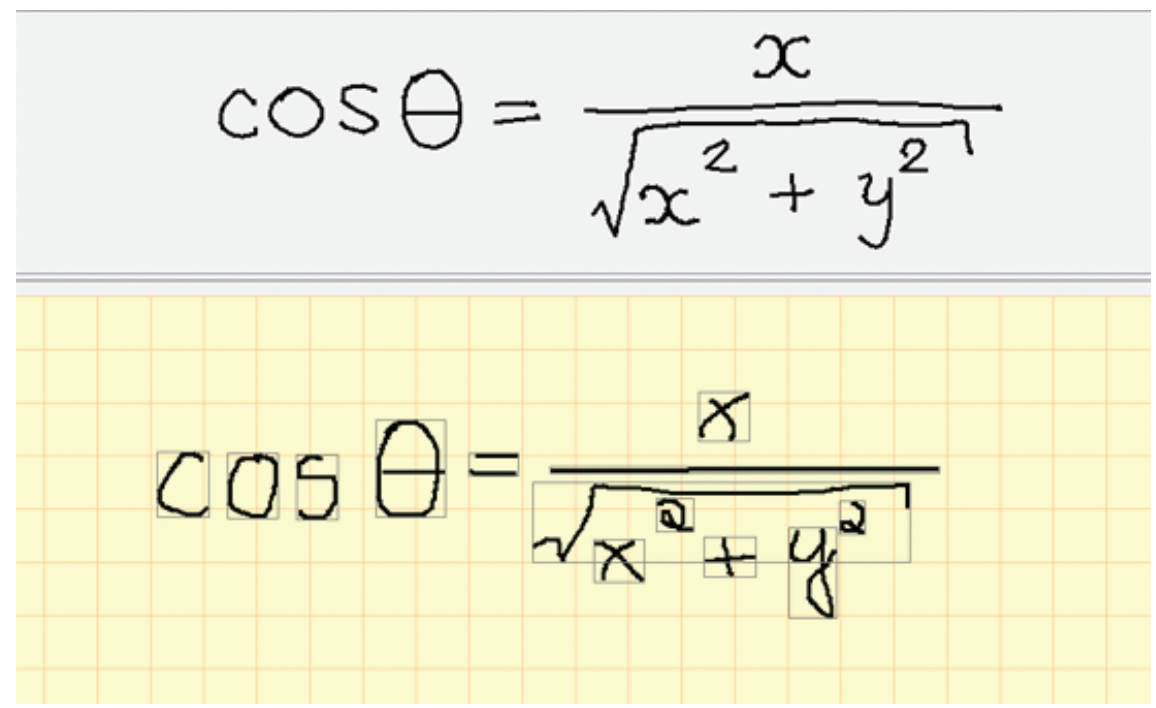

Figura B.2: Exemplo de entrada de uma instância transcrevendo um modelo. Modelo na parte superior e transcrição na parte inferior. 
Uma vez que as expressões tenham sido correspondidas pelo rotulador automático, como mostrado na figura B.3, o administrador tem então a possibilidade de corrigir possíveis erros na rotulação automática através do editor de rótulos.

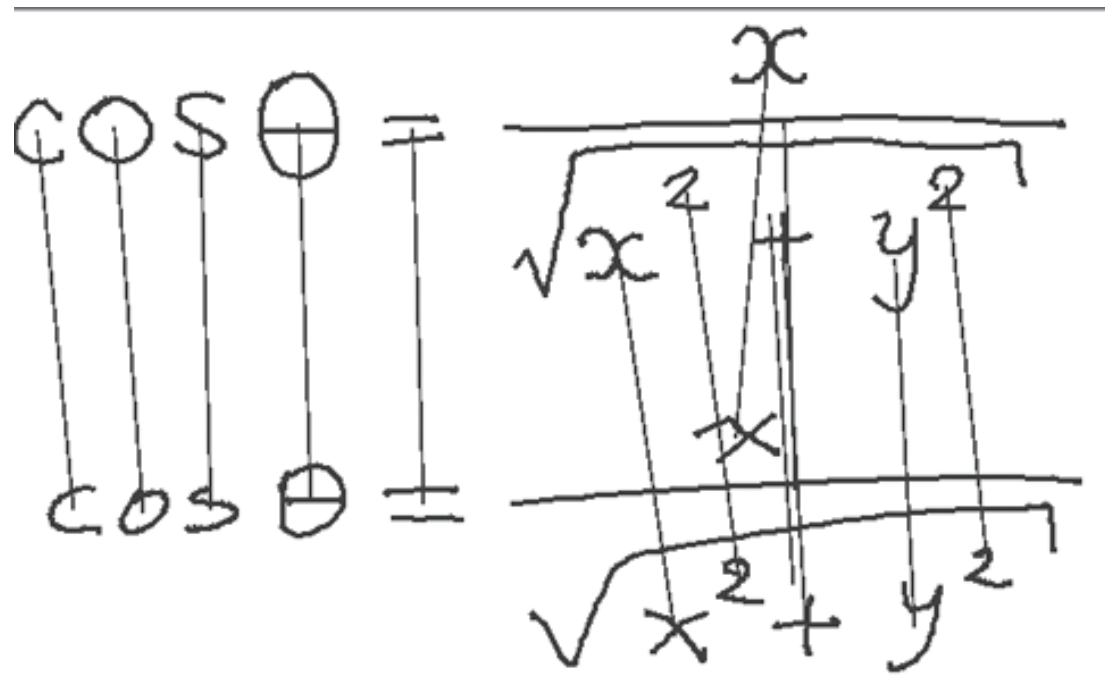

Figura B.3: Exemplo de uma correspondência calculada entre duas expressões. 
APÊNDICE B 


\section{Apêndice C}

\section{WEKA}

O sistema WEKA (Hall et al., 2009) para mineração de dados foi utilizado neste trabalho para fazer seleção de características. Ele pode ser usado por linha de comando, ou a partir de um interface gráfica fornecida que contém muitos dos métodos e opções disponíveis no sistema.

Ao ser iniciada a interface gráfica, temos a tela mostrada na figura C.1.

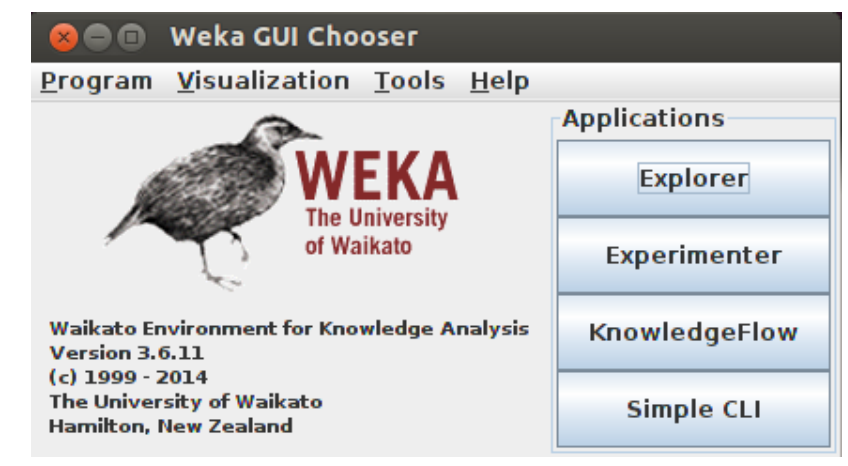

Figura C.1: Tela inicial da interface gráfica do WEKA.

Quatro opções iniciais são mostradas:

- Explorer: Métodos de exploração de dados para análise;

- Experimenter: Ambiente para experimentação de métodos de aprendizado, assim como testes estatísticos para compará-los;

- KnowlegdeFlow: Basicamente as mesmas funções do explorer, porém com funções mais visuais, usando uma interface de arrastar e soltar para formar os processos;

- SimpleCLI: Interface simples de linha de comando própria para executar as funções do WEKA.

Utilizamos o ambiente Explorer, que contém as funções de seleção de características. Ao iniciar o Explorer, obtemos a tela mostrada na figura C.2. 


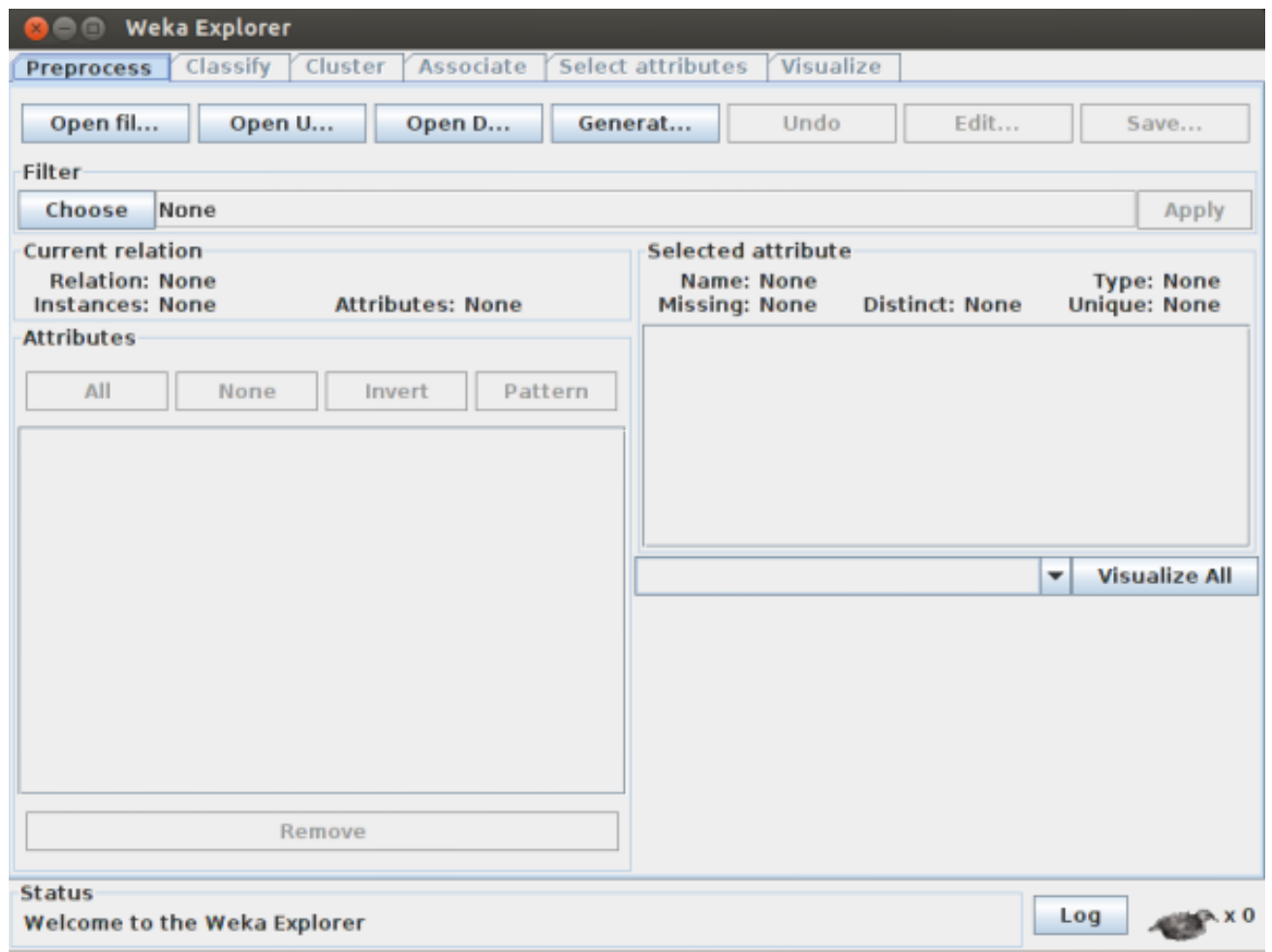

Figura C.2: Tela inicial do Explorer sem dados inseridos.

Clicando no botão Open file, uma janela é aberta para que possamos escolher o arquivo de dados a ser carregado. O sistema reconhece arquivos em um formato chamado ARFF (ARF ). Após a entrada dos dados, a tela do Explorer é atualizada com informações sobre a base de dados inserida, como mostrado na figura C.3.

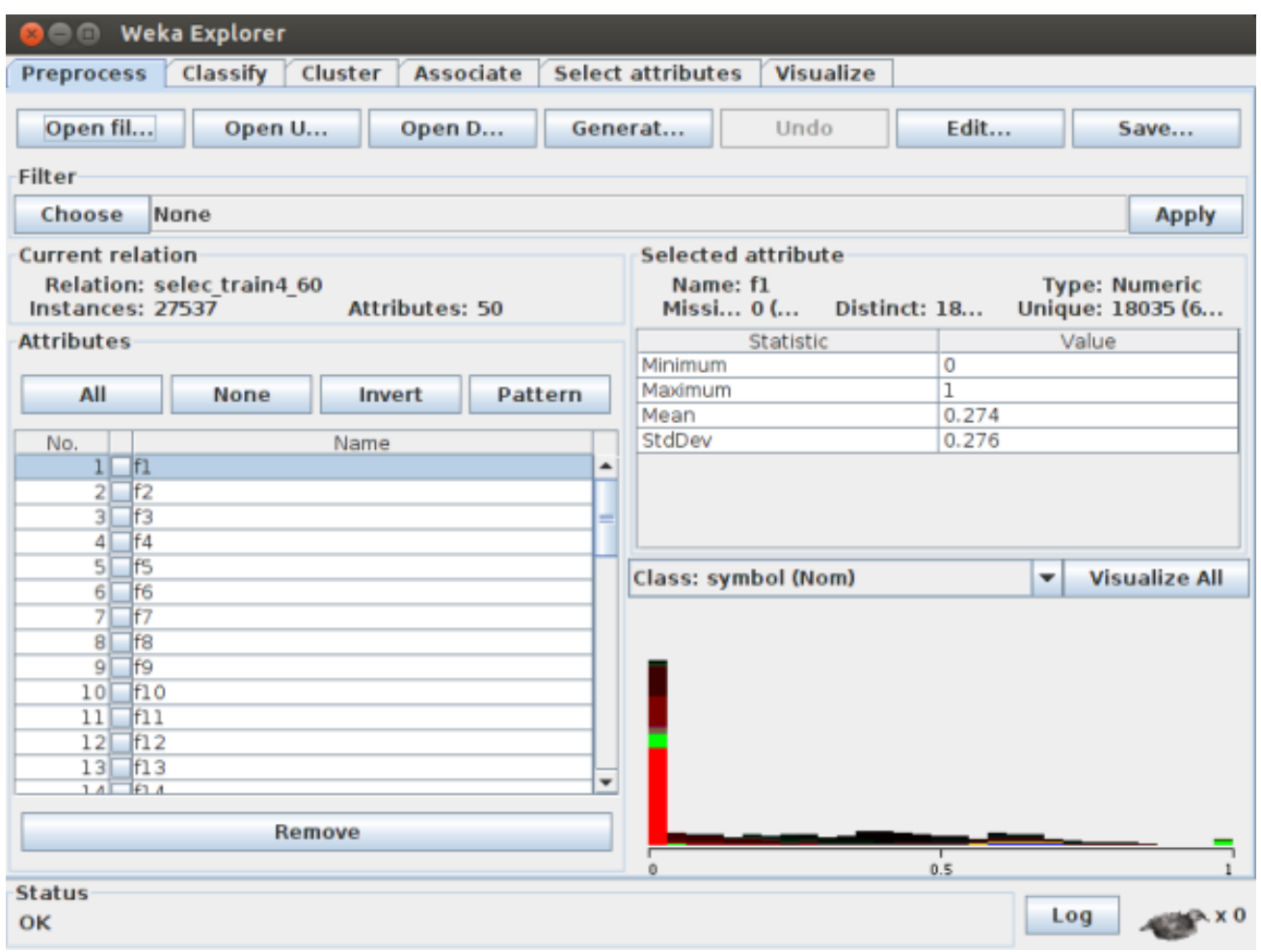

Figura C.3: Tela inicial do Explorer com dados inseridos. 
Nas abas da parte superior da janela, podemos então escolher a Select attributes para entrar na seção de seleção de características, que é mostrada na figura C.4.

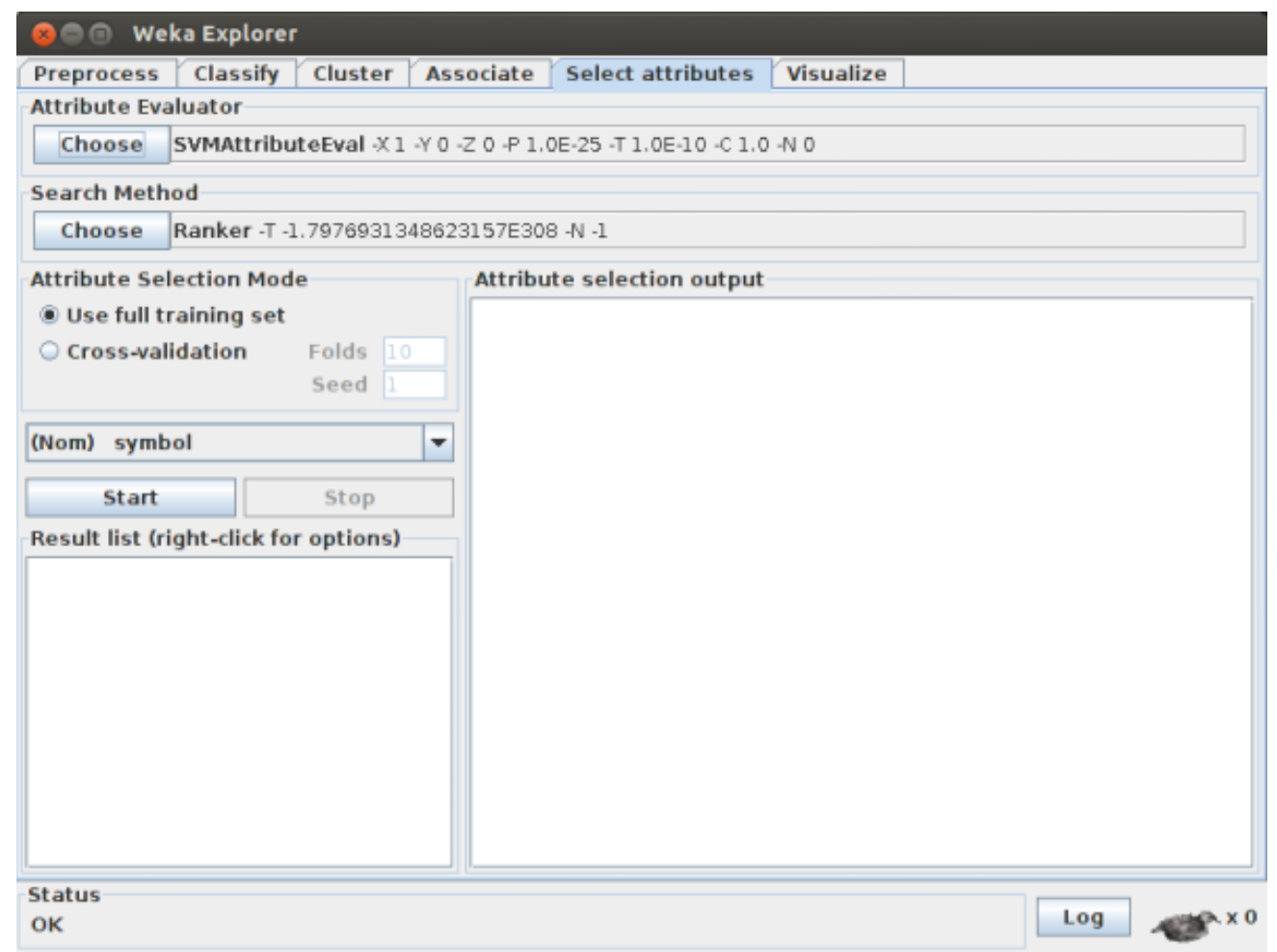

Figura C.4: Tela da aba com a seção de seleção de características.

Nessa seção existem dois aspectos importantes a serem definidos para o método de seleção: o método de avaliação e o método de busca. Como usamos SVMs como classificadores principais, escolhemos um método de avaliação (chamado SVMAttributeEval) que utiliza o treinamento de SVMs de kernel linear para determinar a relevância das características. O método avalia características eliminando-as recursivamente, e testando novamente a cada passo. A relevância de cada característica é calculada a partir da grandeza do coeficiente atribuído a ela no treinamento da SVM.

O único método permitido a ser usado em conjunto com o avaliador de SVMs se chama Ranker. Seu objetivo é simplesmente ordenar características individuais em ordem de importância baseado na avaliação usada.

Os parâmetros de ambos os métodos podem ser alterados. O experimento pode ser feito tanto no contexto de uma validação cruzada, como aplicado ao conjunto total de treinamento.

Mais informações sobre os métodos presentes nesse sistema podem ser encontradas no livro (Witten et al., 2011). 
84 APÊNDICE C 


\section{Referências Bibliográficas}

ARF () Arff. http://www.cs.waikato.ac.nz/ml/weka/arff.html. Último acesso em 19/06/2014. Citado na pág. 82

Ink () Inkml. http://www.w3.org/TR/InkML. Último acesso em 19/06/2014. Citado na pág. 73

Mat () Mathml. http://www.w3.org/TR/MathML. Último acesso em 19/06/2014. Citado na pág. 76

Wik () Wikipedia. http://www.wikipedia.org. Último acesso em 19/06/2014. Citado na pág. 76

Aguilar e Hirata (2012) Frank D. J. Aguilar e Nina S. T. Hirata. Expressmatch: a system for creating ground-truthed datasets of online mathematical expressions. Em Proc. 9th IAPR International Workshop on Document Analysis Systems. Citado na pág. 77

Alpaydin (2004) Ethem Alpaydin. Introduction to Machine Learning. The MIT Press, London, England. Citado na pág. 8

Álvaro et al. (2014) Francisco Álvaro, Joan-Andreu Sánchez e José-Miguel Benedí. Recognition of on-line handwritten mathematical expressions using $2 \mathrm{~d}$ stochastic contextfree grammars and hidden markov models. Pattern Recognition Letters, 35(0):58 67. ISSN 0167-8655. doi: http://dx.doi.org/10.1016/j.patrec.2012.09.023. URL http: //www.sciencedirect.com/science/article/pii/S016786551200308X. Frontiers in Handwriting Processing. Citado na pág. 2, 70

Aly (2005) Mohamed Aly. Survey on multiclass classification methods, 2005. Citado na pág. $7,15,16$

Anquetil e Lorette (1997) E. Anquetil e G. Lorette. Perceptual model of handwriting drawing application to the handwriting segmentation problem. Document Analysis and Recognition, International Conference on, 0:112. Citado na pág. 37

Awal et al. (2014) Ahmad-Montaser Awal, Harold Mouchère e Christian Viard-Gaudin. A global learning approach for an online handwritten mathematical expression recognition system. Pattern Recognition Letters, 35(0):68 - 77. ISSN 0167-8655. doi: http: //dx.doi.org/10.1016/j.patrec.2012.10.024. URL http://www.sciencedirect.com/science/ article/pii/S0167865512003546. Frontiers in Handwriting Processing. Citado na pág. 70

Berzal et al. (2003) Fernando Berzal, Juan-Carlos Cubero, Fernando Cuenca e María J. Martín-Bautista. On the quest for easy-to-understand splitting rules. Data Knowl. Eng., 44(1):31-48. ISSN 0169-023X. doi: 10.1016/S0169-023X(02)00062-9. URL http://dx.doi. org/10.1016/S0169-023X(02)00062-9. Citado na pág. 70 
Bishop (2006) Christopher M. Bishop. Pattern Recognition and Machine Learning. Springer, USA. Citado na pág. 51

Bredensteiner e Bennett (1999) Erin J. Bredensteiner e Kristin P. Bennett. Multicategory classification by support vector machines. Computational Optimizations and Applications, 12:53-79. Citado na pág. 14

Breiman et al. (1984) Leo Breiman, J. H. Friedman, R. A. Olshen e C. J. Stone. Classification and Regression Trees. Statistics/Probability Series. Wadsworth Publishing Company, Belmont, California, U.S.A. Citado na pág. 11

Buntine e Niblett (1992) Wray Buntine e Tim Niblett. A further comparison of splitting rules for decision-tree induction. Mach. Learn., 8(1):75-85. ISSN 0885-6125. doi: 10.1023/ A:1022686419106. URL http://dx.doi.org/10.1023/A:1022686419106. Citado na pág. 70

Chan e Yeung (2000) Kam-Fai Chan e Dit-Yan Yeung. Mathematical expression recognition: A survey, 2000. Citado na pág. 1, 2

Chang (2008) Fu Chang. Techniques for solving the large-scale classification problem in chinese handwriting recognition. Em Proceedings of the 2006 conference on Arabic and Chinese handwriting recognition, SACH'06, páginas 161-169, Berlin, Heidelberg. SpringerVerlag. Citado na pág. 3

Chaudhuri e Garain (2000) B. B. Chaudhuri e Utpal Garain. An approach for recognition and interpretation of mathematical expressions in printed document. Pattern Anal. Appl., 3(2):120-131. Citado na pág. 20

Chen et al. (2005) P. H. Chen, C. J. Lin e B. Schölkopf. A tutorial on $\nu$-support vector machines. Applied Stochastic Models in Business and Industry, 21:111-136. Citado na pág. 51,71

Cover (1965) T. M. Cover. Geometrical and statistical properties of systems of linear inequalities with applications in pattern recognition. IEEE Transactions on Electronic Computers, EC-14:326-334. Citado na pág. 14

Crammer et al. (2001) Koby Crammer, Yoram Singer, Nello Cristianini, John Shawetaylor e Bob Williamson. On the algorithmic implementation of multiclass kernel-based vector machines. Journal of Machine Learning Research, 2:2001. Citado na pág. 14

Delaye e Anquetil (2013) Adrien Delaye e Eric Anquetil. Hbf49 feature set: A first unified baseline for online symbol recognition. Pattern Recogn., 46(1):117-130. ISSN 0031-3203. Citado na pág. 35, 36, 37, 39, 41, 50, 67

Duda et al. (2000) Richard O. Duda, Peter E. Hart e David G. Stork. Pattern Classification. Wiley-Interscience, 2nd ed. Citado na pág. 9, 17, 27

Garain et al. (2004) Utpal Garain, B. B. Chaudhuri e R. P. Ghosh. A multiple-classifier system for recognition of printed mathematical symbols. Em Proceedings of the Pattern Recognition, 17th International Conference on (ICPR'04) Volume 1 - Volume 01, ICPR '04, páginas 380-383, Washington, DC, USA. IEEE Computer Society. Citado na pág. 20

Graham (1972) Ronald L. Graham. An Efficient Algorithm for Determining the Convex Hull of a Finite Planar Set. Information Processing Letters, 1:132-133. Citado na pág. 44 
Günter e Bunke (2003) Simon Günter e Horst Bunke. New boosting algorithms for classification problems with large number of classes applied to a handwritten word recognition task, 2003. Citado na pág. 3

Hall et al. (2009) Mark Hall, Eibe Frank, Geoffrey Holmes, Bernhard Pfahringer, Peter Reutemann e Ian H. Witten. The weka data mining software: An update. SIGKDD Explor. Newsl., 11(1):10-18. ISSN 1931-0145. doi: 10.1145/1656274.1656278. URL http: //doi.acm.org/10.1145/1656274.1656278. Citado na pág. 63, 81

Haykin (2007) Simon Haykin. Redes Neurais: Princípios e prática. Bookman Companhia Editora, Brasil, 2nd ed. Citado na pág. 12

Hirata e Honda (2011) Nina S. T. Hirata e Willian Y. Honda. Automatic labeling of handwritten mathematical symbols via expression matching. Em Proceedings of the 8th International Conference on Graph-based Representations in Pattern Recognition, GbRPR'11, páginas 295-304, Berlin, Heidelberg. Springer-Verlag. Citado na pág. 77

Hu (1962) Ming-Kuei Hu. Visual pattern recognition by moment invariants. Information Theory, IRE Transactions on, 8(2):179-187. ISSN 0096-1000. Citado na pág. 43, 44

Huang et al. (2007) B. Q. Huang, Y. B. Zhang e M. T. Kechadi. Preprocessing techniques for online handwriting recognition. Em Proceedings of the Seventh International Conference on Intelligent Systems Design and Applications, ISDA '07, páginas 793-800, Washington, DC, USA. IEEE Computer Society. Citado na pág. 30, 67

ichi Hanaki et al. (1976) Shin ichi Hanaki, Tsutomu Temma e Hiroshi Yoshida. An online character recognition aimed at a substitution for a billing machine keyboard. Pattern Recognition, 8(2):63 - 71. <e:title>Pattern Recognition Society Monographs $</$ ce:title $>$. Citado na pág. 77

Keshari e Watt (2008) Birendra Keshari e Stephen M. Watt. Online mathematical symbol recognition using svms with features from functional approximation. Em Electronic Proc. Mathematical User-Interfaces Workshop 2008. Citado na pág. 51

Klein (2004) Dan Klein. Lagrange multipliers without permanent scarring. August 2004. URL http://www.cs.berkeley.edu/ $\{$ \}klein/papers/lagrange-multipliers.pdf. Citado na pág. 14

Kumar e Ghosh (1999) Shailesh Kumar e Joydeep Ghosh. Gamls: A generalized framework for associative modular learning systems. Em In Proceedings of the Applications and Science of Computational Intelligence II, páginas 24-34. Citado na pág. 19

Kumar et al. (2002) Shailesh Kumar, Joydeep Ghosh e Melba M. Crawford. Hierarchical Fusion of Multiple Classifiers for Hyperspectral Data Analysis. Pattern Analysis \& Applications, 5(2):210-220. Citado na pág. 19

Labahn et al. (2008) George Labahn, Edward Lank, Mirette S. Marzouk, Andrea Bunt, Scott MacLean e David Tausky. Mathbrush: A case study for pen-based interactive mathematics. Em SBM, páginas 143-150. Citado na pág. 75

Lapointe (2008) A. Lapointe. Issues in Performance Evaluation of Mathematical Notation Recognition Systems. Canadian theses. Queen's University (Canada). ISBN 9780494385326. URL http://books.google.com.br/books?id=qM-Be7BzC48C. Citado na pág. 75 
MacLean et al. (2011) Scott MacLean, George Labahn, Edward Lank, Mirette Marzouk e David Tausky. Grammar-based techniques for creating ground-truthed sketch corpora. Int. J. Doc. Anal. Recognit., 14(1):65-74. ISSN 1433-2833. doi: 10.1007/s10032-010-0118-4. URL http://dx.doi.org/10.1007/s10032-010-0118-4. Citado na pág. 75

Malon et al. (2008) Christopher Malon, Seiichi Uchida e Masakazu Suzuki. Mathematical symbol recognition with support vector machines. Pattern Recogn. Lett., 29(9):1326-1332. Citado na pág. 51

Matsakis (1999) Nicholas Matsakis. Recognition of handwritten mathematical expressions. Dissertação de Mestrado, Massachusetts Institute of Technology, EUA. Citado na pág. 32, 33, 67

Miller e Viola (1998) Erik G. Miller e Paul A. Viola. Ambiguity and constraint in mathematical expression recognition. Em In Proceedings of the 15'th National Conference on Artificial Intelligence (AAAI-98), páginas 784-791. AAAI. Citado na pág. 2

Mingers (1989) John Mingers. An empirical comparison of selection measures for decision-tree induction. Mach. Learn., 3(4):319-342. ISSN 0885-6125. doi: 10.1023/A: 1022645801436. URL http://dx.doi.org/10.1023/A:1022645801436. Citado na pág. 70

Mitchell (1997) Thomas M. Mitchell. Machine Learning. McGraw-Hill, Inc., New York, NY, USA, 1 ed. ISBN 0070428077, 9780070428072. Citado na pág. 9

Mouchere et al. (2011) Harold Mouchere, Christian Viard-Gaudin, Dae Hwan Kim, Jin Hyung Kim e Utpal Garain. Crohme2011: Competition on recognition of online handwritten mathematical expressions. Em Proceedings of the 2011 International Conference on Document Analysis and Recognition, ICDAR '11, páginas 1497-1500, Washington, DC, USA. IEEE Computer Society. ISBN 978-0-7695-4520-2. doi: 10.1109/ICDAR.2011.297. URL http://dx.doi.org/10.1109/ICDAR.2011.297. Citado na pág. 75

Oong e Isa (2012) Tatt Hee Oong e Nor Ashidi Mat Isa. One-against-all ensemble for multiclass pattern classification. Applied Soft Computing, 12(4):1303 - 1308. Citado na pág. 15,16

Preparata e Shamos (1985) Franco P. Preparata e Michael I. Shamos. Computational geometry: an introduction. Springer-Verlag New York, Inc., New York, NY, USA. ISBN 0-387-96131-3. Citado na pág. 44

Quiniou et al. (2011) Solen Quiniou, Harold Mouchere, Sebasti’n Pen Saldarriaga, Christian Viard-Gaudin, Emmanuel Morin, Simon Petitrenaud e Sofiane Medjkoune. Hamex - a handwritten and audio dataset of mathematical expressions. Document Analysis and Recognition, International Conference on, 0:452-456. ISSN 1520-5363. doi: http://doi.ieeecomputersociety.org/10.1109/ICDAR.2011.97. Citado na pág. 76

Rhee e Kim (2009) Taik Heon Rhee e Jin Hyung Kim. Efficient search strategy in structural analysis for handwritten mathematical expression recognition. Pattern Recognition, 42(12):3192 - 3201. ISSN 0031-3203. doi: http://dx.doi.org/10.1016/j.patcog.2008.10.036. URL http://www.sciencedirect.com/science/article/pii/S0031320308004421. New Frontiers in Handwriting Recognition. Citado na pág. 70

Rifkin e Klautau (2004) Ryan Rifkin e Aldebaro Klautau. In defense of one-vs-all classification. Journal of Machine Learning Research, 5:101-141. Citado na pág. 15, 69 
Rubine (1991) Dean Rubine. Specifying gestures by example. SIGGRAPH Comput. Graph., 25(4):329-337. ISSN 0097-8930. doi: 10.1145/127719.122753. URL http://doi. acm.org/10.1145/127719.122753. Citado na pág. 38

Smithies et al. (1999) Steve Smithies, Kevin Novins e James Arvo. A handwriting-based equation editor. Em Proceedings of the 1999 conference on Graphics interface '99, páginas 84-91, San Francisco, CA, USA. Morgan Kaufmann Publishers Inc. Citado na pág. 27

Stria et al. (2012) J. Stria, M. Bresler, D. Prusa e V. Hlavác. Mfrdb: Database of annotated on-line mathematical formulae. Em Frontiers in Handwriting Recognition (ICFHR), 2012 International Conference on, páginas 542-547. doi: 10.1109/ICFHR.2012.231. Citado na pág. 76

Tapia (2004) Ernesto Tapia. Undertanding Mathematics: A System for the Recognition of On-line Handwritten Mathematical Expressions. dissertation, Freie Universität Berlin. Citado na pág. 30,67

Tapia e Rojas (2003) Ernesto Tapia e Raúl Rojas. Recognition of on-line handwritten mathematical formulas in the e-chalk system. Em In Proceedings of the Seventh International Conference on Document Analysis and Recognition (ICDAR). Citado na pág. 29

Tapia e Rojas (2007) Ernesto Tapia e Raúl Rojas. A survey on recognition of on-line handwritten mathematical notation, 2007. Citado na pág. 2

Tappert et al. (1990) C. C. Tappert, C. Y. Suen e T. Wakahara. The state of the art in online handwriting recognition. IEEE Trans. Pattern Anal. Mach. Intell., 12(8):787-808. Citado na pág. 27

Uchida e Sakoe (2005) Seiichi Uchida e Hiroaki Sakoe. A survey of elastic matching techniques for handwritten character recognition. IEICE - Trans. Inf. Syst., E88-D(8): 1781-1790. Citado na pág. 19

Vapnik (1995) Vladimir N. Vapnik. The nature of statistical learning theory. SpringerVerlag New York, Inc., New York, NY, USA. Citado na pág. 9

Vuong et al. (2008) Ba-Quy Vuong, Siu-Cheung Hui e Yulan He. Progressive structural analysis for dynamic recognition of on-line handwritten mathematical expressions. Pattern Recogn. Lett., 29:647-655. ISSN 0167-8655. doi: http://dx.doi.org/10.1016/j.patrec.2007. 11.017. URL http://dx.doi.org/10.1016/j.patrec.2007.11.017. Citado na pág. 70

Watt e Xie (2005) Stephen M. Watt e Xiaofang Xie. Recognition for large sets of handwritten mathematical symbols. Em ICDAR, páginas 740-744. Citado na pág. 19

Willems e Niels (2008) D.J.M. Willems e R. Niels. Definitions for features used in online pen gesture recognition. Relatório técnico, NICI, Radboud University Nijmegen. Citado na pág. 36,46

Witten et al. (2011) Ian H. Witten, Eibe Frank e Mark A. Hall. Data Mining: Practical Machine Learning Tools and Techniques. Morgan Kaufmann Publishers Inc., San Francisco, CA, USA, 3rd ed. ISBN 0123748569, 9780123748560. Citado na pág. 83 